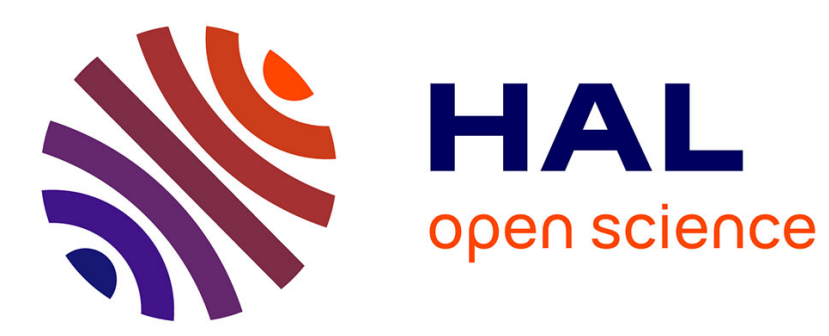

\title{
Progress in corrosion science at atomic and nanometric scales
}

\author{
Vincent Maurice, Philippe Marcus
}

\section{To cite this version:}

Vincent Maurice, Philippe Marcus. Progress in corrosion science at atomic and nanometric scales. Progress in Materials Science, 2018, 95, pp.132-171. 10.1016/j.pmatsci.2018.03.001 . hal-02354119

\section{HAL Id: hal-02354119 \\ https://hal.science/hal-02354119}

Submitted on 7 Nov 2019

HAL is a multi-disciplinary open access archive for the deposit and dissemination of scientific research documents, whether they are published or not. The documents may come from teaching and research institutions in France or abroad, or from public or private research centers.
L'archive ouverte pluridisciplinaire HAL, est destinée au dépôt et à la diffusion de documents scientifiques de niveau recherche, publiés ou non, émanant des établissements d'enseignement et de recherche français ou étrangers, des laboratoires publics ou privés. 


\title{
Progress in Corrosion Science at Atomic and
}

\section{Nanometric Scales}

\author{
Vincent Maurice, Philippe Marcus \\ PSL Research University, CNRS - Chimie ParisTech, \\ Institut de Recherche de Chimie Paris / Physical Chemistry of \\ Surfaces Group \\ 11 rue Pierre et Marie Curie, 75005 Paris, France
}

Correspondence:

V. Maurice

E-mail: vincent.maurice@ chimie-paristech.fr

P. Marcus

E-mail : philippe.marcus@ chimie-paristech.fr 


\section{TABLE OF CONTENTS}

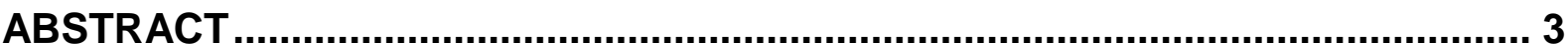

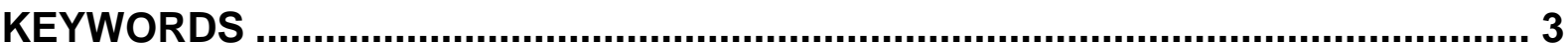

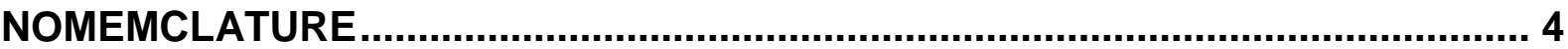

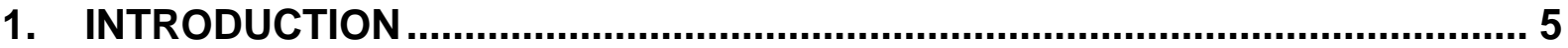

2. THE METAL-WATER INTERFACE STRUCTURE ....................................... 7

2.1 Water structure and bonding at metal surfaces under UHV conditions .......................................... 7

2.2 Bridging the "immersion gap"

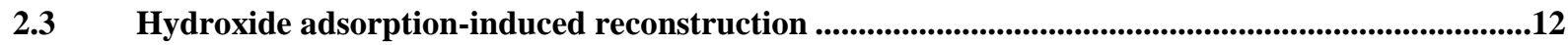

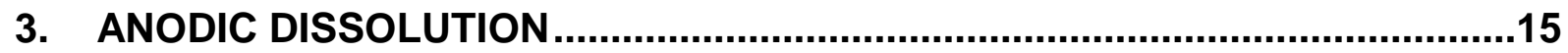

3.1 Dissolution of pure metals and adlayer effects ............................................................................................15

3.2 Dissolution in the presence of 2D passive layers ...........................................................................18

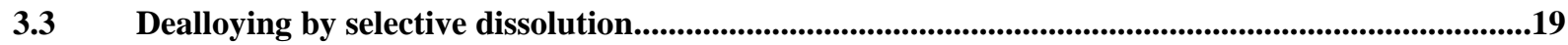

4. PASSIVATION OF METALS AND ALLOYS .............................................22

4.1 Structure of oxide passive films on copper, nickel, iron and chromium .............................................24

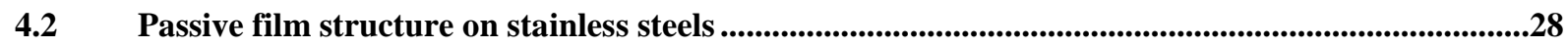

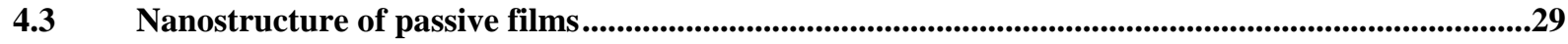

5. PASSIVITY BREAKDOWN AND INITIATION OF LOCALIZED CORROSION.32

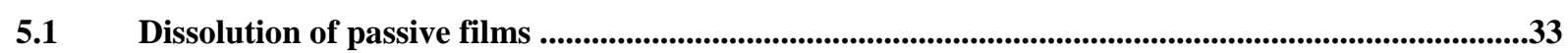

5.2 Reactive Molecular Dynamics modeling ...................................................................................................35

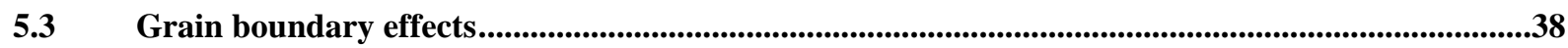

5.4 Local electronic properties at passive film grain boundaries ..................................................................41

6. CORROSION INHIBITION ..............................................................................4

6.1 Atomistic DFT modeling of benzotriazole adsorption on copper ...................................................45

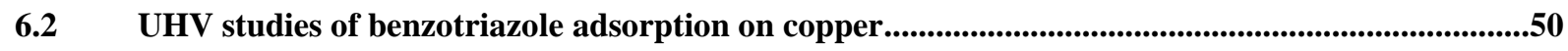

6.3 Direct nanoscale in situ EC-STM observations.............................................................................51

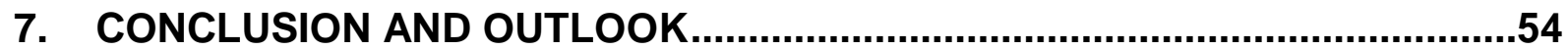

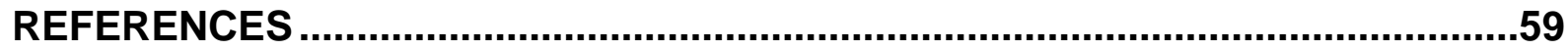

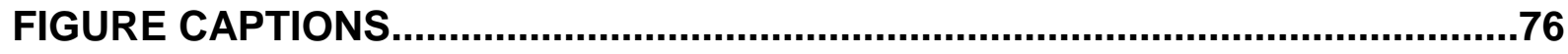




\begin{abstract}
Contemporary aspects of corrosion science are reviewed to show how insightful a surface science approach is to understand the mechanisms of corrosion initiation at the atomic and nanometric scales. The review covers experimental approaches using advanced surface analytical techniques applied to single-crystal surfaces of metal and alloys exposed to corrosive aqueous environments in well-controlled conditions and analysed in situ under electrochemical control and/or ex situ by scanning tunnelling microscopy/spectroscopy, atomic force microscopy and x-ray diffraction. Complementary theoretical approaches based on atomistic modeling are also covered. The discussed aspects include the metal-water interfacial structure and the surface reconstruction induced by hydroxide adsorption and formation of 2D (hyd)oxide precursors, the structure alterations accompanying anodic dissolution processes of metals without or with 2D protective layers and selective dissolution (i.e. dealloying) of alloys, the atomic structure, orientation and surface hydroxylation of ultrathin passive films, the role of step edges at the exposed surface of oxide grains on the dissolution of passive films and the effect of grain boundaries in polycrystalline passive films acting as preferential sites of passivity breakdown, the differences in local electronic properties measured at passive films grain boundaries, and the structure of adlayers of organic inhibitor molecules.
\end{abstract}

\title{
Keywords
}

Solid/liquid interface; Corrosion; Passivation; Metals; Alloys; Surface analysis and modelling 


\section{Nomemclature}

AFM atomic force microscopy

AP-XPS ambient pressure x-ray photoelectron spectroscopy

C-AFM conductive atomic force microscopy

EC-STM electrochemical scanning tunneling microscopy

EC-TS electrochemical tunneling spectroscopy

DFT density functional theory

$f c c$ face centered cubic

GIXD grazing incidence $\mathrm{x}$-ray diffraction

hcp hexagonal close packed

IRAS infrared reflection absorption spectroscopy

MD molecular dynamics

ML monolayer

OCP open circuit potential

ReaxFF reactive force-field

SAM self-assembled monolayer

STM scanning tunneling microscopy

SDOS surface density of states

STS scanning tunneling spectroscopy

TS tunneling spectroscopy

UHV ultra high vacuum

UPS ultraviolet photoelectron spectroscopy

XAS x-ray absorption spectroscopy

XPS x-ray photoelectron spectroscopy

$\mathrm{I}_{\mathrm{t}} \quad$ tunneling current

$\mathrm{U}_{0} \quad$ Nernst equilibrium potential

$\mathrm{U}_{\mathrm{C}} \quad$ critical potential

$\mathrm{U}_{\mathrm{S}} \quad$ sample potential

$\mathrm{U}_{\mathrm{T}} \quad$ tip potential

$\mathrm{V}_{\mathrm{t}} \quad$ tunneling voltage 


\section{Introduction}

The premature failure of solid metallic materials caused by corrosion is a major problem of our advanced society since it affects numerous technical fields where metal and alloy components are used for their structural or functional properties. Not only corrosion reduces the performance and durability of components or infrastructures with a very high economical cost, estimated to about $3 \%$ of the yearly gross domestic product [1], but it can compromise safety in fields such as aeronautics or nuclear electricity production. It can also jeopardize environment in e.g. oil and gas transport, and even health due to corrosion of metallic bioimplants in the human body.

Corrosion is a degradation phenomenon of a metallic material resulting from the chemical or electrochemical interaction with its environment. It is ubiquitous because most metals (and thus alloys) are reactive in their functioning environments. Besides corrosion takes many forms since metals and alloys of various types are exposed to a large variety of aggressive environments. Despite this multiple character, our understanding of corrosion is well advanced, thanks to an ever growing number of studies performed to investigate corrosion phenomena and their propagation and to test and validate the various means to mitigate corrosion and to develop corrosion protection. This is attested by an ever growing publication record and by a growing attendance at the yearly international conferences on corrosion, that bring together scientists from the academic world and engineers from the industry.

Corrosion and its mechanisms, methods and modelling have been the subject of recent books (see e.g. [2-4]). The present review focuses on knowledge advances made on corrosion mechanisms at the atomic or molecular scale or at a scale of a few nanometers (the nanoscale) in aqueous environments. Progress in corrosion science at these scales enables us to better understand the mechanisms of corrosion initiation. Corrosion initiation refers to the very early 
stages triggering a corrosion process before its propagation. It takes place on complex metal(alloy)/environment interfaces. The surfaces can be metallic (i.e. in the active state), or oxidized with a covering ultrathin protecting oxide film (i.e. in the passive state), or even coated by a protective organic or inorganic film, and they are interacting with the corroding aggressive environment. Aggressive species causing corrosion and inhibiting molecules added to mitigate corrosion can be both present in the aqueous environment. Understanding the corrosion initiation phenomena at the atomic or nanometric scales requires a research effort that not only uses state-of-the-art analytical techniques providing relevant surface and interface information at these scales but also necessitates the design of model systems that are relevant for the complexity of the processes and interfaces at play. Such an approach has rarely been adopted in the corrosion community, however with breakthrough results when successful (see e.g. [5-7]).

This review emphasizes recent progress made adopting a surface science approach of corrosion, combining experimental approaches using advanced surface analytical and electrochemical methods with theoretical approaches based on atomistic modeling. It discusses the link between atomic/nanometric scale mechanisms and the macroscopic corrosion manifestations. What happens when a metal surface is exposed to water, i.e. formation of the metal-water interface, is first discussed, before focusing on recent advances in the understanding of anodic dissolution processes (i.e. etching) of metals and selective dissolution (i.e. dealloying) of alloys. Next, we discuss how metals and alloys passivate, a central issue in corrosion science and engineering since the formation of ultra-thin surface oxide films is the best of all means for protection of metallic materials against corrosion, and a key for their use in our environment. The next section covers recent advances in the nanoscale understanding of how passivity breaks down and localized corrosion initiates, a major issue for pitting corrosion of passivable metallic materials. Finally, we discuss recent 
advances in corrosion inhibition by adsorbed organic molecules, an area in which atomic scale progress has been recently achieved by quantum chemical calculations (DFT) supporting experimental studies.

\section{The metal-water interface structure}

Understanding the formation of the metal-water interface is relevant for many physical and chemical processes at interfaces, including corrosion in aqueous environments but also electrochemical and photochemical processes, surface reactions in heterogeneous catalysis, and environmental science. It has thus attracted a very large interest from the surface science community and many studies have investigated water adsorption, the structure formed at low temperature and upon dissociation and the simulation of the electrified metal-water interface, all studied with a large panel of experimental microscopic, vibrational, spectroscopic and diffraction surface science techniques, complemented with theoretical modelling mostly by DFT. Extensive overviews and shorter reviews have been regularly published on the subject [8-14]. Here we select some examples on aspects which are more relevant for corrosion science, including the adsorption of hydroxide ions which is the first step in the growth of anodic oxide in aqueous environment.

\subsection{Water structure and bonding at metal surfaces under UHV conditions}

Most studies of the adsorption of water on metal surfaces have been performed on single crystalline, well defined surfaces in UHV environment at low, cryogenic temperature. UHV is needed for precise control of the purity of the interface and it also facilitates the application of most of the surface science techniques employed. At low temperature surface mobility reduces and the interface "freezes", easing structure characterization with or without water dissociation. Even for such model interfacial systems the picture is fairly complicated at 
the atomic scale. This is because water adsorption, the formed structures and their stability are determined by a compromise between water-metal interactions and water-water hydrogen bonding. Experimental and modelling results have been comprehensively compared for small water aggregates formed at coverage in the sub-monolayer range, for monolayers and multilayers adsorbed on close-packed $f c c$ surfaces, i.e. (111)-oriented surfaces of $\mathrm{Pd}, \mathrm{Pt}, \mathrm{Au}$, $\mathrm{Rh}, \mathrm{Ag}, \mathrm{Cu}$ and $\mathrm{Ni}$, on $\mathrm{Ru}(0001)$, and on some open $f c c$ surfaces, i.e. (110)-oriented [11,13]. Description by a conventional ice 'bilayer', where water only slightly distorts compared to the bulk ice structure, is no longer valid (Figure 1). Instead, significant distortions of the local arrangement of the H-bonds results from the optimization of the water-metal interaction in water monolayers. As a consequence, ice aggregates have their geometry and lateral size modified, monolayer structures are impacted and first water layer wetting and growth are altered in multilayers. A high sensitivity to the structure of the metal surface was also concluded. Details on the structure of clusters and monolayers of non-dissociated water molecules can be found in the cited reviews and references therein $[11,13,14]$.

[INSERT Figure 1]

Water dissociation and the formation of hydroxyls are important in corrosion since $\mathrm{OH}$ provides the oxygen reactant for anodic oxidation of the metal. The stabilization of water by co-adsorbed hydroxyls on several close packed faces under cryogenic UHV conditions has been reviewed $[10,11,13,14]$. On $\mathrm{Pt}(111)$ and $\mathrm{Pd}(111)$, there is formation of mixed $\mathrm{OH} / \mathrm{H}_{2} \mathrm{O}$ hexagonal structures with both species lying flat and adsorbed atop the metal atoms via oxygen. H-bonding between co-adsorbed species results in so-called proton ordering. On $\mathrm{Ni}(111)$, hydroxyls do not appear to take part in the network of hydrogen bonds. On $\mathrm{Ru}(0001)$, more complicated structures are formed as depicted in Figure 2 [14,15]. After deposition at $145 \mathrm{~K}$, narrow stripes composed of intact water molecules ordered in hexagons by $\mathrm{H}$-bonding are formed. After prolonged time at $145 \mathrm{~K}$, these water stripes transform into 
mixed hexagonal rings of molecular water and hydroxyl species. The hydroxyl groups were found to be located primarily inside these linear structures. The driving force for the stripe formation has been attributed to the hydrogen liberated during the dissociation process, which prefers to adsorb on the $\mathrm{Ru} f c c$ sites located between the $\mathrm{H}_{2} \mathrm{O}-\mathrm{OH}$ stripes and outside the hexagonal rings. Some $\mathrm{H}$ atoms can be trapped at the center of mixed water-hydroxyl hexagons (Figure $2 \mathrm{~b}$ ). At around $230 \mathrm{~K}$, the partially dissociated structures desorb from the $\mathrm{Ru}(0001)$ surface.

[INSERT Figure 2]

Coadsorption with alkalis, $\mathrm{O}$, and $\mathrm{CO}$ can modify the structure of the water-metal interface by site blocking and change binding and dissociation activation energies $[9,10]$. On $\mathrm{Ru}(0001)$, pre-adsorbed oxygen was found to increase the binding energy of water and promote its dissociation due to H-bonding between the co-adsorbed species [14,16,17]. Partial dissociation was found to require low oxygen coverage to occur and thus vacancies in the preadsorbed oxygen layer. At higher oxygen coverages between 0.25 and $0.5 \mathrm{ML}$, dissociation becomes inhibited due to the lack of $\mathrm{O}$ vacancies and the intact water molecules are bound atop to $\mathrm{Ru}$ and hydrogen-bonded to two neighboring pre-adsorbed oxygen atoms. When all atop Ru sites are blocked, water adsorption shifts half of the oxygen atoms from $h c p$ sites to $f c c$ sites. A honeycomb structure with water molecules strongly bonded to the exposed Ru atoms is thus created. The reconstruction of the oxygen layer is energetically balanced by the favorable adsorption of water on the newly exposed $\mathrm{Ru}$ atoms.

\subsection{Bridging the "immersion gap"}

Understanding the details of the metal-water interface formed under UHV cryogenic conditions at the atomic or molecular scale is not enough to significantly describe electrochemical systems in liquid water at or near ambient temperature. Indeed, charge 
transfer takes place between topmost metal atoms and water molecules at an electrode surface, which causes dissociation into cationic or anionic species depending on electrode potential and subsequent rearrangement of the inner and outer Helmhotz layers of the electrified interface. In turn, these rearrangements modify the potential drop at the interface. Two different approaches have been adopted to bridge this "immersion gap" between UHVbuilt and in-liquid-water interfaces. One is to take advantage of the possibilities brought by the UHV environment to simulate and measure the role of polarized electric double layers as inferred from electrochemical studies, the other is to develop the application of in situ spectroscopic techniques to characterize at or near ambient conditions the metal-water interface.

The UHV-electrochemical approach has been applied to study electric double layers effects on a metal substrate relevant for electrocatalytic application [10]. On $\mathrm{Pt}(111)$ singlecrystal surfaces, the potential dependence of water adsorption as $\mathrm{H}, \mathrm{H}_{2} \mathrm{O}$ and $\mathrm{H}_{3} \mathrm{O}^{+}$and the replacement of $\mathrm{H}_{3} \mathrm{O}^{+}$by bisulfate anions $\left(\mathrm{HSO}_{4}{ }^{-}\right)$at increasing potentials towards OCP were first characterized in situ in sulfuric acid solutions by IRAS. Then model electrode surfaces were reconstituted under $\mathrm{UHV}$ by adsorption of $\mathrm{SO}_{3}$ on pre-adsorbed $\mathrm{H}_{2} \mathrm{O}$ in order to reproduce the real electrode surfaces at various electrode potentials. Annealing-induced water desorption was then used to simulate the changes of the actual double layer structures. Combined LEED, TDS and IRAS analysis showed that the co-adsorbed layer forms a $(\sqrt{3} \times \sqrt{7})$ ordered structure of bisulfate $\left(\mathrm{HSO}_{4}^{-}\right)$, as also found in situ in sulfate-containing electrolytes on closed-packed (111)-oriented Au [18-22], Pt [23], Rh [24], Ir [25], Pd [26], Cu [27] and $\mathrm{Ru}(0001)$ [28], with at least 2 water bonded molecules $\left(\mathrm{H}_{2} \mathrm{O}\right.$ and $\left.\mathrm{H}_{3} \mathrm{O}^{+}\right)$. Subsequent temperature increase/decrease reversibly converted the $(\sqrt{3} \times \sqrt{7})$ structure in a $(\sqrt{ } 3 \times \sqrt{ } 3)$ structure of neutral $\mathrm{H}_{2} \mathrm{SO}_{4}$ by desorption/re-adsorption of water. In addition IRAS revealed a reversible structural change of the first and second water layers with the water molecules 
ordering. It was concluded that the orientations of the dipoles of the anionic $\left(\left(\mathrm{OH}^{-}\right)_{n}\left(\mathrm{H}_{2} \mathrm{O}\right)_{\mathrm{n}}{ }^{\prime}\right)$ or cationic $\left(\left(\mathrm{H}_{3} \mathrm{O}^{+}\right)_{\mathrm{n}}\left(\mathrm{H}_{2} \mathrm{O}\right)_{\mathrm{n}}{ }^{\prime}\right)$ water molecules at the inner and outer Helmholtz layers govern the potential drop near an electrode surface. For a Pt(111) electrode polarized at sufficiently negative potential in $0.5 \mathrm{M} \mathrm{H}_{2} \mathrm{SO}_{4}$, a well oriented high density (quasi close-packed) cationic water phase is predominantly formed. In contrast, for the same interface polarized at positive potential, the well oriented high density (quasi close-packed) water phase is anionic.

The in situ spectroscopic approach for studying water adsorption at or near ambient conditions has paralleled the recent development of ambient pressure X-ray photoelectron spectroscopy (AP-XPS). The AP-XPS design includes differential pumping stages and electrostatic focusing which allows to overcome the limitations of traditional XPS to UHV because of the electrons short mean free path in gas phase. Combined with the use of intense synchrotron X-ray source, in situ XPS can be performed at pressures in the Torr range are possible and some applications have been reviewed [29,30]. Such measurements are limited to pressures inferior to the Torr range if a conventional X-ray source is used to limit the radiation-induced damage [31]. AP-XPS studies can be performed on electrochemical system components in situ in environmental conditions and on catalytic systems in operando conditions.

\section{[INSERT Figure 3]}

Concerning metal-water interfaces relevant to corrosion science, we take the example of water adsorption on (110)- and (111)-oriented copper surfaces that highlights how water dissociation impacts wetting at water vapor pressures typical of environmental conditions [29,32]. Figure 3 shows the AP-XPS O 1s spectra recorded in situ during water adsorption at a 1 Torr pressure corresponding to 5\% relative humidity at room temperature. On $\mathrm{Cu}(110)$, a mixed $\mathrm{H}_{2} \mathrm{O}: \mathrm{OH}$ monolayer saturates the surface with $\mathrm{O}$ 1s components at about 532.5 and 531 $\mathrm{eV}$ binding energies, respectively. In contrast the $\mathrm{Cu}(111)$ surface is adsorbate-free under 
identical exposure conditions, which reveals the differences between two surfaces of different geometric and electronic structure in surface reactivity for water dissociation and in stability of the adsorbed $\mathrm{H}_{2} \mathrm{O}: \mathrm{OH}$ surface complex. On $\mathrm{Cu}(111)$, pre-adsorbing atomic oxygen increases reactivity and results in a mixed $\mathrm{H}_{2} \mathrm{O}: \mathrm{OH}$ layer with an hydroxyl coverage having twice the initial value of atomic oxygen. Thus the presence of pre-adsorbed oxygen is shown to tune the $\mathrm{Cu}(111)$ surface from intrinsically hydrophobic to hydrophilic by promoting water dissociation which allows reversing the surface wetting properties.

\subsection{Hydroxide adsorption-induced reconstruction}

For metal electrodes polarized anodically in aqueous solution, water dissociation produces hydroxide ions that can strongly interact with reactive metal atoms and not only structurally modify the metal-water interface but also initiate the growth of anodic oxide films. Studying these hydroxide-induced structural modifications on a model metal surface is thus highly relevant for understanding the early stages of interactions between metal and oxygen reactant in anodic oxidation and how the build-up of corrosion protection, i.e. passive, layers is initiated. We take here the example of a 2D (hydr)oxide adlayer grown on a singlecrystal copper surface in hydroxide-containing alkaline solution to illustrate this aspect.

[INSERT Figure 4]

On copper, hydroxide ions adsorb in the potential range preceding 3D anodic oxidation as characterized by in situ Raman spectroscopy [33,34], which induces surface reconstruction and formation of 2D adlayers as observed by EC-STM [35-38]. For $\mathrm{Cu}(111)$ in $0.1 \mathrm{M} \mathrm{NaOH}$, this process is observed at $-0.6 \mathrm{~V} / \mathrm{SHE}$ before $3 \mathrm{D}$ growth of (111)-oriented $\mathrm{Cu}_{2} \mathrm{O}$ at $\mathrm{US}_{\mathrm{S}}>-$ 0.2 V/SHE (Figure 4). Figure 4a shows typical voltammograms characterizing the anodic formation and electrochemical reduction of the 3D passive film on $\mathrm{Cu}(111)$ and the reversible adsorption/desorption of hydroxides $\left(\mathrm{OH}^{-}\right)$in the potential range preceding 3D oxidation 
(inset). In Figure 4b, the EC-STM sequence recorded at -0.6 V/SHE shows the surface terraces (marked m.), initially bare and atomically smooth. Darker appearing 2D islands (marked ad.) progressively grow with time until coalescence to cover completely the terraces. The adsorbed layer growth is initiated preferentially at the step edges, showing that these preexisting defect sites react preferentially like for dissolution (see Section 3.1). At the end of the growth process, the step edges are displaced and monoatomic protruding adislands are formed, which results in both cases from the topmost $\mathrm{Cu}$ plane being reconstructed upon adsorption of the hydroxide anions. $\mathrm{Cu}$ atoms are ejected from the topmost plane by the reconstruction. They aggregate at step edges after diffusion on the surface which causes the step edges advance. When the $2 \mathrm{D}$ adlayer covers most of the surface in the final stages of the adsorption process, the mobility of the ejected $\mathrm{Cu}$ atoms is reduced on the $\mathrm{OH}$-covered terraces which promotes their aggregation to form the observed adislands. Dissolution of the ejected $\mathrm{Cu}$ atoms in the electrolyte may also occur during this process.

Figure 4c presents an image recorded in situ at atomic scale of the ordered and reconstructed adlayer and its model following a $\mathrm{OH}_{\mathrm{ads}} / \mathrm{Cu}_{\mathrm{R}} / \mathrm{Cu}(111)$ sequence from the topmost plane. The lattice is hexagonal and has a parameter of $0.6 \pm 0.02 \mathrm{~nm}$ with one minimum (assigned to $\mathrm{OH}_{a d s}$ ) and four maxima (assigned to $\mathrm{Cu}_{\mathrm{R}}$ atoms of the reconstructed topmost metal plane) of intensity per unit cell. A period of $\sim 0.3 \mathrm{~nm}$ is measured for the $\mathrm{Cu}_{\mathrm{R}}$ sub-lattice, which exceeds the value $(0.256 \mathrm{~nm})$ for the $\mathrm{Cu}(111)$ plane in the bulk and confirms that the topmost $\mathrm{Cu}$ plane is reconstructed into a $\mathrm{Cu}_{\mathrm{R}}$ plane of lower density. The intensity minima density gives a value of $\sim 0.2$ for the $\mathrm{OH}_{\text {ads }}$ coverage that matches the value of 0.19 given by voltammetry measurements of the electrochemical charge transfer (inset of Figure 4a). According to the STM data, the $\mathrm{OH}_{\text {ads }}$ groups sit in the three-fold hollow sites and form a $(2 \times 2)$ superstructure with respect to the reconstructed $\mathrm{Cu}_{\mathrm{R}}$ plane. This topmost $\mathrm{OH}_{\mathrm{ads}} / \mathrm{Cu}_{\mathrm{R}}$ structure reproduces that of the $\mathrm{O}$ and $\mathrm{Cu}$ sub-lattices in $\mathrm{Cu}_{2} \mathrm{O}$ oriented (111) and 
presented in Section 4.1). The (hydr)oxide adlayer thus formed at the surface can be viewed as a $2 \mathrm{D}$ building block for initiation of the $3 \mathrm{D}$ growth of the (111)-oriented $\mathrm{Cu}_{2} \mathrm{O}$ oxide at higher anodic potential.

On silver, hydroxide adsorption-induced surface reconstruction also precedes the growth of 3D anodic oxides $[39,40]$. However, the potential $\left(\mathrm{U}_{\mathrm{S}}>-0.1 \mathrm{~V} / \mathrm{SHE}\right)$ required for surface reconstruction is more anodic than that $\left(\mathrm{U}_{\mathrm{S}}>-0.45 \mathrm{~V} / \mathrm{SHE}\right)$ required for adsorbing hydoxides $\left(\mathrm{OH}_{\text {ads }}^{\gamma-}\right)$ as inferred from cyclic voltammetry data [41-43] and verified in situ by Raman spectroscopy and ex situ by XPS [43-45]. EC-STM on Ag(111) in $0.1 \mathrm{M} \mathrm{NaOH}$ revealed no superstructure between -0.45 and $-0.1 \mathrm{~V} / \mathrm{SHE}$ [40] but streaked atomically smooth terraces instead. This was interpreted as due to $\mathrm{OH}_{a d s}^{\gamma-}$ species possibly incompletely discharged $(0<\gamma<1)$ and weakly bonded after adsorption and thus mobile on the surface. For $-0.1<\mathrm{U}_{\mathrm{S}} \leq 0.3 \mathrm{~V} / \mathrm{SHE}$, the surface is partially reconstructed and the resulting adlayer consists of 2D ordered islands mimicking the $\mathrm{Ag}_{2} \mathrm{O}(111)$ building blocks and coexisting with areas where no reconstruction occurs with likely predominance of mobile $\mathrm{OH}_{a d s}^{\gamma-}$ species [40].

On nickel, the hydroxides adsorb at potentials preceding the peak corresponding to 3D anodic oxidation [46-51] however without characteristic peaks in voltammetry data [48,5153]. EC-STM on $\mathrm{Ni}(111)$ in $0.1 \mathrm{M} \mathrm{NaOH}$ revealed surface local ordering prior to hydroxide adsorption-induced surface reconstruction forming a 2D passive layer at increasing anodic potential $[54,55]$. Local ordering was characterized by the islands having a $(2 \times 2)$ structure and limited in lateral extension, interpreted as mobile $\mathrm{H}_{2} \mathrm{O}_{\text {ads }}$ and $\mathrm{OH}_{a d s}^{-}(0<\gamma<1)$ species locally stabilized by coadsorption [55]. Surface reconstruction was characterized by 2D nanocrystals ( $\sim \mathrm{nm}$ lateral size $)$ having a lattice of hexagonal symmetry and $0.31 \pm 0.01 \mathrm{~nm}$ 
period and assigned to (0001)-oriented $\mathrm{Ni}(\mathrm{OH})_{2}$ possibly grown on (111)-oriented $\mathrm{Ni}$ in strained epitaxy [54].

\section{Anodic dissolution}

Any metal in contact with an aqueous environment undergoes anodic oxidation at potential positive to the Nernst potential $\mathrm{U}_{0}$ of the $M e \leftrightarrow M e^{z+}+z e^{-}$reaction. If the anodic oxides are thermodynamically unstable or dissolve fast, passive layers cannot form and metal dissolution can proceed with very high current densities. This typically occurs in strongly acidic solutions, but also in strongly alkaline electrolytes for metals that are amphoteric like aluminium. If the overpotential $\left(\Delta U=U_{S}-U_{0}\right)$ is anodic and low, charge transfer controls the process with exponential variation of current versus potential. At more positive potentials, the process may become limited by mass transport as it gets more intense. The oxidized metal atoms dissolve in the environment where they re-combine with solvent molecules. Corrosion products may redeposit on the surface. In this section, we discuss progress made on the atomic and nanometer scale knowledge of anodic dissolution processes of metals and alloys at low anodic overpotentials (i.e. slow etching rate), including the effect of adsorbed halide species such as sulfur and chlorides, and of protecting 2D (hydr)oxide adlayers. For alloys, the initiation of dealloying by selective dissolution is also discussed.

\subsection{Dissolution of pure metals and adlayer effects}

Studies performed by EC-STM on copper surfaces in acidic solutions [56-64] are selected to illustrate this topic. At low $\mathrm{pH}(<5), \mathrm{Cu}(\mathrm{I})$ and $\mathrm{Cu}(\mathrm{II})$ oxides dissolve rapidly and cannot form a stable passive film. The copper surface is oxide-free at anodic overpotentials. 
Figure 5 depicts the evolution of atomically flat (001)-oriented single-crystal $\mathrm{Cu}$ surfaces dissolving in $\mathrm{H}_{2} \mathrm{SO}_{4}$ and $\mathrm{HCl}$ at moderate overpotentials [60]. A step flow mechanism of anodic dissolution is evidenced with step edges retracting. The pre-existing step edges are the reactive sites for preferential etching by kink removal as previously deduced and discussed from ex situ observations of iron dissolution [65]. These surface defects are caused by the residual misalignment of the crystallographic orientation with respect to the nominal orientation (here (001)) terminating the terraces. Their density, and thus the dissolution kinetics, markedly increases for surfaces increasingly disoriented from the crystallographic poles ((001), (110) and (111) for a cubic system). Step edges can also be viewed as models of emerging screw dislocations in terms of surface reactivity. The selective etching of step edge atoms is a consequence of their reduced coordination to nearest neighbors compared to terrace atoms. If anions do not form a strongly bonded adlayer, etching tends to stabilize step edges constituted of atoms having maximized coordination and thus aligned parallel to the substrate close-packed crystallographic directions. This stabilization process has been observed along atomically smooth $\langle 1-10\rangle$ directions for $f c c$ metals on e.g. $\mathrm{Cu}(001)$ [57] and $\mathrm{Cu}(111)$ [56], on $\mathrm{Ag}(111)$ [66] and on $\mathrm{Ni}(111)$ [67] and, accordingly, along <10-10> on hcp $\operatorname{Co}(0001)$ [68].

If anions form a strongly adsorbed layer, the etching anisotropy is strongly influenced (Figure 5). In sulfuric acid solution, the mobile adsorbed layer of sulfate formed on $\mathrm{Cu}(001)$ is disordered. As a result, the steps are etched isotropically in no preferential direction because of the disorder in the adlayer [59]. In contrast, in hydrochloric(bromic) acid solutions, a highly ordered $\mathrm{c}(2 \times 2)$ layer of adsorbed chloride(bromide) is formed. This adsorption layer stabilizes $<100>$-oriented step edges, i.e. parallel to the adlayer superstructure close-packed directions [57-60,62].

[INSERT Figure 6] 
In Figure $6 a$, the square adlattice corresponding to the $c(2 \times 2)$ structure of the adlayer of $\mathrm{Cl}$ on dissolving $\mathrm{Cu}(001)$ is shown at near atomic resolution. Dissolution is observed at the kinks present along the step edges oriented parallel to the [100] and [010] directions. The $\mathrm{Cl}$ adlayer primitive unit cells, containing one adsorbed $\mathrm{Cl}$ atom and two $\mathrm{Cu}$ atoms, are successively etched. At potentials below the onset of net dissolution, local removal and redeposition processes cause equilibrium fluctuations of these step edges $[59,62]$, as observed in the image sequence presented in Figure 6a. At potentials of prevailing dissolution, removal dominates but with re-deposition still occuring.

Figure 6a also reveals unexpected dissolution anisotropy of the step edges oriented along the symmetrical $<100\rangle$ directions with one orientation of the step edges dissolving more rapidly than the other $[59,60,62,69]$. The model shown in Figure $6 \mathrm{~b}$ tentatively illustrates how this can be related to the $\mathrm{c}(2 \times 2)$ superstructure that induces structural anisotropy of the step edges because of the varying coordination of the outmost $\mathrm{Cu}$ atom forming the dissolving kink to $\mathrm{Cl}$ atoms of the adlayer [62]. At the reactive and stable kink sites, the $\mathrm{Cu}$ atoms are coordinated to two and one adsorbed $\mathrm{Cl}$ atoms, respectively. At the reactive kink site along one of the symmetrical $<100>$ directions, the $\mathrm{CuCl}_{2}{ }^{-}$dissolving complex would thus already formed on the surface initiating preferential dissolution. Ordered $\mathrm{c}(2 \times 2)$ adlayers have also been reported for $\mathrm{Br}$ on $\mathrm{Cu}$ [61], S on $\mathrm{Ni}$ [70], I on $\mathrm{Ag}$ [71] and $\mathrm{Pd}$ $[69,72]$ with a similar anisotropic effect on the dissolution of the (001)-oriented metal.

\section{[INSERT Figure 7]}

A receding step flow mechanism of anodic dissolution also takes place in the presence of non-passivating 2-dimensional compound layers formed on the metal substrates as observed on $\mathrm{Cu}(111)$ and $\mathrm{Cu}(100)$ in iodide-containing sulfuric acid solution [63,73]. On both substrates, the 2D CuI film formation initiates via nucleation and growth of a $\mathrm{Cu} / \mathrm{I}$ bilayer on top of the preadsorbed I template phase with a structure mimicking the building blocks of the 
(111)-oriented bulk crystalline structure of CuI (zinc blende type). In advanced stages of formation, the copper terraces are directly transformed into the $2 \mathrm{D} \mathrm{CuI} \mathrm{film} \mathrm{at} \mathrm{the} \mathrm{reactive}$ boundary between metallic copper and the growing $2 \mathrm{D} \mathrm{CuI}$ film. The $\mathrm{Cu}$ atoms that do not integrate the $\mathrm{CuI}$ film dissolve. At surface saturation, 2D CuI film on top of the I adsorbed template does not passivate the substrate against oxidative dissolution (Figure 7) [73]. The dissolution reaction has been proposed to involve the concerted receding of four atomic layers and concomitant advance of three atomic layers as depicted on Figure 7: the CuI bilayer, the I adsorbed template and the sub-lying copper plane on T2' receding terraces and the $\mathrm{CuI}$ bilayer and I adsorbed template on advancing T1' terraces, respectively. Thus, dissolution still proceeds at defects sites such as step edges by a receding step flow mechanism in the presence of non-passivating 2D surface compounds, however with more atomic layers involved than in the presence of $2 \mathrm{D}$ adsorbed atomic layers.

\subsection{Dissolution in the presence of $2 D$ passive layers}

As discussed in Section 2.3, the adsorption of hydroxide ions can reconstruct the metalwater interface and induce the formation of 2D surface (hyd)oxide adlayers at potential negative to the 3D growth of anodic oxides. On $\mathrm{Ag}(111)$, this adlayer consists of 2D ordered islands mimicking the $\mathrm{Ag}_{2} \mathrm{O}(111)$ building blocks and coexisting with areas where no reconstruction takes place with likely predominance of $\mathrm{OH}_{a d s}^{\gamma-}$ adspecies. The EC-STM dissolution sequence shown in Figure 8 reveals how the heterogeneity of this 2D protective adlayer impacts the anodic dissolution process. It was acquired at a potential of $0.15 \mathrm{~V} / \mathrm{SHE}$, still below the potential required for 3D oxide growth ( $\left.U_{S} \geq 0.3 \mathrm{~V} / \mathrm{SHE}\right)[40]$.

[INSERT Figure 8] 
Nucleation of 2D etch pits is observed on the terraces (Figure 8a), which was attributed to topmost metal atoms dissolving from the weakest (i.e. defective) sites of the $\operatorname{Ag}_{2} \mathrm{O}(111)$ like adlayer. No characterization of the local chemical nature of these sites was performed. Still it seems possible that the bonding of the topmost Ag atoms with their Ag nearest neighbors weakens upon formation of the reconstructed adlayer by sub-surface relocation of $\mathrm{OH}$ adsorbates, This could lead to the formation of $\left[\mathrm{Ag}(\mathrm{OH})_{2}\right]^{-}$complexes observed to dissolve for this system by XAS [74]. After initiation, 2D pit growth propagates at the newly created step edges that preferentially dissolve (Figure 8b,c,d), like at pre-existing step edges in the case of preferential active dissolution. Hence, this mechanism is also prevalent for 2D pit propagation on $\mathrm{Ag}(111)$ in the presence of the $2 \mathrm{D} \mathrm{Ag}_{2} \mathrm{O}(111)$-like adlayer.

The structure of the surface oxide layer being poorly ordered, the step edges do not align along preferential crystallographic directions upon dissolution. This is consistent with non-ordered adlayers inducing step roughening as discussed in Section 3.1. The local resistance of the adlayer also governs the dissolution reaction and how it propagates irregularly in the topmost atomic layer of the terraces. As a result, dissolution channels isolating ordered fragments are formed in the topmost terraces with the ordered fragments resisting dissolution (Figure $8 \mathrm{c}, \mathrm{d})$. 3D grains assigned to the $\mathrm{Ag}(\mathrm{I})$ oxide nuclei and initially present at the surface also block the propagation of dissolution, which illustrates, at the nanoscale, the barrier property of anodic oxides grown at the surface against dissolution of the metal substrate.

\subsection{Dealloying by selective dissolution}

Dealloying is the process of selective removal by anodic dissolution of the reactive elements of an alloy, the non-reactive noble element(s) enriching the surface and eventually leading to "passivation" by an ultra-thin film of noble metal. This passive-like behavior may 
break down at a critical potential $U_{c}$ that can be markedly higher than the respective Nernst potential $\mathrm{U}_{0}$ of the reactive elements if the content of reactive elements in the alloy is high enough (above the so-called parting limit), as shown for $\mathrm{Cu}_{3} \mathrm{Au}$ in Figure 9a. The dissolution current is then massive and a surface film of nanoporous noble metal is formed. Dealloying is widely utilized for developing high surface area catalysts, sensors and electrodes for energy storage but it is a dangerous corrosion process for structure materials and components $[5,7,75,76,77]$

\section{[INSERT Figure 9]}

Recent significant progress on the understanding of the mechanisms of dealloying by selective dissolution has been made on the atomic and nanometric scales applying surface analytical methods, mostly STM or AFM performed in situ or ex situ, and GIXD experiments performed in situ with synchrotron light source [5,7,78-89]. $\mathrm{Cu}-\mathrm{Au}$ alloys have been extensively studied as model systems because of the large difference of equilibrium potential $\left(\mathrm{U}_{0}\right)$ of their two elements. Such model studies have not been reported for practical alloys such as stainless steel, aluminium, titanium or magnesium alloys. This is due to the difficulty to prepare and to maintain in situ an oxide-free, atomically flat and slowly dissolving active state.

In acidic solutions, copper selectively dissolve from $\mathrm{Cu}-\mathrm{Au}$ alloys and does not form any stable oxides which leads to surface enrichment in Au and to sequential build-up of a nanoporous gold layer at the so-called critical potential $\left(U_{c}\right)$ for macroscopic dealloying,. At potentials slightly above the copper equilibrium potential, copper dissolution occurs both at the alloy substrate step edges and on terraces leading to clustering of vacancies in the first layer as observed by EC-STM on (111)-oriented $\mathrm{Au}_{3} \mathrm{Cu}$ [80] and $\mathrm{Cu}_{3} \mathrm{Au}$ [83] and on (001)oriented $\mathrm{Au}_{3} \mathrm{Cu}$ and $\mathrm{Cu}_{3} \mathrm{Au}$ [82]. This forms an interconnected network of one atom deep pits (i.e. 2D voids) with gold-rich islands in-between. The presence of chlorides was concluded to 
enhance surface diffusion, coarsening pits and islands and leading to interconnected gold islands with an average height of $2 \mathrm{ML}$ and dissolution channels. For (001)-oriented $\mathrm{Cu}_{3} \mathrm{Au}$, a Moiré pattern was imaged by EC-STM [82], which is consistent with the formation of a goldrich surface layer of lattice parameter near that of pure gold passivating the $\mathrm{Cu}_{3} \mathrm{Au}$ substrate of parameter near that of pure copper.

On (111)-oriented $\mathrm{Cu}_{3} \mathrm{Au}$, in situ GIXD measurements brought more details on the interface atomic structure and build-up sequence of the nanoporous gold layer (Figure 9) $[7,81,83]$. At potentials slightly above the copper equilibrium potential, the surface was found covered by a gold-rich film reaching about $3 \mathrm{ML}$ in thickness, which protects the alloy from further selective dissolution of $\mathrm{Cu}$. The difference between the unit cells parameters of the gold-rich layers and the alloy substrate strains the freshly formed interface, leading to reverse $f c c$ stacking (CBA instead of $\mathrm{ABC}$ ) of the atomic planes in the ultra-thin gold-rich surface film. Upon further dealloying at intermediate higher overpotentials (at $0.45 \mathrm{~V}$ in Figure 9b), 10 to 15 ML thick gold islands are formed with identical reverse stacking sequence. Slightly below the critical potential $U_{c}$ measured by voltammetry (at $0.6 \mathrm{~V}$ in Figure $9 \mathrm{a}, \mathrm{b}$ ), the "passivating" gold barrier layer breaks down and nanoporosity consisting of ligaments of ABC-stacked nearly pure gold develops with increasing applied potential as a result of uniform further dealloying $[7,83]$. The change from $\mathrm{CBA}$ to $\mathrm{ABC}$ stacking at higher potentials was attributed to dominating surface diffusion and to increased interlayer exchange (observed at lower potentials by STM). Indeed the formation of a complete layer of stackingreversed CBA gold islands always precedes the emergence of the $\mathrm{ABC}$ gold structures. At higher potentials close to $\mathrm{U}_{\mathrm{c}}$, the transformation from initial $\mathrm{CBA}$ to $\mathrm{ABC}$ layers is fast. With addition of bromide or chloride in the solution, GIXD studies of (111)-oriented $\mathrm{Cu}_{3} \mathrm{Au}$ surfaces showed an unchanged build-up sequence with an initial ultra-thin CBAstacked gold-rich layer, followed by pure gold islands, and ending with ABC-stacked 
nanoscale ligaments (nanoporosity), like in additive-free sulfuric acid solution $[84,90]$. The potential for the structural transitions was shifted cathodically compared to pure sulfuric acid solution which was proposed to result from enhanced surface diffusion with the additives present. In the presence of iodide, there is no passivation by a gold film and the formation of a nanoporous surface occurs at low potentials and relatively short times [84]. At lower overpotentials, AFM showed that copper dissolves uniformly resulting in gold island formation on the terraces as well as along the step edges, like in iodide-free sulfuric acid solution. However, at higher overpotentials, $\mathrm{CuI}$ precipitation influenced the surface morphology with interconnected larger islands covering the terraces. At higher dissolution rates above Uc, porous structures with bimodal length scales resulted from such precipitation of CuI layers.

Self-assembled organic monolayers (SAMs) of thiol or selenol are often used for surface functionalization of materials. They can also form surface layers for effective inhibition of oxidation or corrosion (See Section 6.1). $\mathrm{Cu}-\mathrm{Au}$ alloy surfaces dealloy differently in the presence of SAM overlayers [83,86-88]. Uniform dealloying at the critical potential $\left(\mathrm{U}_{\mathrm{c}}\right)$ is overruled and becomes localized. At low potentials above the copper equilibrium potential, the main effect of the organic surface layer is to suppress surface diffusion and thus inhibit uniform dealloying corrosion. At higher potentials of passivity breakdown, dealloying proceeds in localized areas. With dealloying progress, surface cracks appear that initiate following local stress accumulation caused by volume shrinking of dealloyed nanoporous gold [91].

\section{Passivation of metals and alloys}

Passivity of metals and alloys is a central issue in corrosion science and engineering since the formation of ultra-thin surface oxide films is the best of all means for protection of 
metallic materials against corrosion, and a key for their use in our environment. Passivity results from the growth of an oxide film on the surface of metal and alloy substrates. The oxide film is either thermodynamically stable, or it dissolves very slowly, so that it protects the metal against corrosion. The oxide passive films have a thickness most commonly limited to a few nanometers; they are hydroxylated and form a well adherent and effective barrier between corrosive environment and the substrate [92-98]. They are self-healing and may reform if they are locally removed.

The application of surface analytical methods have been widely used to characterize the passivity of numerous metals and alloys $[3,93-96,98]$. However, it is the combination with a genuine surface science approach employing single-crystal substrate surfaces that has brought insight in the nanoscale morphology of passive oxide films and their atomic structure. Most passive films are crystalline as demonstrated with STM and AFM on pure metal substrates like $\mathrm{Cu}$ [35-38,99-101], Ni [54,55,67,102-108], Fe [109-114], Cr [115,116] and Co [68,117], and on alloy substrates like stainless steel $[118,122,123,124,125]$ and nickel-based alloys [126]. This finding has been confirmed and complemented for Ni [107,127], Fe [128,129] and Co [130] by in situ GIXD experiments. At the nanometer scale, the microstructure is polycrystalline and textured with grain boundaries separating oxide grains adopting a preferential crystallographic orientation. The intergranular areas can be non-ordered, in particular under non stationary conditions during the growth process. They act as preferential sites for passivity breakdown and the initiation of localized corrosion (see Section 5) [131134]. In this section, the growth mechanisms of passive films, their atomic structure and their nanostructure are discussed using selected studies performed on single-crystal surfaces of copper, nickel, iron, chromium and stainless steel. 


\subsection{Structure of oxide passive films on copper, nickel, iron and chromium}

On copper, studies combining electrochemical characterization with surface analysis using X-Ray Photoelectron Spectroscopy (XPS) [135-138], ion scattering spectroscopy [135], photo-acoustic spectroscopy [139], in situ Raman [33,140,141] and infrared [142] spectroscopies have brought qualitative and quantitative insight on the composition of the oxide passive films. Hydroxide anions adsorption, inducing surface reconstruction as discussed in Section 2.3, precedes the 3D growth of oxide layers at higher potential. The overpotential ( $\Delta U=U_{S}-U_{0}$ ), which is the driving force for anodic oxidation, not only influences the growth of passive films but also their crystallization and structure as illustrated in Figure 10 for (111)-oriented copper polarized in the $\mathrm{Cu}(\mathrm{I})$ oxidation range in alkaline solution $[35,36,100]$.

[INSERT Figure 10]

If the overpotential for oxide growth is low $\left(\mathrm{U}_{\mathrm{S}}=-0.25 \mathrm{~V} / \mathrm{SHE}\right.$, Figure 10a), the metal substrate is partially covered by oxide islands that are one monolayer thick and poorly crystallized and that preferentially nucleate at step edges. The observed numerous islands result from a high density of nucleation sites for initiating the growth of the oxide [100]. Local areas of the ordered hydroxide adlayer described in Section 2 separate the oxide islands. If the oxidation overpotential is higher $\left(\mathrm{U}_{\mathrm{S}}=-0.2 \mathrm{~V} / \mathrm{SHE}\right.$, Figure $\left.10 \mathrm{~b}\right)$, the metal substrate gets fully covered by oxide films that are several monolayer thick and well crystallized. The charge transfer measured during subsequent cathodic reduction scans allow deducing the oxide layer equivalent thickness: $\sim 0.5$ and $7 \mathrm{ML}$ (equivalent monolayers) for films grown at 0.25 and $-0.2 \mathrm{~V} / \mathrm{SHE}$, respectively. One equivalent monolayer corresponds to one stacking building block of the (111)-oriented cuprite structure (one $\mathrm{O}^{2-}-\mathrm{Cu}^{+}-\mathrm{O}^{2-}$ slab as shown in Figure 10c). The atomic lattice of the oxide layer has a hexagonal unit cell at the surface with a $\sim 0.3 \mathrm{~nm}$ parameter (inset in Figure $10 \mathrm{~b}$ ), matching the $\mathrm{Cu}$ sub-lattice of $\mathrm{Cu}_{2} \mathrm{O}$ oriented along 
(111). The epitaxy of $f c c \mathrm{Cu}_{2} \mathrm{O}$ on $f c c \mathrm{Cu}$ is defined by a parallel (or anti-parallel) relationship: $\mathrm{Cu}_{2} \mathrm{O}(111)[1 \overline{1} 0] \| \mathrm{Cu}(111)[1 \overline{1} 0]$ or [1 10]. On (001)-oriented $\mathrm{Cu}$ [38], a few $\mathrm{ML}$ thick crystalized oxide film is also formed. The unit cell is square at the surface and also of $\sim 0.3 \mathrm{~nm}$ parameter, which matches the $\mathrm{Cu}$-sub-lattice of $\mathrm{Cu}_{2} \mathrm{O}$ oriented along (001). The $\mathrm{Cu}_{2} \mathrm{O}(001)$ close-packed [1 $\overline{1} 0$ ] direction is rotated by $45^{\circ}$ with respect to the $\mathrm{Cu}(001)$ closepacked direction: $\mathrm{Cu}_{2} \mathrm{O}(001)[1 \overline{1} 0] \| \mathrm{Cu}(001)[100]$.

The passive films consisting of $\mathrm{Cu}(\mathrm{I})$ oxide expose surfaces that are faceted by the presence of periodic step edges (Figure 10b), which is indicative of a few degree tilt between the orientations of the oxide and substrate lattices (Figure 10c). The large mismatch of 17\% between the two lattices causes stress at the metal/oxide interface that is thought to be, at least in part, relaxed by the tilt. The chemical termination of the $\mathrm{Cu}_{2} \mathrm{O}$ oxide terraces is identical as indicated by the step height of $1 \mathrm{ML}$ of cuprite measured at the surface of the oxide layers. The surface of the oxide layer forming the interface with the aqueous solution is most likely hydroxylated and it has been confirmed by DFT modelling that the $\mathrm{Cu}$ sub-lattice unreconstructed structure measured in situ by STM is stabilized by $\mathrm{OH}$ adsorption on the surface of the $\mathrm{Cu}_{2} \mathrm{O}(111)$ oxide lattice [143]. In the potential range of $\mathrm{Cu}(\mathrm{II})$ anodic oxidation, the passive film has a $\mathrm{Cu}(\mathrm{I}) / \mathrm{Cu}(\mathrm{II})$ duplex structure which is also crystalline. The lattice of $\mathrm{Cu}$ (II) outer layer corresponds to (001)-oriented $\mathrm{CuO}$ with surface hydroxylation stabilizing this otherwise polar orientation [101].

On nickel, the passive film consists of $\mathrm{Ni}(\mathrm{II})$ (hydr)oxides with a bilayer structure. The inner layer consists of $\mathrm{NiO}$ terminated by a hydroxylated surface or covered by a 3D $\mathrm{Ni}(\mathrm{OH})_{2}$ outer layer depending on $\mathrm{pH}$. In acid solutions, the passive film has been reported to be 0.9 to $1.2 \mathrm{~nm}$ thick [144-150], and to increase up to $2.5 \mathrm{~nm}$ with increasing potential in some studies $[50,105,107]$. In alkaline solution, the outer hydroxide layer is $\sim 1.5 \mathrm{~nm}$ thick in the whole 
$\mathrm{Ni}(\mathrm{II})$ passive range in contrast with the inner oxide layer that grows linearly from 0 up to 3 $\mathrm{nm}$ thick with potential [50].

On nickel, the oxide passive film displays similar structural characteristics to that on copper as demonstrated using single-crystal substrates. The passive film surface also exhibits terraces separated by step edges typical of a faceted termination as observed on (111)-oriented nickel passivated in a pH 2.9 sulfuric acid solution (Figure 11a). Like on copper, the termination of the crystallized passive film by regular step edges is indicative of a slight epitaxial tilt between the barrier oxide layer formed by the $\mathrm{NiO}$ lattice and the substrate $\mathrm{Ni}(111)$ lattice. In this case, the lattice mismatch of $16 \%$ causes interfacial stress that the tilt would contribute to relax. In situ GIXD measurements have confirmed the (111) orientation of the $\mathrm{NiO}$ lattice and its tilt of about $3^{\circ}$ with respect to the (111)-oriented Ni substrate [127]. There is an anti-parallel epitaxy relationship between the $f c c$ oxide and substrate lattices: $\mathrm{NiO}(111)[1 \overline{1} 0]|| \mathrm{Ni}(111)[\overline{1} 10]$. The atomic lattice of the terminating terraces has an hexagonal unit cell of $0.3 \pm 0.02 \mathrm{~nm}$ parameter matching (111)-oriented $\mathrm{NiO}[102,103,105,107]$.

\section{[INSERT Figure 11]}

Having the $\mathrm{NaCl}$ structure, the surface of $\mathrm{NiO}$ is polar and thus unstable if (111)oriented and unreconstructed like in the bulk. This surface orientation of the passive film is however obtained. DFT modelling confirms that adsorption of a monolayer of hydroxyl groups stabilizes the surface $[151,152]$. Figure $11 \mathrm{~b}$ presents the model for such a hydroxylated surface faceted by step edges. The oxide passive film has thus a growth direction governed by the minimization of both (i) the interface energy by a tilted epitaxy and (ii) the oxide surface energy by the hydroxyl/hydroxide group termination.

On iron, STM [110] and AFM [111] have also evidenced the formation of crystalline passive films. In a weakly alkaline (pH 8.4) borate buffer electrolyte, $\mathrm{Fe}(\mathrm{II})$ and $\mathrm{Fe}(\mathrm{III})$ species constitute the film, the Fe(III) fraction increasing with potential [153]. With 
increasing potential, the film grows up to $\sim 2 \mathrm{~nm}$ thick [154]. In situ and ex situ GIXD studies showed epitaxial growth with (001)- and (111)-oriented $f c c$ oxide on (001)- and (110)oriented $b c c$ substrate, respectively, and the oxide [ $\overline{1} 10]$ direction parallel to Fe[100] $[128,129]$. A complex atomic structure, the so-called LAMM phase, owes to the distribution of the cations assumed uniform in these studies. The structure has an $\mathrm{O}$ anion sub-lattice identical to that in the $\mathrm{Fe}_{3} \mathrm{O}_{4}$ and $\gamma-\mathrm{Fe}_{2} \mathrm{O}_{3}$ spinel structures however with cation sites that are differently occupied [Figure 12]. There are 32 anion sites and 24 cation sites (16 octahedral and 8 tetrahedral) in the unit cell. The LAMM phase of the passive film has Fe(III) and Fe(II) cations occupying $80 \pm 10 \%$ and $66 \pm 10 \%$ of the octahedral and tetrahedral sites, respectively. Cations also occupy $12 \pm 4 \%$ and $0 \%$ of the octahedral and tetrahedral interstitial sites, respectively. This is in contrast with $\mathrm{Fe}_{3} \mathrm{O}_{4}$ where the occupancy of the octahedral and tetrahedral is $100 \%$, and with $\gamma-\mathrm{Fe}_{2} \mathrm{O}_{3}$ where $25 \%$ of the octahedral sites are occupied at $33 \%$ and where all tetrahedral sites as well as $75 \%$ of the octahedral sites are occupied at $100 \%$. Besides these spinel structures of $\gamma-\mathrm{Fe}_{2} \mathrm{O}_{3}$ and $\mathrm{Fe}_{3} \mathrm{O}_{4}$ contain no interstitials.

[INSERT Figure 12]

DFT modelling has been applied to describe the atomic structure at the interface formed by the iron oxide film and metal substrate [155]. For simplicity, the LAMM phase was simulated in this study by the magnetite structure assuming a $\mathrm{Fe}[100](001) \| \mathrm{Fe}_{3} \mathrm{O}_{4}[110](001)$ epitaxial relationship. The results show that, among the interface geometries considered for modelling, only two (one with Fe termination the other with $\mathrm{FeO}_{2}$ termination of the (001)oriented magnetite) are stable and undergo substantial relaxation of the atomic structure after energy minimization. The work of separation of the interface was calculated as the minimum energy necessary for separating the two surfaces forming the interface and similar values $(\gamma \approx$ $1.42 \mathrm{~J} / \mathrm{m}^{2}$ ) were obtained for the two geometries. 
On chromium, the development of an inner layer enriched in $\mathrm{Cr}(\mathrm{III})$ oxide species is promoted by the increase of both passivation potential and passivation time for passive films formed in acid solution $\left(0.5 \mathrm{M} \mathrm{H}_{2} \mathrm{SO}_{4}\right)$ [115]. At low potential, the highly hydrated passive film consists mainly of $\mathrm{Cr}$ (III) hydroxide with a poorly developed $\mathrm{Cr}$ (III) oxide inner layer. The structure is then mostly disordered and can be viewed as consisting of a disordered $\mathrm{Cr}(\mathrm{III})$ hydroxide matrix embedding small $\mathrm{Cr}(\mathrm{III})$ nanocrystals. At higher potential, the passive film is increasingly dehydrated and its inner part increasingly consists of $\mathrm{Cr}$ (III) oxide. The structure contains then larger crystals [115]. EC-STM has evidenced a crystalline structure-extending over several tens of nanometers and with a faceted termination [116]. The lattice of the nanocrystals matches the sub-lattice of $\mathrm{O}$ in the (0001)-oriented corundum structure of chromium oxide $\left(\alpha-\mathrm{Cr}_{2} \mathrm{O}_{3}\right)$. The (0001) basal plane of the hcp O sub-lattice grows parallel to the (110)-oriented $b c c \mathrm{Cr}$ lattice.

\subsection{Passive film structure on stainless steels}

Stainless steels are highly important in technology and of widespread application. Their use benefits from the high resistance to corrosion provided by the formation $\mathrm{Cr}$ (III)-enriched oxide passive layers, as shown by XPS and other analytical studies performed on passivated ferritic Fe-Cr [93,120,156-169] and Fe-Cr-Mo [160,163,170-172] stainless steels as well as on austenitic Fe-Cr-Ni [122,173-178] and Fe-Cr-Ni-Mo [125,173,174,176,179-191] counterparts. In acid aqueous environment, the dissolution rate of $\mathrm{Cr}(\mathrm{III})$ oxide is extremely small compared to that of $\mathrm{Fe}(\mathrm{II}) / \mathrm{Fe}$ (III) oxides causing the strong chromium enrichment in the passive range. In the transpassive range, chromium dissolves as $\mathrm{Cr}(\mathrm{VI})$ which decreases $\mathrm{Cr}$ enrichment. In alkaline solutions, $\mathrm{Fe}(\mathrm{II}) / \mathrm{Fe}(\mathrm{III})$ oxides are less soluble also decreasing the $\mathrm{Cr}$ enrichment in the passive film. For Ni-bearing stainless steels, passive films contains no or very little $\mathrm{Ni}(\mathrm{II})$ and there is $\mathrm{Ni}(0)$ enrichment in the metallic alloy region underneath the 
oxide $[122,125,173-178]$. The passive film is 1 to $3 \mathrm{~nm}$ thick depending and passivation conditions [120,122,125,160,162,163,164,174,183,188]. Like for Cr metal, a major finding of atomic and nanometric scale studies performed on these alloys is that passivation potential and ageing time markedly impact the passive film crystallization as shown by STM $[115,120$ $122,124]$ and their dehydroxylation as observed by XPS [115,120,122].

\section{[INSERT Figure 13]}

Figure 13 illustrates the structure changes observed with increasing passivation time [120-122,124]. Fe-22Cr [120] and Fe-18Cr-13Ni alloys [122] passivated for up to 65 hours evidenced a crystallinity increase of the film and the development of coalesced $\mathrm{Cr}$ (III) oxide nanocrystals in the inner oxide. Like on chromium, the measured atomic lattice matches that of the $\mathrm{O}$ sub-lattice of the (0001)-oriented $\alpha-\mathrm{Cr}_{2} \mathrm{O}_{3}$ corundum structure. On the austenitic alloy, the crystallization rate is faster than on the ferritic one [192]. The regulation of the chromium supply on the alloy surface by nickel was proposed as explanation. Crystallization would be promoted by a lower rate of $\mathrm{Cr}$ enrichment, in accordance with the data obtained on $\mathrm{FeCr}$ alloys of increasing $\mathrm{Cr}$ content that showed that, for short passivation periods ( $\leq 2$ hours), the increasing $\mathrm{Cr}$ content of the alloy decreases crystallinity in the passive films $[118,119]$.

\subsection{Nanostructure of passive films}

Even when grown on single-crystal substrates, surface oxide films have a polycrystalline microstructure with grains of nanometric lateral dimensions. This is a result of a high density of sites for oxide nucleation in their initial stages of formation, as illustrated in Figure 10a for a copper surface polarized at low oversaturation and that already displays numerous oxide islands at the nanometer scale. On nickel, values of the grains dimensions have been obtained from STM, AFM and GIXD data. They range from $\sim 2 \mathrm{~nm}$ for nucleating 
passive films to 30 to $230 \mathrm{~nm}$ for stationary 3D passive films as determined from the topography observed by STM and AFM [54,55,103,105,107,131]. A 8 nm average value was derived from GIXD measurements of the NiO single-crystal domain size on passivated Ni [107,127]. Such a difference can be expected since multiple sub-grain boundaries or twins existing in the passive film but not markedly emerging at its topmost surface may not be resolved by STM and AFM topographic measurements.

On iron, the average lateral dimension of the grains was $5 \mathrm{~nm}$ and $6-8 \mathrm{~nm}$ as measured in situ by GIXD on passivated (110)- and (100)-oriented surfaces, respectively [128,129]. The value obtained ex situ by STM on sputter deposited pure iron films after passivation was $5 \mathrm{~nm}$ [113]. Passivation time would not promote crystallization or grain coarsening according to these studies. However, coarsening of the crystalline terraces to values larger than $6 \mathrm{~nm}$ with increasing polarization potential was revealed by ex situ $\mathrm{STM}$ for short $(\mathrm{t}=15 \mathrm{~min})$ passivation time, suggesting that crystallization of the passive film after short polarization periods is promoted at increasing passivation potential [114]. The ordered oxide terraces have a lattice parameter of $0.32 \pm 0.02 \mathrm{~nm}$ as measured by STM, which agrees with the O sub-lattice parameter $(0.297 \pm 0.001 \mathrm{~nm}$ parallel to the substrate surface $)$ of the LAMM phase measured by GIXD.

On alloys such as stainless steels, the film also consists of grains separated by intergranular boundaries, but with crystallinity depending on formation conditions as discussed in Section 4.2. However, not only the structure exhibits nanoscale defects such as intergranular sites but the most recent studies suggest that the $\mathrm{Cr}$ enrichment, which is a key parameter for the corrosion resistance, is not uniform at the nanoscale, and varies between the nanograins themselves [193] and also depends on the coordination sites (steps vs. terraces) of the substrate because of the growth mechanism of the oxide film [124,125]. This is illustrated by Figure 14 for a FeCrNiMo(100) single-crystal alloy surface [125]. 
[INSERT Figure 14]

The presented STM image (Figure 14), obtained after passivation in sulfuric acid solution, displays the topography of the alloy surface with terraces and steps covered by the oxide film having a granular nanoscale morphology. The increase of the lateral grain dimension, $11.5 \pm 2.6 \mathrm{~nm}$ for the passive film versus $5.3 \pm 0.9 \mathrm{~nm}$ for the native air-formed oxide film, evidences a coalescence phenomenon of the oxide grains induced by electrochemical passivation. Noteworthy is the presence of depressions. Their penetration depth $(2.27 \pm 0.25 \mathrm{~nm})$ is not only larger than before passivation $(1.02 \pm 0.20 \mathrm{~nm})$ but exceeds the thickness of $1.9 \mathrm{~nm}$ measured for this passive oxide film [125]. These depressions result from transient dissolution that compete with the transformation of the oxide film induced by passivation. Hence nanoscale roughening occurs due to local competition between dissolution and oxide transformation during passivation. The oxide becomes further enriched in chromium after passivation: the $\mathrm{Cr}(\mathrm{III})$ cation fraction increases from 57 to $67 \%$ and the $\mathrm{Fe}(\mathrm{II})-\mathrm{Fe}(\mathrm{III})$ cation fraction decreases from 41 to $29 \%$ as measured by XPS analysis [125]. It can be concluded that dissolution is a marker for the least Cr-enriched areas of the passivated surface. Further examining the surface also reveals that dissolution is not preferentially located at the step edges of the substrate but on the terraces. This may appear counter intuitive from a surface science perspective and also based on the mechanism of active dissolution of pure metals showing preferential reactivity at step edges (Section 3.1). This difference arises from the competing passivation by $\mathrm{Cr}$ enrichment of the oxide film, favored at step edges and thus promoting the protection of these substrate sites. As a result, dissolution is re-located on the substrate sites where the protection provided by the oxide film is less effective because of a lower local Cr-enrichment on the oxide film. Preferential passivation at step edges and roughening of substrate terraces were also observed for $\mathrm{FeCrNi}(100)$ passivated in similar 
conditions [124]. These data suggest that the homogeneity of the Cr enrichment in the passive film is a key issue for the local corrosion resistance.

[INSERT Figure 15]

Nanoscale inhomogeneity of the passive film on stainless steel is confirmed by AFM data obtained on 316L stainless steel passivated in simulated PWR (pressurized water reactor) environment (water at $325^{\circ} \mathrm{C}$ ) [193]. Owing to growth at higher temperature at near neutral $\mathrm{pH}$, the passive film is thicker ( $\sim 5 \mathrm{~nm}$ after a 2 min exposure) in these conditions of formation and consists of a $\mathrm{Cr}$ (III)-rich inner barrier layer mixed with Fe(II,III) species and a mostly Fe(II,III)-rich outer layer. The nanograins are larger $(29.1 \pm 2.4 \mathrm{~nm})$ than those formed at room temperature. Investigation of the barrier properties of the film by mapping the electrical resistance by conductive AFM shows the oxide film has local electrical resistance variations spread over $\sim 1$ order of magnitude with larger variations, reaching 2-3 orders of magnitude, observed locally (Figure 15). These variations were assigned to the composition and related resistivity of the $\mathrm{Cr}$ (III)-rich inner layer of the oxide film varying from $\mathrm{Cr}(\mathrm{III})\left(\mathrm{Cr}_{2} \mathrm{O}_{3}\right)$ in the zones of highest resistance (resistivity) to $\mathrm{Cr}(\mathrm{III})$ mixed with $\mathrm{Fe}(\mathrm{II})\left(\mathrm{FeCr}_{2} \mathrm{O}_{4}\right)$ in the zones of lower resistance (resistivity). The grains of lowest resistivity suggest large variations of the $\mathrm{Cr}$ enrichment between the nanograins themselves, and thus non-uniform resistance to passivity breakdown at the nanometer scale.

\section{Passivity breakdown and initiation of localized corrosion}

Understanding passivity breakdown and initiation of localized corrosion is a key for improving the durability of the self-protection provided to metallic materials by oxide passive films. Indeed, passive films may locally break down which eventually leads, if aggressive species such as chloride ions are present in the environment, to pitting with the metal locally dissolving fast whereas the rest of the surface remains well protected [194-203]. 
The failure of the passive film and its breakdown initiates the process that leads to localized corrosion. Three main mechanisms have been proposed and are still discussed: (i) the mechanism of film thinning induced by aggressive ions that competitively adsorb with hydroxyls at the surface of the passive film [195,197,201-210], (ii) the mechanism of penetration of the aggressive species in the oxide lattice, integrated in the Point Defect Model [211], and that proceeds by insertion under the oxide surface followed by transport to the interface with the metal [196,197,201-203] and the development of voiding [212,213], and (iii) the mechanism of inhibited healing of the passive film that considers continuous breakdown/repair events and poisoning of the repair stage in the presence of the aggressive species [201,202,203,214-217]. A uniform passive film homogeneously blocking ion migration through the (hydro)oxide lattice is hypothesized in the three models.

In this section, we discuss recent progresses made at the nanoscale on the understanding of the breakdown of passive films and localized corrosion initiation. They are based on local measurements performed in situ with STM or ex situ with AFM on model passivated surfaces, and complemented by DFT and MD simulation and modelling. Scanning tunneling spectroscopy data are also discussed in order to better understand the role played by grain boundaries in polycrystalline oxide passive films.

\subsection{Dissolution of passive films}

Passive films exhibit step edges at their surface that are important for dissolution in the passive state. This is highly relevant for passivity breakdown since dissolution of the oxide passive film, catalyzed by complexation of adsorbed chlorides with metal cations at the topmost surface and reducing the passive layer thickness until eventually reaching the substrate surface thus triggering intense localized dissolution, is a key aspect of the adsorption mechanism of passivity breakdown. The EC-STM imaging sequence in Figure 16 illustrates 
the dissolution process on passivated $\mathrm{Ni}(111)$ recorded in situ independently of the absence or presence of chlorides in the electrolyte [132,133,218]. The step edges resulting from the tilted epitaxial growth of (111)-oriented $\mathrm{NiO}$ on (111)-oriented $\mathrm{Ni}$ (Section 4.1) are the sites where the oxide dissolves, like in the case discussed in Section 3.1 of oxide-free metal surfaces slowly dissolving at moderate overpotential. The generated 2D step flow is receding and depends on the orientation of the step edges with the oxide lattice terminated by step edges aligned in the closed-packed directions being less reactive and dissolving much less rapidly, because of the higher coordination of the atoms forming these step edges. This structuredependent dissolution mechanism stabilizes facets terminated along the $<1-10>$ directions, and produces $\{100\}$-oriented steps adopting the $\mathrm{NiO}$ structure most stable orientation. Figure $16 \mathrm{~b}$ presents a model for such a surface.

\section{[INSERT Figure 16]}

DFT modeling has been applied to hydroxylated $\mathrm{NiO}(111)$ surfaces in order to study the interaction with $\mathrm{Cl}^{-}$and its effect on the dissolution of the oxide $[151,152,219]$. Based on experimental results, a periodic $\mathrm{NiO}$ model (Figure 17) simulating a passive film faceted by step edges was constructed (Figure 11) [152]. It is (533)-oriented and includes (111)-oriented terraces separated by (010)-oriented monoatomic step edges. $\mathrm{Cl}$ atoms were substituted to surface $\mathrm{OH}$ groups to model adsorption at coverages from 25 to $100 \%$ and for each coverage one $\mathrm{Cl}$ in the resulting topmost $\mathrm{OH}: \mathrm{Cl}$ mixed layer was exchanged with one atom of the first sub-surface O layer to model $\mathrm{Cl}$ insertion in the oxide. After DFT optimization of the adsorbed structures, the surface was characterized by the formation of $\mathrm{Ni}(\mathrm{OH})_{2}, \mathrm{Ni}(\mathrm{OH}) \mathrm{Cl}$ or $\mathrm{Ni}(\mathrm{Cl})_{2}$ complexes detaching from the step edges, as shown in Figure 17, confirming that step edges act predominantly to dissolve the oxide. Calculations of the detachment energies of the of $\mathrm{Ni}(\mathrm{OH})_{2}, \mathrm{Ni}(\mathrm{OH}) \mathrm{Cl}$ or $\mathrm{Ni}(\mathrm{Cl})_{2}$ complexes showed that those including $\mathrm{Cl}$ atoms detach more easily from the step edges and thus that $\mathrm{Cl}$ adsorption at the step edges can promote the 
oxide dissolution, which confirms $\mathrm{Cl}$ adsorption-induced thinning as a possible mechanism leading to breakdown of the oxide passive film.

[INSERT Figure 17]

In contrast, the model structures with $\mathrm{Cl}$ inserted in the sub-surface oxide lattice did not reveal a detachment of $\mathrm{Ni}(\mathrm{OH}) \mathrm{Cl}$ or $\mathrm{Ni}(\mathrm{OH})_{2}$ complexes after DFT optimization. Thus dissolution of the oxide film would not be promoted once $\mathrm{Cl}$ atoms are inserted in the subsurface lattice, unlike with adsorbed structures. At $100 \% \mathrm{Cl}$ surface coverage, the structures with inserted $\mathrm{Cl}$ atoms were found to be energetically favored compared to the structure with adsorbed $\mathrm{Cl}$ atoms, indicating their higher stability and that the passivity breakdown mechanism may switch from oxide thinning-driven to a penetration-driven if $\mathrm{Cl}$ enters the oxide lattice. Noteworthy, $\mathrm{Cl}$ entry does not require that adsorbed $\mathrm{Cl}$ saturates the terraces of the defect-free oxide surface but only the step edges and their immediate vicinity, pointing to a nanoscale local effect of step edges that would promote the sub-surface insertion (i.e. penetration) of chlorides in the passive film and a possible switch in Cl-induced breakdown mechanism.

\subsection{Reactive Molecular Dynamics modeling}

In reactive MD atomic scale simulations, reactive methods are implemented with variations of charge or charge transfer and conventional molecular dynamics is combined with charge states that evolve with time [220-222]. These methods can treat particles numbers larger than $1 \times 10^{5}$. In the very few studies addressing passive film breakdown so far [223,224], reactive force-field (ReaxFF) [225] was used. This polarizable charge calculation method is geometry-dependent and based on a bond order/bond distance concept [226]. ReaxFF treats metal chlorides and oxides compounds [227,228]. 
Figure 18 shows a system built for simulation of passivated copper [223]. It consists of a (111)-oriented $\mathrm{Cu}$ slab covered by two $\mathrm{Cu}_{2} \mathrm{O}$ films of $0.6-0.7 \mathrm{~nm}$ thickness, one exposing a O-enriched (bottom) the other a O-deficient (top) termination. The system is periodically repeated along the $x, y, z$ axes. Neither the actual and somehow larger (up to $1.2 \mathrm{~nm}$ ) thickness nor the actual (111) orientation experimentally observed for the passive film grown in the $\mathrm{Cu}(\mathrm{I})$ oxidation range on $\mathrm{Cu}(111)$ is taken into account $[135,36-37,38]$. The system was initially relaxed at $300 \mathrm{~K}$ for $10 \mathrm{ps}$ (Figure 18 , left) before adding a 10 or $20 \mathrm{M}[\mathrm{Cl}]$ aqueous solution in the space gap (Figure 18, middle). These $\mathrm{Cl}$ concentrations are unrealistic high, even for pits in the propagation stage, but were used in order to reach passivity breakdown by accelerated kinetics within the limited time scales (300 ps) of the MD simulations. Figure 18 (right) shows the system after 250 ps relaxation.

\section{[INSERT Figure 18]}

It is shown that terminating the oxide film by O-deficient layer promotes the adsorption of $\mathrm{Cl}$. This was confirmed more recently with data focusing on the effect of the deviation from the $\mathrm{Cu}_{2} \mathrm{O}$ stoichiometry [224]. Examination of the $\mathrm{Cu}$ density distribution along the surface normal (z direction) shows that $\mathrm{Cu}$ atoms are preferentially removed from the $\mathrm{O}$ deficient termination of the oxide in the presence of adsorbed $\mathrm{Cl}[223,224]$. The effect proceeds by formation of non-uniform $\mathrm{Cu}-\mathrm{Cl}$ complexes that subsequently dissolve as $\mathrm{CuCl}$, $\mathrm{CuCl}_{2}$ or $\mathrm{CuCl}_{3}$ especially at $\mathrm{O}$-deficient surfaces thus leading to oxide thinning. The role played by the dynamics of solvation at the interface on dissolving $\mathrm{Cu}$ has been explored [224]. Well-ordered quasi-2D layers of adsorbed water molecules were found to form in the vicinity of oxide films over-stoichiometric in $\mathrm{O}$, as indicated by hydrogen bond lifetimes and high residence probabilities. For films of near $\mathrm{Cu}_{2} \mathrm{O}$ stoichiometry, the chloride ions were found to be repelled by the $2 \mathrm{D}$ ordered layers of adsorbed water away from the oxide surface into the aqueous medium disordered regions. For films sub-stoichiometric in $\mathrm{O}$, it was found 
that $\mathrm{Cl}$ adsorption disrupts the ordered adsorbed water layers and promotes $\mathrm{Cu}$ removal and thereby thinning of the passive oxide film.

[INSERT Figure 19]

The passive films were not perforated by $\mathrm{Cl}$ in these conditions of simulation, but perforation was observed at $373 \mathrm{~K}$ after 300 ps where a defect site has been initially implemented in the form of a 1 ML-thick circular island of $\mathrm{O}$ vacancies of $0.8 \mathrm{~nm}$ radius in the topmost plane of the O-enriched passive film [223]. Figure 19 shows the $\mathrm{Cu}$ and $\mathrm{Cl}$ density distributions and the $\mathrm{Cl}$ average charge distribution along the $\mathrm{z}$ direction of the system after 1 and 300 ps optimization. The passivated slab has its $\mathrm{Cu}$ density spread out at the top/bottom sides and $\mathrm{Cl}$ atoms infiltrating its bulk as well as the topmost planes of the substrate, which confirms the passive film perforation. The distribution of charge on the $\mathrm{Cl}$ atoms supports the formation of copper chloride. The time evolution of the distribution of $\mathrm{Cu}-$ $\mathrm{Cl}$ pairs (not shown) indicates a steady increase of formation of copper chloride clusters. Examination of the right-hand and left-hand $\mathrm{Cu}_{2} \mathrm{O}$ films of the cross-sections in Figure 19 further shows that $\mathrm{Cl}$ penetrates the passive films independently of the presence at the surface of $\mathrm{O}$ vacancies island, only the penetration intensity is impacted and increases if the presence of a defect island of $\mathrm{O}$ vacancies. Locally depleted regions are evidenced in the aqueous solutions on both sides of the slab by the $\mathrm{Cl}$ density distribution as a result of $\mathrm{Cl}$ consumption by the corrosion reaction. This suggests that sustained corrosion in the locally depleted sites requires far-field $\mathrm{Cl}$ diffusion.

The three main mechanisms of passivity breakdown that are still discussed in the literature were not specifically addressed by these ReaxFF MD simulations. However, the results simulating the displacement of $\mathrm{Cu}$ atoms from passive film into aqueous medium and the formation of clusters of copper chloride are in support of the mechanism of film thinning induced by the adsorption of aggressive ions, like observed by DFT modelling after chloride 
adsorption on passivated nickel (see Section 5.1). The ReaxFF MD simulations also suggest $\mathrm{Cl}$ atoms penetration into oxide passive films. However, testing the breakdown mechanism of penetration of the aggressive species in the oxide lattice with induced-voiding requires more detailed and relevant studies. $\mathrm{O}$ vacancies should be implemented as point defects in the bulk of the oxide passive films and not only at the surface as done so far. Also the oxide films should be constructed with appropriate crystalline lattice and epitaxy when known. In the future, the passivated surfaces should be simulated more realistically with atomic structure, defects and nanostructural features modelling the experimental knowledge when available. Implementation of $\mathrm{pH}$ effects and potential-driven atomic transport is also a future challenge for simulating passivity and its breakdown.

\subsection{Grain boundary effects}

STM and AFM studies performed on well-defined substrate surfaces have also revealed the major role played by intergranular boundaries in passivity breakdown [131-133,229]. These nanostructure defects act as preferential sites for passivity breakdown and pit initiation independently of the presence of chlorides in the corrosive solution. This is shown by AFM in Figure 20 for (111)-oriented nickel surfaces passivated in sulfuric acid solution (pH 2.9) $[131,133]$. Polarization in the lower part of the passive domain $(0.55 \mathrm{~V} / \mathrm{SHE})$ in the chloridefree electrolyte produces a surface fully covered by the afore-discussed polycrystalline passive film (Figure 20a). The grains exhibit the typically faceted surface resolved by STM and presented above (see e.g. Figure 16).

[INSERT Figure 20]

Without or with chloride ions in the solution, the pre-passivated surface corrodes locally with formation of nanopits at the boundaries between grains when the surface is increasingly polarized (up to $1.05 \mathrm{~V} / \mathrm{SHE}$ ) in the passive range (Figure $20 \mathrm{~b}$ and c). Without chloride ions 
in the solution, the nanopits dimensions are $20-30 \mathrm{~nm}$ at the opening and 2.2-3.8 $\mathrm{nm}$ in depth (some are circled in Figure 20b). The measured depth provides evidence for the local enhancement of the substrate corrosion since it is larger than the variation of the surface level at grain boundaries after pre-passivation $(0.4-1.4 \mathrm{~nm})$, and also exceeds the thickness $(<2$ $\mathrm{nm})$ of the grown oxide layer $[105,107,148]$. This local removal of the substrate material implies that, even in the absence of chlorides, transient depassivation followed by repassivation of the pre-passivated surface occurred leading to the formation of (metastable) nanopits at the less resistive sites that are the grain boundaries of the passive film.

With chloride ions in the solution, the nanopits growth is promoted (Figure 20c). Most of the nanopits have dimensions similar to those formed in chloride-free solution and described above. However, markedly larger ones (some are marked) are also formed at the grain boundaries of the passive film with dimensions of 40-50 nm at the opening and 5-6 nm in depth. Their density $\left(\sim 2 \times 10^{9} \mathrm{~cm}^{-2}\right)$ is a factor of $1 / 10$ lower compared to the smaller nanopits, showing that only a fraction of the less resistive sites of the pre-passivated surface is impacted by the effect of chlorides during the depassivation/repassivation process. Figure $20 \mathrm{~d}$ shows nanoscale localized corrosion initiated at what was possibly a multiple point of intersecting intergranular boundaries of the passive film before local breakdown and nanopit formation.

The higher susceptibility to passivity breakdown of the oxide films grain boundaries has been rationalized using a model that postulates that the potential drop is locally redistributed at the electrolyte/oxide/metal interface $[133,134]$. The defect sites (i.e. oxide grain boundaries) take over less potential drop because they are less resistive to ion migration. Thus, for an electrolyte/oxide/metal interface with a given total potential difference from electrolyte to metal, the electrolyte/oxide and/or the oxide/metal interfaces at grain boundaries 
will take over a larger drop with consequent acceleration of the electrochemical reactions at the interfacial boundary sites (Figure 21).

[INSERT Figure 21]

If the electrolyte/oxide interfacial potential drop is predominant, the passive film can breakdown via faster local thinning due to more intense dissolution at the defective grain boundary sites (Figure 21a). If in contrast the oxide/metal interfacial potential drop is predominant, the passive film can breakdown via two different mechanisms, depending on the predominant species, cations or anions, diffusing through the oxide. For predominant cationic transport (Figure 21b), the increase of the oxide/metal interfacial potential drop accelerates the cation transfer and thus accelerates the formation of metallic vacancies in the metal surface at the interface with the defective sites of the oxide. If diffusion toward the metallic bulk does not compensate the injection of vacancies, their condensation leads to voiding at the interface. Continuously growing metal voids will develop stress in the no more-supported oxide layer leading to local depassivation (local breakdown) by collapse of the oxide film. For predominant anionic transport (Figure 21c), anions $\left(\mathrm{O}^{2-}\right.$ or $\left.\mathrm{Cl}^{-}\right)$penetrate the oxide preferentially at the defective grain boundary sites and diffuse locally faster to the interface. The increase of the oxide/metal interfacial potential drop promotes the local growth of metal compound particles $\left(\mathrm{MeO}_{\mathrm{x}} \mathrm{Cl}_{\mathrm{y}}\right)$, which generates stress. Continuous growth of these particles causes local disbonding of the interface, eventually leading to passive film breakdown. The possibility of an increase in the potential drop at both interfaces cannot be discarded and certainly leads to an intermediate situation where breakdown develops according to a combination of the mechanisms discussed above. Also, depending on the structure of the oxide grain boundary, one of these mechanism may prevail locally, implying that the breakdown mechanism may differ locally if the passive film presents grain boundaries of 
varying structure. The presence of aggressive species (e.g. chlorides) is not required for these breakdown mechanisms to occur. The processes can be catalyzed in the presence of chlorides.

\subsection{Local electronic properties at passive film grain boundaries}

As discussed above, passive films of nanometer thickness contain grain boundaries that are defective sites for the barrier properties and are prone to preferentially react and breakdown. Investigating the local electronic properties at such defects in passive films appears then highly relevant in order to bring insight on how passivity breaks down and pits initiate. This can be done using scanning tunneling spectroscopy (STS), first developed for application in ultra-high vacuum environmental conditions [230,231].

In STS, tunneling current $\mathrm{I}_{\mathrm{t}}$ is recorded versus surface-to-tip bias voltage $\mathrm{V}_{\mathrm{t}}$. The spectroscopic recording is combined with STM imaging with the $\mathrm{I}_{\mathrm{t}}-\mathrm{V}_{\mathrm{t}}$ curves recorded at preselected locations on the imaged surface. Post-treatment yields the surface density of electronic states (SDOS) by extraction of the normalized differential conductance $\left(\mathrm{dI}_{t} / \mathrm{dV}_{\mathrm{t}}\right) /\left(\mathrm{I}_{\mathrm{t}} / \mathrm{V}_{\mathrm{t}}\right)$. Geometric and electronic surface structures are thus probed simultaneously at the same resolution. When first applied in situ in an electrochemical cell, the tunneling spectroscopic $I_{t}-V_{t}$ measurements (TS) were limited to a range of a few hundred $m V$ for $V_{t}$ [232,233] owing mostly to tip limitations. Besides they were not combined with imaging, thus not allowing one to correlate the local spectroscopic information to the nanostructural features. Later developments enlarged the $V_{t}$ range of in situ spectroscopic measurements to nearly 3 V (EC-TS) and were applied to study anodic oxides grown on iron [234-237] and copper [238].

In EC-TS, one records $\mathrm{I}_{\mathrm{t}}-\mathrm{V}_{\mathrm{t}}$ curves at varying polarization potential which allows to extract the potential dependence of the conductance at the electrode surface. Variations induced by the environmental conditions (e.g electrolyte $\mathrm{pH}$ or $\mathrm{Cl}$ concentration) can be 
studied. To date, EC-TS data have only been acquired at random points on the surface, i.e. in the absence of combined STM imaging that allows pre-selecting the recording points. The results discussed below were obtained with STS, i.e. by combining TS spectroscopic recording and STM imaging, in ex situ conditions, i.e. on surfaces pre-passivated and not electrochemically polarized $[97,239,240]$. Until now, only STS has been applied to study how electronic properties are impacted by the presence of grain boundaries in passive films. Its application is illustrated below for the passive film formed in sulfuric acid $(\mathrm{pH} 2.3)$ solution on (111)-oriented single-crystalline nickel surfaces (Figure 22) [97,239].

[INSERT Figure 22]

The normalized differential conductance curves are plotted versus surface-to-tip bias $\left(\mathrm{V}_{\mathrm{t}}=\mathrm{U}_{\mathrm{S}}-\mathrm{U}_{\mathrm{T}}\right)$. They were averaged from 55 and $251 \mathrm{I}_{\mathrm{t}}-\mathrm{V}_{\mathrm{t}}$ curves measured on grain boundaries and grains, respectively. These curves highlight the effect of the presence of grain boundaries in the passive film on the local density of states of the surface. The energy band model schematically illustrates the effect.

At negative bias, one probes the occupied electronic states. On the grains, the SDOS increases for $\mathrm{V}_{\mathrm{t}} \leq-0.54 \pm 0.03 \mathrm{~V}$, which allows us positioning the valence band top edge about $0.5 \mathrm{~V}$ below the Fermi level (at $\mathrm{V}_{\mathrm{t}}=0 \mathrm{~V}$ ), as also measured by UPS for $\mathrm{NiO}$ [241]. Below this Ev position, the grains of the passive film are sites where the occupied states donate electrons, as sketched in the energy band model by arrows pointing from the surface. The passive film electronic gap having a width of about $3.5 \mathrm{~V}$ [242,243], the Ev position implies a p-type character of the passivated surface which relates to metallic vacancies as dominant point defect of the passive film structure $\left(\mathrm{Ni}_{(1-\delta)} \mathrm{O}\right)$ [244,245]. At the grain boundaries, the SDOS increase is slightly shifted to $V_{t} \leq-0.66 \pm 0.03 \mathrm{~V}$ suggesting a slight attenuation of the $\mathrm{p}$ character on these sites of the passive film either due to a decrease concentration of metallic vacancies or to the presence of oxygen vacancies. 
For $-0.54 \pm 0.03<\mathrm{V}_{\mathrm{t}}<0.20 \pm 0.03 \mathrm{~V}$ and $-0.64 \pm 0.03<\mathrm{V}_{\mathrm{t}}<0.51 \pm 0.03 \mathrm{~V}$ on grains and at grain boundaries, respectively, the SDOS is minimum, as expected from the electronic gap of the semi-conductive passivated surface. Still, direct tunneling from/to the occupied/empty substrate electronic states cannot be excluded at negative/positive bias, as sketched in the model by arrows pointing from/to the passivated surface. The ultra-thin $(<2 \mathrm{~nm})$ passive film grown in the selected passivation conditions renders this direct mechanism possible $[105,107,148]$.

At positive bias, the unoccupied states are probed. On the grains, SDOS peaks are observed for $0.5<\mathrm{V}_{\mathrm{t}}<1.5 \mathrm{~V}$. Since the passive film gap is about $3.5 \mathrm{~V}$ wide and thus extends up to $\mathrm{V}_{\mathrm{t}} \sim 3 \mathrm{~V}$, these SDOS peaks suggest that surface states are present as sketched by ovals in the model. Indirect electronic transfer to the substrate empty states can be promoted by these surface states as sketched by the arrows in the model. At the grain boundaries, one notices a marked decrease of the normalized differential conductance for $0.5<\mathrm{V}_{\mathrm{t}}<1.2 \mathrm{~V}$, indicating that the density of the passive film surface states is markedly reduced in this range whereas it is similar to that on the grains above $1.2 \mathrm{~V}$. The proposed explanation for this marked decrease is that the $\mathrm{NiO}$ passive film contains oxygen vacancies at the grain boundaries, which is in line with the shift of the p-type character observed at negative bias. Indeed, an increase of the metallic ions concentration at the passive film grain boundaries can be excluded since it should increase and not decrease the density of the $\mathrm{Ni} 3 \mathrm{~d}$ unoccupied surface states for $0.5<\mathrm{V}_{\mathrm{t}}<1.5 \mathrm{~V}$. In contrast, each added oxygen vacancy in the oxide lattice will leave two electrons that fill the unoccupied $3 \mathrm{~d}$ levels of the surrounding metallic ions, thus decreasing their density as observed at positive bias. The dominant defects of the $\mathrm{NiO}$ passive film at grain boundaries thus remain the metallic vacancies since the film remains ptype in these sites however with oxygen vacancies $\left(\mathrm{Ni}_{(1-\delta)} \mathrm{O}_{(1-\kappa)}\right.$ with $\left.\delta>\kappa\right)$. The oxygen vacancies can be expected to promote anionic transport in these sites, and related effects on 
passivity breakdown as discussed in Section 5.2. They should thus promote the local entry and transport of chlorides in the passive film grain boundaries.

\section{Corrosion inhibition}

For metallic materials in environmental conditions in which effective self-protection by passivation does not function, inhibitors can be a major mean of corrosion protection. Corrosion inhibitors are additives, inorganic or organic molecules, added to the material environment in order to mitigate corrosion, either in generalized or localized form, by decreasing the rate of the corrosion processes. Amines or zinc dithiophosphates on steel and benzotriazole (BTAH, $\mathrm{C}_{6} \mathrm{H}_{4} \mathrm{~N}_{3} \mathrm{H}$ ) on copper and its alloys are widely used organic corrosion inhibition systems of empirically-verified effectiveness. It is commonly believed that, for inhibition to function, the inhibitor molecule must adsorb on the substrate, that the interaction with the surface must be strong and that a protective film must be formed. Experimental studies of corrosion inhibition are numerous [246-249] but the development of atomistic theoretical simulations is more recent [250-252]. However, even for the BTAH/Cu system, the most studied both experimentally and computationally [253-256], the molecular details of the interaction with metal surfaces, the resulting inhibiting layer structure and the role played by the surface oxide in the inhibition mechanism are still debated.

In this section, we first review recent advances made in the understanding of corrosion inhibition by adsorbed organic molecules using atomistic DFT modeling and then STM experiments made in UHV at the molecular scale. Next, we discuss the few direct observations of inhibiting effects made in aqueous solution by in situ EC-STM at the nanometer and sub-nanometer scales. Emphasis is on the most studied BTAH/Cu system. 


\subsection{Atomistic DFT modeling of benzotriazole adsorption on copper}

DFT modeling is increasingly applied to study the interaction between inhibitor molecules on solid surfaces and to seek detailed insight for guiding the design of new corrosion inhibitors. For the BTAH/Cu system, the effects of the adsorbed configuration, the molecule deprotonation and coverage, the coordination of the metal surface atoms at adsorption sites, the presence of surface metal adatoms or of a surface oxide on the adsorption energy have been discussed, as well as the type of method used for computation $[255,256,257]$.

On oxide-free copper surfaces, DFT calculations at low coverage have shown that benzotriazole adsorbs in different configurations and bind weakly to strongly mostly depending on deprotonation (Figure 23) [255]. All identified adsorbed configurations adsorb more strongly than water and the variability in adsorption geometry can be viewed as an indicator of its capability to adopt several configurations and thus to sustain various situations depending on the local conditions at the surface. Whatever the adsorption mode, bonding is enhanced on $\mathrm{Cu}$ atoms of decreasing coordination passing from $\mathrm{Cu}(111)$ to $\mathrm{Cu}(100)$ and $\mathrm{Cu}(110)$ and even more when going to surface defects (step edges, kinks, adclusters) of increasingly lower coordination (Figure 23j). This suggests that the molecule is able to preferentially adsorb and thus inhibit corrosive reactions at the more reactive, less coordinated surface sites where corrosion preferentially attacks as shown with step edges and kinks in Section 3.1. Figure $23 \mathrm{j}$ also shows that, when compared to the adsorption of aggressive species like $\mathrm{Cl}$, only the adsorption of the deprotonated form compete energetically and that it competes increasingly on low coordinated defect sites, confirming the ability of the molecule to competitively adsorb and block or at least poison the most reactive sites for corrosion. The markedly weaker binding energy of the non dissociated forms of the adsorbed molecules has been proposed to explain the lower efficiency of benzotriazole at low $\mathrm{pH}$. Namely, in acidic 
media (and low potentials) the adsorbed deprotonated $\mathrm{BTA}_{\mathrm{ads}}$ may transform to $\mathrm{BTAH}_{\mathrm{ads}}$ as observed experimentally [258] and eventually desorb since $\mathrm{BTAH}_{\mathrm{ads}}$ bonding to the surface is found markedly weaker. The DFT simulations on $\mathrm{Cu}(111)$ show that $\mathrm{BTAH}_{\mid+\mathrm{H}}$ is the most probable adsorbate in such conditions with the molecule physisorbed in parallel configuration and forming a network with neighbor BTAH molecules via hydrogen-bonding (Figure 23d).

The deprotonated BTA molecule binds even more strongly when forming BTA-Cu adsorbed complexes including $\mathrm{Cu}$ adatoms. All $\mathrm{N}$ atoms are then saturated by bonding to $\mathrm{Cu}$ atoms as shown in Figure 23h,i [255]. The gain in energy per BTA molecule was found to be small, only about $0.1-0.2 \mathrm{eV}$, with respect to the perpendicular BTA configuration without $\mathrm{Cu}$ adatom but it is balanced by the energy $(0.76 \mathrm{eV}$ on $\mathrm{Cu}(111))$ needed to extract the $\mathrm{Cu}$ atoms from the topmost metal plane. This implies that the BTA-Cu bonding is much stronger in the organometallic complex than in the stand-alone adsorbed configuration and suggests that the complexes are better resistant to recombination with hydrogen. Thus the experimental conclusion [254] that benzotriazole inhibits corrosion via surface formation of organometallic complexes is supported by DFT results obtained at low coverage. It remains unstudied by DFT if the formation of these organometallic complexes result from a solid surface reaction between adsorbed BTA and/or BTAH and dissolving $\mathrm{Cu}$ atoms or from the redeposition of dissolved $\mathrm{Cu}(\mathrm{I})$ atoms after reaction in solution with $\mathrm{BTAH}$ molecules to form non soluble complexes.

Modeling of coverage effects by increasing the density of adsorbed molecules has shown that increasing coverage has nearly no effect on adsorption energy for parallel physisorbed BTAH but markedly weakens surface bonding for the perpendicularly adsorbed $\mathrm{BTAH}_{\mathrm{ads}}$ molecules. This is because a large permanent dipole moment causes repulsive interactions between the dipoles of the perpendicular $\mathrm{BTAH}_{\mathrm{ads}}$ molecules at long range. This coverage effect is not observed for the deprotonated $\mathrm{BTA}_{\mathrm{ads}}$ molecules for which adsorption 
considerably reduces the dipole due to charge transfer and thus the dipole-dipole interactions. As surface coverage increases, deprotonation becomes more favorable because the repulsion between weakly chemisorbed $\mathrm{BTAH}_{\mathrm{ads}}$ molecules is increasingly stronger and the lateral interactions between $\mathrm{BTA}_{\mathrm{ads}}$ molecules weaker.

Implementation of van der Waals interactions in the functionals used in DFT has also been applied to include dispersion forces in the optimization of protonated and deprotonated adsorbates on (111)-oriented copper and to better account for coverage effects [256]. At low coverage, the H-bonded BTAH molecules were confirmed to preferentially adsorb flat while at high coverage the upright configuration is preferred and, at intermediate coverage, mixed flat and upright structures were observed. The change in $\mathrm{BTAH}_{\mathrm{ads}}$ configuration from flatlying physisorbed to upright chemisorbed was found to be driven by steric interactions. At low coverage, the use of vdW-inclusive exchange-correlation functional make tilted structures competitive with flat-lying structures for isolated molecules. At high coverage, the better description of the interaction between the benzene groups of the upright molecules leads to shorter equilibrium distance between neighbor molecules and increased adsorption energy. For the deprotonated BTA molecule, BTA- $\mathrm{Cu}_{\mathrm{ad}}-\mathrm{BTA}$ dimers or $\left(\mathrm{BTA}-\mathrm{Cu}_{\mathrm{ad}}-\mathrm{BTA}\right) \mathrm{n}$ polymers including $\mathrm{Cu}$ adatoms were confirmed to be lowest energy structures in the high coverage regime. The molecules adsorb via the azole group and stand vertical. Stacked configurations of the BTA- $\mathrm{Cu}_{\mathrm{ad}}-\mathrm{BTA}$ dimers are stabilized by the vdW interactions between the benzene rings. The gain in adsorption energy was found to be about $2 \mathrm{eV}$ per adsorbed molecule for BTA with respect to BTAH, similar to that found with non vdW-inclusive calculations (Figure 23j). It was concluded from these coverage-dependent calculations performed on $\mathrm{Cu}(111)$ and including vdW interactions that the formation of close packed adlayers, that could act as a physical barrier blocking the adsorption of corrosive species, destabilizes the system for both BTAH and BTA but only weakly as judged from the variation 
of adsorption energy per molecule. For the stacked BTA- $\mathrm{Cu}_{\mathrm{ad}}-\mathrm{BTA}$ dimers, a stabilization of the system of $\sim 0.2 \mathrm{eV} \mathrm{mol}^{-1}$ has even been calculated.

Copper oxides do not dissolve at $\mathrm{pH}>5$, which results in surface passivation by oxide films (see Section 4.1). Literature is controversial on the effect of the surface oxide on benzotriazole adsorption, some studies suggesting that surface oxides play an important role while other studies do not (see [254] and references therein). The adsorption of benzotriazole has been studied by DFT on (111)-oriented $\mathrm{Cu}_{2} \mathrm{O}$ surfaces $[255,257,259]$ corresponding to the actual growth direction of the $\mathrm{Cu}(\mathrm{I})$ oxide passive film on (111)-oriented copper [36,37]. Like on oxide-free surfaces, benzotriazole was found to bond to $\mathrm{Cu}$ sites of $\mathrm{Cu}_{2} \mathrm{O}$ surfaces via the nitrogen atoms of the triazole group. Deprotonated BTA forms at least two bonds between N and $\mathrm{Cu}$ and BTAH at most two; BTAH is also relatively strongly $\mathrm{H}$-bonded to one surface $\mathrm{O}$ anion [257]. Also like on metallic surfaces, BTAH binds considerably weaker to $\mathrm{Cu}_{2} \mathrm{O}$ surfaces than BTA and bonding is markedly stronger to coordinatively unsaturated $\mathrm{Cu}$ sites. The calculated binding energies of BTAH are -0.4 and $-1.5 \mathrm{eV}$ on coordinatively saturated sites of non-stoichiometric $\mathrm{Cu}_{2} \mathrm{O}(111)$ (i.e. without $\mathrm{Cu}$ unsaturated termination) and coordinatively unsaturated sites of stoichiometric $\mathrm{Cu}_{2} \mathrm{O}(111)$, respectively, to be compared to -1.7 and $2.8 \mathrm{eV}$ for BTA, respectively. The bonding of benzotriazole to coordinatively unsaturated sites overcompensates the thermodynamic deficiency of stoichiometric $\mathrm{Cu}_{2} \mathrm{O}(111)$ (i.e. with $\mathrm{Cu}$ unsaturated termination). Van der Waals dispersion interactions stabilize the adsorbed structures by about $0.4 \mathrm{eV} \mathrm{mol}^{-1}$ on average without changing the relative stability trends. Comparison between oxide and metallic surfaces shows that BTAH binds considerably stronger to $\mathrm{Cu}_{2} \mathrm{O}$ surface exhibiting sites of reduced coordination than to metallic $\mathrm{Cu}$ surfaces, in contrast to deprotonated BTA for which bonding to metallic $\mathrm{Cu}$ surfaces is markedly stronger. Only the BTA bonding to coordinatively unsaturated sites on the oxide is comparably strong to the BTA bonding to coordinatively saturated sites on 
$\mathrm{Cu}(111)$; still BTA is less strongly bonded on the oxide than to under-coordinated surface defects on close-packed $\mathrm{Cu}$ surfaces or to more open $\mathrm{Cu}(\mathrm{hkl})$ metallic surfaces.

In acidic conditions, benzotriazole is a less effective inhibitor than in alkaline conditions. Based on DFT data, this can be explained by a lower adsorption energy of the protonated BTAH molecules forming a close packed barrier layer and their higher probability for desorption. Besides, if the close packed barrier layer is or becomes defective, its local failure cannot be compensated by the growth of stable anodic oxide passivating the surface. In neutral or alkaline condition where $\mathrm{Cu}$ oxide films grow in the anodic oxidation range, the oxide-free copper surface may be covered by more strongly adsorbed BTA at potential below the Nernst oxidation potential. Anodic oxidation at Nernst potential may be poisoned or even blocked by the strongly adsorbed inhibitor molecules. However, if the close packed inhibitor layer is incomplete or defective, oxide patches may grow locally, and get covered by strongly adsorbed BTAH. The boundary between oxide patches and metallic areas, covered by BTAH and BTA, respectively, according to the DFT data, may be sites poorly resistive to corrosive attack where the inhibitor is less or not effective owing to the mixed oxide/metallic state of the surface at these sites. At high oversaturation potential, anodic oxidation displaces the strongly adsorbed BTA on the metallic surface and anodic oxides will form unless their growth is poisoned by aggressive species like $\mathrm{Cl}$. The efficiency of the inhibitor is then dependent on its role on the competitive adsorption between $\mathrm{Cl}$ and $\mathrm{OH}$. These competing reactions of inhibitor adsorption, anodic oxidation and poisoning adsorption of aggressive species remain to be tested by DFT modeling and studied experimentally with appropriate model systems. 


\subsection{UHV studies of benzotriazole adsorption on copper}

UHV-STM observations of BTAH adsorption on $\mathrm{Cu}(111)$, combined with TPD and HREELS measurements, confirmed that physisorbed and chemisorbed phases are formed depending on coverage and evidenced a highly ordered organometallic phase at saturation coverage [260,261]. At low coverage BTAH adsorbs weakly (physisorption) and form mobile flat lying species that react with under-coordinated $\mathrm{Cu}$ atoms at surface defects and step edges to form deprotonated chemisorbed species in upright configuration and assigned to BTA-CuBTA dimers at step edges and Cu-BTA monomers at surface defects [260]. The BTA-CuBTA dimers and Cu-BTA monomers tend to condense into chains, sections of which diffuse on the terraces. At intermediate coverage, the density of molecular chains increases and a pseudo hexagonal structure is observed next to $(2 \times 1)$ reconstructed adsorbate-free regions (Figure 24a).

The ordered pseudo hexagonal phase covers the surface at saturation coverage and is still observed below physisorbed phases at multilayer coverage. Its lattice vectors are $\sim 4.2 \mathrm{~nm}$ and it contains about 360 surface atoms (Figure 24). It can be described as made of three buiding blocks rotated $60^{\circ}$ with respect to each other (Figure 24b). Each building block consists of three upright BTA-Cu-BTA dimers aligned parallel to the close packed $\langle 110\rangle$ directions and two upright $\mathrm{Cu}-\mathrm{BTA}$ monomers whose orientation cannot be inferred from their STM appearance and possibly rotating or vibrating more freely than the dimers (inset of Figure 24b). The exact adsorption sites for these adsorbed molecular species was not retrieved in this study and are hypothesized in the models. TPD measurements showed that the physisorbed and chemisorbed species coexist at low coverage, with desorption observed between 350 and $375 \mathrm{~K}$ and between 550 and $600 \mathrm{~K}$, respectively. HREELS and STM showed increased ordering after complete desorption of the physisorbed layer. 
The pseudo hexagonal phase that could provide inhibition since formed at saturation coverage was not predicted by the DFT modelling studies described in Section 6.1, mostly because of its huge dimensions. Still, its building blocks contain the organometallic adsorbed complexes predicted by DFT to be among the most stable configurations. As observed in Figure $24 \mathrm{~b}$, this phase contains distorted triangular and hexagonal sites of nanometric dimensions that appear free of adsorbed inhibitor molecules. These sites can be assimilated to pores for molecular or ionic aggressive species from the environment. Hence this phase, which could be thought as providing inhibition since formed at saturation coverage, does not seem to have a high enough compacity to be a fully effective barrier layer for the metal substrate.

\subsection{Direct nanoscale in situ EC-STM observations}

Nanometer and sub-nanometer scale insight on how corrosion inhibitors protect the surface can be brought using atomically flat single-crystal surfaces polarized below or close to the Nernst potential for anodic dissolution and analyzed in situ by EC-STM. For BTAH on copper, the $\mathrm{Cu}(001)$ surface has been used to address the effect of the organic molecule in acid solutions $[60,262,263,264]$. Comparative studies addressing the role of the surface structure have been reported for $\mathrm{Cu}(110)$ and $\mathrm{Cu}(111)$ in perchloric acid solution [264] and for $\mathrm{Cu}(111)$ in sulfuric acid solution [265]. Adsorption of 5-mercapto-1-phenyl-tetrazole was studied on $\mathrm{Cu}(111)$ in $\mathrm{H}_{2} \mathrm{SO}_{4}$ solution [266]. Alkanethiol self-assembled monolayers, strongly bonding to copper, have also been studied as model inhibiting layers on $\mathrm{Cu}(001)$ in $\mathrm{HCl}$ solution [267].

Figure 25 exemplifies how an adsorbed layer of inhibiting organic species modifies the nanoscale dissolution mechanism. The uniform receding step flow process described in Section 3 is no longer observed. Instead, the dissolution proceeds locally and leads to surface 
roughening via the formation of pits of monoatomic depth that nucleate and grow on the terraces. The effect, observed with the inhibitor adsorbed at sub-monolayer coverage, is explained by the preferential adsorption of the inhibiting species at the coordinately unsaturated metal step edges like calculated by DFT modeling (Section 6.1), and thus by preferential protection or "passivation" of the step edges against dissolution. The pits form on the terraces presumably at failure sites where the inhibiting adlayer is defective and fails to protect against corrosion, like in the presence of defective 2D passive layers (Section 3.2). Depending on the electrolyte concentration in BTAH inhibitor, the onset of dissolution is shifted anodically from 0.05 to $0.3 \mathrm{~V}$ as observed by EC-STM, (Figure 25(Top)).

[INSERT Figure 25]

Comparative observations made in the double layer potential region in sulfuric and hydrochloric acid solutions on $\mathrm{Cu}(001)$ were made to address the reduced inhibiting efficiency of BTAH on the dissolution of $\mathrm{Cu}$. The inhibitor forms ordered adlayers for potentials $<-0.6 \mathrm{~V}_{\mathrm{SCE}}$ in both solutions. The resulting $(\sqrt{5} \mathrm{x} \sqrt{5}) \mathrm{R} 26.6^{\circ}$ superstructure has been assigned to $\mathrm{BTAH}_{\mathrm{ads}}$ molecules standing upright (or slightly tilted), stacked parallel and bonded via the triazole group to $\mathrm{Cu}(001)$. In $\mathrm{HCl}$ solution, increasing the potential (>-0.6 $\mathrm{V}_{\mathrm{SCE}}$ ) does not modify the surface structure nor the surface dynamic behavior compared to that observed in BTAH-free solutions (Section 3.1). Figure 26 shows that the ordered structure of $\mathrm{BTAH}_{\mathrm{ads}}$ molecules is displaced by formation of a $\mathrm{c}(2 \times 2)$ structure of adsorbed chloride ions that is also produced in the absence of inhibitor.

[INSERT Figure 26]

In $\mathrm{H}_{2} \mathrm{SO}_{4}$ solution, the inhibitor adlayer is not displaced and is stable in the whole region preceding dissolution. With increasing potential, the surface structure becomes chainlike which has been assigned to the polymerization of a $\mathrm{Cu}(\mathrm{I}) \mathrm{BTA}_{\mathrm{ads}}$ adlayer. This EC-STM 
interpretation is in line with the strongly adsorbed molecular configurations later calculated by DFT [255,256]. Based on these molecular scale EC-STM data [262,263], it has been advanced that the lower efficiency of the inhibitor in Cl-containing electrolyte would find its origin in the mechanism of formation of the $\mathrm{Cu}(\mathrm{I}) \mathrm{BTA} \mathrm{Ads}_{\mathrm{ads}}$ adlayer. The $\mathrm{Cl} \mathrm{c}(2 \times 2)$ adlayer formed in $\mathrm{HCl}$ would hinder the polymerization of the $\mathrm{Cu}(\mathrm{I}) \mathrm{BTA}_{\text {ads }}$ phase by direct conversion of the chemisorbed $\mathrm{BTAH}_{\mathrm{ads}}$ layer. As a result, no $\mathrm{BTAH}_{\mathrm{ads}}$ or $\mathrm{Cu}(\mathrm{I}) \mathrm{BTA}_{\mathrm{ads}}$ adlayer would form a barrier protecting the surface in the potential range of dissolution in $\mathrm{HCl}$ solution and the surface would dissolve by the same receding step flow mechanism observed by EC-STM in BTAH-free conditions. $\mathrm{Cu}$ (I)BTA would be formed in the solution by dissolving species $\left(\mathrm{CuCl}_{2}^{-}\right)$reacting with $\mathrm{BTAH}$, and subsequently deposited by precipitation on the copper surface covered by the $\mathrm{Cl} \mathrm{c}(2 \times 2)$ adlayer. The protection efficiency of this inhibiting layer produced by dissolution/re-deposition would be lower than that of the inhibiting layer formed on the $\mathrm{Cl}_{\mathrm{ads}}$-free surface in sulfuric acid solutions and directly produced at the surface by extracted $\mathrm{Cu}(\mathrm{I})$ ions reacting with adsorbed BTAH molecules in the $\mathrm{Cu}(\mathrm{I})$ oxidation range.

On copper, EC-STM and EC-AFM observations limited to the nanoscale were also used to study or optimize corrosion inhibition on polycrystalline substrates. For instance, 2mercaptobenzoxazole (MBO) was investigated by EC-STM in $\mathrm{NaCl}$ solution [268]. The topographic images revealed that a 3D and compact film is rapidly formed with an inhibition efficiency of $99 \%$. XPS showed that the film contained copper as $\mathrm{Cu}(\mathrm{I})$ and that sulfur and nitrogen had an altered bonding configuration. Like for BTAH in Cl-containing solution, it was concluded that the inhibiting film is constituted by a copper complex produced by reaction of the $\mathrm{MBO}$ inhibitor-with dissolving $\mathrm{Cu}(\mathrm{I})$ species and insoluble in water. EC-AFM brought insight on the morphological aspects of the optimization of corrosion inhibition by a non-toxic "green" molecule, sodium heptanoate. [269]. Optimal efficiency (obtained at pH 8, 
$\left[\mathrm{C}_{7} \mathrm{H}_{13} \mathrm{O}_{2} \mathrm{Na}\right]=0.08 \mathrm{M}$ ) was shown to be linked to the formation of a continuous thin film of metallic soap, acting as a blocking barrier and mainly constituted of copper heptanoate. Reduced efficiency (obtained at pH 5.7 or 11) was found to be associated with the formation of discontinuous films acting as a defective barrier and including copper heptanoate or copper oxides crystals.

\section{Conclusion and outlook}

Experimental approaches using advanced surface analytical and electrochemical methods applied to model solid-liquid interfaces and combined with theoretical approaches based on atomistic modeling enable progress in corrosion science at the atomic and nanometric scales. It brings deep insight into the reaction mechanisms occurring in the very first stages triggering a corrosion process and it is the basis for developing advanced strategies of corrosion protection acting on corrosion initiation, i.e. before a corrosion process propagates. In this review, contemporary aspects of corrosion science have been covered to show how insightful atomic and nanometric scale characterization is to understand the metalwater interface and its structure, anodic dissolution and dealloying, self-protection against corrosion by passivation, passivity breakdown and localized corrosion initiation, and corrosion inhibition by organic molecules.

Much progress in the knowledge of the structure of metal-water interface at the atomic scale has been achieved thanks to UHV studies performed on numerous metals at cryogenic temperature mostly by STM coupled to DFT modeling. Significant distortions of the conventional ice 'bilayer' structure resulting from a strongly material- and structure-dependent balance between water-metal interactions and water-water hydrogen bonding have been evidenced, as well as the alterations and stabilization induced by hydroxyl groups and hydrogen atoms produced by water dissociation. Co-adsorption of oxygen has been shown to 
markedly promote water dissociation at low coverage. Bridging the "immersion gap" to obtain detailed structural information at or near atomic level at the solid/liquid interface remains a challenging issue. Anion adsorption has been widely studied albeit not covered in the present review focusing on the structural aspects of the adsorption of hydroxide ions. The studies performed in situ show that hydroxide ions adsorption precedes 3D oxide growth and produces 2D overlayer structures of adsorbed hydroxyl groups acting as structural precursors for passive films 3D growth. The topmost metal plane is reconstructed to mimic the building blocks found in the 3D oxide (passive film) grown at higher anodic overpotential. These aspects are yet to be studied for reactive metals $(\mathrm{Fe}, \mathrm{Al}, \mathrm{Ti}, \mathrm{Mg})$ and their alloys widely used as structure or components materials, the challenge being the preparation of atomically flat surfaces and the precise control of an oxide-free surface at the solid/liquid interface.

Anodic dissolution and dealloying is an aspect of corrosion science on which the use of a surface science approach has brought a deep insight at the atomic scale. The studies performed on pure metals have shown a major role played at the surface by the under coordinated atomic sites (i.e. step edges). Atoms at these defect sites preferentially dissolve thereby causing active dissolution to proceed by step flow with the surface atomic structure affecting the anisotropy of the mechanism. Adlayers of strongly adsorbed anions do not alter this mechanism but influence the anisotropy of active dissolution. The same is true for nonpassivating 2D compound layers. In the presence 2D layers of passivating oxides and/or hydroxides, the dissolution mechanism is altered. It becomes preferential at the non-ordered sites of the protective layer and thus promoted at its weakest sites. As a result, nanopitting is initiated on the substrate terraces first two dimensionally and then three dimensionally by a repeated mechanism. For dealloying, the $\mathrm{CuAu}$ system has been most thoroughly studied. Dissolution of the less noble $\mathrm{Cu}$ occurs uniformly both at the alloy substrate step edges and on terraces, in contrast with pure metals. GIXD studies showed that the dealloyed surface layers 
are sequentially built-up. An ultra-thin and gold-rich layer is first formed with CBA inverted stacking, followed by an island layer of pure gold, and finally by a nanoporous layer of nanoscale ligaments with $\mathrm{ABC}$ substrate oriented stacking. Iodide, chloride, or bromide ions would enhance surface diffusion thereby promoting the structural transition of the build-up sequence. The main effect of organic surface layer SAMs modeling corrosion inhibitors is to inhibit uniform dealloying corrosion by suppression of surface diffusion. Dealloying proceeds then in localized regions. A similar level of information on dealloying or selective dissolution remains lacking for more reactive alloys such as stainless steel, aluminum, titanium or magnesium alloys. Like on pure reactive metals, this is due to the difficulty to prepare and to maintain in situ an oxide-free, atomically flat and slowly dissolving active state.

A surface science approach has also been employed to thoroughly study the passivation of metals and alloys at the atomic and nanometric scales. Passive films studied on pure copper, nickel, iron, chromium, cobalt metals and on stainless steels were found crystallized in most cases. They are polycrystalline and textured with nanoscale grains. The grains expose a facetted surface because the oxide lattice grows in slightly tilted epitaxy on the metal lattice. The oxide surface is hydroxylated. Chromium-rich passive films required to be aged under polarization to crystallize. On stainless steel, the $\mathrm{Cr}$ enrichment of the passive films may be inhomogeneous at the nanoscale, influencing the local resistance to localized corrosion initiation.

Passivity breakdown is a major issue at the origin of localized corrosion of passivable metallic materials. The model studies performed on single-crystal surfaces of pure nickel have revealed that, in the passive state, dissolution proceeds by a step flow mechanism with preferential removal of the oxide lattice at the passive film step edges. DFT modeling suggests that the passive film may breakdown by a thinning mechanism promoted by chloride adsorption at step edges with formation of $\mathrm{Ni}(\mathrm{OH}) \mathrm{Cl}$ or $\mathrm{Ni}(\mathrm{Cl})_{2}$ dissolving complexes. For 
step edges saturated by $\mathrm{Cl}$ adsorption, a penetration-induced mechanism of passivity breakdown may become prevalent as suggested by calculations. Reactive MD calculations suggest that chloride ions preferentially interact with passive film surfaces that are deficient in oxygen. At the nanometer scale, grain boundaries in polycrystalline oxide passive films on metals are prevalent defect sites where passive films break down and localized corrosion initiates as observed locally on nickel. Local electronic properties probed on passivated nickel show a markedly different surface density of states at the passive film grain boundaries explained by the presence of oxygen vacancies. Anionic transport and chloride entry can be expected to be locally promoted in these sites.

Like for the metal-water interface, corrosion inhibition by organic molecules, and most notably benzotriazole adsorption on copper, has been widely studied experimentally under UHV and computationally by DFT. The results show that benzotriazole adsorb in a variety of different forms shaped by H-bonding, steric repulsions and van der Waals interactions. It bonds stronger to the metal surface in the deprotonated BTA form and to the oxide surface in the protonated BTAH form. Perpendicular adsorption via the triazole group is favored at high coverage. BTA dimers or chains incorporating $\mathrm{Cu}$ adatoms, also observed by STM, were the structures found to be the most stable on copper independently of coverage. Bonding is stronger to unsaturated (i.e. defect) $\mathrm{Cu}$ sites both on $\mathrm{Cu}$ metal and on $\mathrm{Cu}_{2} \mathrm{O}$ oxide surfaces. The data show a capability of the molecule to efficiently comply with various surface states and structures, thus providing inhibition by strong bonding competitive to that of aggressive elements. Much less experimental work has been performed in situ on similar model systems at sub-nanometer scale, although with striking output that revealed inhibition of the preferential sites (i.e. step edges) of corrosion and delocalization on terraces sites where the inhibitor layer is defective. In acidic conditions, failure of the inhibition has been directly observed to proceed by displacement of the inhibitor layer by aggressive anions $\left(\mathrm{Cl}^{-}\right)$forming 
a strongly adsorbed substitute layer. Similar investigation in conditions where the metal surface is able to passivate at the defects of the inhibitor layer are yet to be performed to study the corrosion mechanisms in conditions where anodic dissolution, promoted by aggressive ions adsorption, can be mitigated both by competing oxide growth and inhibitor adsorption.

On the aspects related to the adsorption of water or inhibitor molecules on oxide-free surfaces, we foresee a continuing research effort combining UHV experimental studies coupled to atomistic DFT modeling which has proven the most insightful approach to unravel atomic details. This should bring deeper knowledge on the effects of the substrate material and its structure on adsorption configuration and dissociation, and on the role of adsorbate coverage, co-adsorbed oxygen and surface oxides as well as that of the competing adsorption of species known as aggressive in aqueous media. Still this approach will remain limited by the "immersion gap" with questionable relevance to real solid/liquid interfaces and their reactivity in corrosive conditions. It is a widely shared conviction that all reacting solid/liquid interfaces even when modeled must be tested in situ as well as characterized in situ whenever feasible or ex situ with minimum alteration. This approach has revealed most powerful to bring atomic but also nanometric insight into the mechanisms of anodic dissolution and dealloying, passivation and residual dissolution in the passive state, passivity breakdown and corrosion inhibition mechanisms. Despite its success, this approach is developed by a small number of research groups in the corrosion science community, mostly because of the difficulty to prepare model solid/liquid interfaces well controlled at atomic or nanometric scale, particularly for highly reactive metals like $\mathrm{Ti}, \mathrm{Al}, \mathrm{Mg}$ and their alloys. We think that future progress in corrosion science at atomic and nanometric scales will be made by combining UHV facilities for surface preparation and characterization with in situ electrochemical testing of the corrosion properties and characterization of the corrosioninduced alterations. A prerequisite to such a combined approach is to ensure minimum or no 
alteration during return transfer from UHV to liquid. The design of model interfaces relevant for the studied corrosion process and the availability of equipments combining UHV surface characterization techniques (microscopy and spectroscopy) with electrochemistry will be a key to the success of this approach.

Coupling with DFT calculations will remain necessary for atomic scale characterization of the designed interfaces. The data obtained experimentally on corroded and/or passivated surfaces, including atomic structure, nanostructure and defects, must be used to design the models used in DFT calculations. Implementation of $\mathrm{pH}$ effects and potential-driven atomic transport and $\mathrm{pH}$ is necessary. On can foresee that specific steps of complex corrosion pathways will be tested more accurately using DFT while the complete reaction pathways will be tested thanks to the development of MD simulations.

\section{References}

[1] Paul Virmani, Y. Corrosion Costs and Preventive Strategies in the United States. Publication No. FHWA-RD-01-156. http://www.corrosioncost.com.

[2] Marcus P, editor. Corrosion Mechanisms in Theory and Practice, 3rd Edition. CRC Press, Taylor and Francis; 2011.

[3] Marcus P, Mansfeld F, editors. Analytical Methods in Corrosion Science and Engineering. CRC Press, Taylor and Francis; 2006.

[4] Taylor CD, Marcus P, editors. Molecular Modeling of Corrosion Processes - Scientific Development and Engineering Applications. John Wiley \& Sons; 2015.

[5] Erlebacher J, Aziz MJ, Karma A, Dimitrov N, Sieradzki K. Evolution of nanoporosity in dealloying. Nature 2001;410:450-453.

[6] Maurice V, Despert G, Zanna S, Bacos MP, Marcus P. Self-assembling of atomic vacancies at an oxide/intermetallic alloy interface. Nature Mater. 2004;3:687-691.

[7] Renner FU, Stierle A, Dosch H, Kolb DM, Lee TL, Zegenhagen J. Initial corrosion observed on the atomic scale. Nature 2006;439:707-710.

[8] Thiel P, Madey T. The interaction of water with solid-surfaces: Fundamental aspects. Surf. Sci. Rep. 1987;7:211-385. 
[9] Henderson MA. The interaction of water with solid-surfaces: Fundamental aspects revisited. Surf. Sci. Rep. 2002;46:1-308.

[10] Ito M. Structures of water at electrified interfaces: Microscopic understanding of electrode potential in electric double layers on electrode surfaces Surf. Sci. Rep. 2008;63:329389.

[11] Hodgson A, Haq S. Water adsorption and the wetting of metal surfaces. Surf. Sci. Rep. 2009;64:381-451.

[12] Schirosa T, Andersson KJ, Pettersson LGM, Nilssona A, Ogasawara H. Chemical bonding of water to metal surfaces studied with core-level spectroscopies. J. Elect. Spectros. Rel. Phen. 2010;177:85-98.

[13] Carrasco J, Hodgson A, Michaelides A. A molecular perspective of water at metal interfaces. Nature Mater. 2012;11:667-674.

[14] Maier S, Salmeron M. How Does Water Wet a Surface? Acc. Chem. Res. 2015;48:2783-2790.

[15] Maier S, Stass I, Cerdá JI, Salmeron M. Unveiling the Mechanism of Water Partial Dissociation on Ru(0001). Phys. Rev. Lett. 2014;112:126101.

[16] Cabrera-Sanfelix P, Sanchez-Portal D, Mugarza A, Shimizu TK, Salmeron M, Arnau A. Water Adsorption on $\mathrm{O}(2 \times 2) / \mathrm{Ru}(0001)$ : STM Experiments and First-Principles

Calculations. Phys. Rev. B: Condens. Matter Mater. Phys. 2007;76:205438.

[17] Maier S, Cabrera-Sanfelix P, Stass I, Sanchez-Portal D, Arnau A, Salmeron M. WaterInduced Surface Reconstruction of Oxygen $(2 \times 1)$ Covered Ru(0001). Phys. Rev. B:

Condens. Matter Mater. Phys. 2010, 82, 075421.

[18] Gewirth AA, Niece K. Electrochemical applications of in situ scanning probe microscopy. Chem. Rev. 1997;97:1129-1162.

[19] Itaya K. In situ scanning tunneling microscopy in electrolyte solutions. Prog. Surf. Sci. 1998;58:121-247.

[20] Kolb DM. Electrochemical surface science. Angew. Chem., Int. Ed. 2001;40:1162-1181.

[21] Magnussen OM. Ordered anion adlayers on metal electrode surfaces. Chem. Rev. 2002;102:679-725.

[22] Itaya K. Recent Progresses of Electrochemical Surface Science - Importance of Surface Imaging with Atomic Scale. Electrochemistry 2015;83:670-679.

[23] Funtikov AM, Stimming U, Vogel R. Anion adsorption from sulfuric acid solutions on $\mathrm{Pt}(111)$ single-crystal electrodes. J. Electroanal. Chem. 1997;428:147-153.

[24] Wan LJ, Yau SL, Itaya K. Atomic structure of adsorbed sulfate on Rh(111) in sulfuric acid solution. J. Phys. Chem. 1995;99:9507-9513.

[25] Wan LJ, Hara M, Inukai J, Itaya K. In situ STM of well-defined $\operatorname{Ir}(111)$ surface: high resolution imaging of adsorbed sulfate. J. Phys. Chem. B 1999;103:6978-6983.

[26] Okada J, Inukai J, Itaya K. Underpotential and bulk deposition of copper on $\operatorname{Pd}(111)$ in sulfuric acid solution studied by in situ scanning tunneling microscopy. Phys. Chem. Chem. Phys., 2001;3:3297-3302. 
[27] Lennartz M, Broekmann P, Arenz M, Stuhlmann C, Wandelt K. Sulfate adsorption on $\mathrm{Cu}(111)$ studied by in-situ IRRAS and STM: revealing the adsorption site and desorption behavior. Surf. Sci. 1999;442:215-222.

[28] Lu PC, Yang CH, Yau SL, Zei MS. In situ Scanning Tunneling Microscopy of (Bi)sulfate, Oxygen, and Iodine Adlayers Chemisorbed on a Well-Defined Ru(001) Electrode Prepared in a Non-Ultrahigh-Vacuum Environment. Langmuir (2002);18:754-762.

[29] Yamamoto S, Bluhm H, Andersson K, Ketteler G, Ogasawara H, Salmeron M, Nilsson A. In situ X-ray photoelectron spectroscopy studies of water on metals and oxides at ambient conditions. J. Phys.: Condens. Matter. 2008;20:184025.

[30] Stoerzinger KA, Hong WT, Crumlin EJ, Bluhm H, Shao-Horn Y, Insights into Electrochemical Reactions from Ambient Pressure Photoelectron Spectroscopy. Acc. Chem. Res. 2015;48:2976-2983.

[31] Jürgensen A, Esser N, Hergenröder R. Near ambient pressure XPS with a conventional X-ray source. Surf. Interface Anal. 2012;44:1100-1103.

[32] Yamamoto S, Andersson K, Bluhm H, Ketteler G, Starr D, Schiros T, Pettersson LGM, Salmerón M, Ogasawara H, Nilsson A. Hydroxyl-Induced Wetting of Metals by Water at Near-Ambient Conditions. J. Phys. Chem. C 2007;111:7848-7850.

[33] Mayer ST, Muller RH. An In situ Raman Spectroscopy Study of the Anodic Oxidation of Copper in Alkaline Media. J. Electrochem. Soc. 1992;139:426-434.

[34] Härtinger S, Pettinger B, Doblhofer K, Cathodic formation of a hydroxyde adsorbate on copper (111) electrodes in alkaline electrolyte. J. Electroanal. Chem. 1995;397:335-338.

[35] Maurice V, Strehblow H-H, Marcus P. In situ STM study of the initial stages of oxidation of $\mathrm{Cu}$ (111) in aqueous solution. Surf. Sci. 2000;458:185-194.

[36] Kunze J, Maurice V, Klein LH, Strehblow H-H, Marcus P. In situ scanning tunneling microscopy study of the anodic oxidation of $\mathrm{Cu}(111)$ in $0.1 \mathrm{M} \mathrm{NaoH}$. J. Phys. Chem. B 2001;105:4263-4269.

[37] Kunze J, Maurice V, Klein LH, Strehblow H-H, Marcus P. In situ STM study of the effect of chlorides on the initial stages of anodic oxidation of $\mathrm{Cu}(111)$ in alkaline solutions. Electrochim. Acta 2003;48:1157-1167.

[38] Kunze J, Maurice V, Klein LH, Strehblow H-H, Marcus P. In situ STM study of the anodic oxidation of $\mathrm{Cu}(001)$ in $0.1 \mathrm{M} \mathrm{NaOH}$. J. Electroanal. Chem. 2003;554:113-125.

[39] Kunze J, Strehblow H-H, Staikov G, In situ STM study of the initial stages of electrochemical oxide formation at the $\mathrm{Ag}(111) / 0.1 \mathrm{M} \mathrm{NaOH}(\mathrm{aq})$ interface. Electrochem. Comm. 2004;6:132-137.

[40] Maurice V, Klein LH, Strehblow H-H, Marcus P. In situ STM study of the surface structure, dissolution, and early stages of electrochemical oxidation of the Ag (111) electrode. J. Phys. Chem. C 2007;111:16351-16361.

[41] Zemlyanov DY, Savinova ER, Scheybal A, Doblhofer K, Schlögl R. XPS observation of OH groups incorporated in an Ag (111) electrode. Surf. Sci. 1998;418:441-456.

[42] Jovic BM, Jovic V.D, Stafford G. R. Cyclic voltammetry on $\operatorname{Ag}(111)$ and $\operatorname{Ag}(100)$ faces in sodium hydroxide solutions. Electrochem. Comm. 1999;1:247-251. 
[43] Savinova ER, Zemlyanov D, Pettinger B, Scheybal A, Schlögl R, Doblhofer K. On the mechanism of $\mathrm{Ag}$ (111) sub-monolayer oxidation: a combined electrochemical, in situ SERS and ex situ XPS study. Electrochim. Acta 2000;46:175-183.

[44] Savinova ER, Kraft P, Pettinger B, Doblhofer K. In situ Raman spectroscopy studies of the interface between silver(111) electrodes and alkaline NaF electrolytes. J. Electroanal. Chem. 1997;430:47-56.

[45] Savinova ER, Zemlyanov D, Scheybal A, Schedelniedrig T, Doblhofer K, Schlögl R. Ex situ X-ray Photoelectron Spectroscopy Study of the Interface between a $\operatorname{Ag}(111)$ Electrode and an Alkaline Electrolyte. 2. Structure of the Double Layer. Langmuir 1999;15:6552-6556.

[46] Beden B, Floner D, Leger J-M, Lamy C. A voltammetric study of the formation on hydroxides and oxyhydroxides on nickel single-crystal electrodes in contact with an alkaline solution. Surf. Sci. 1985;162:822-829.

[47] Hahn F, Beden B, Croissant MJ, Lamy C. In situ UV visible reflectance spectroscopic investigation of the nickel electrode-alkaline solution interface Electrochim. Acta 1986;31:335 342 .

[48] Simpraga R, Conway BE. Realization of monolayer levels of surface oxidation of nickel by anodization at low temperatures. J. Electroanal Chem. 1990;280:341-357.

[49] Paik WK, Szklarska-Smialowska Z. Reflectance and ellipsometric study of anodic passive films formed on nickel in sodium hydroxide solution. Surf. Sci. 1980;96:401-412.

[50] Hoppe HW, Strehblow H-H. XPS and UPS examinations of the formation of passive layers on $\mathrm{Ni}$ in $1 \mathrm{M}$ sodium hydroxide and $0.5 \mathrm{M}$ sulphuric acid. Surf. Interf. Anal. 1989;14:121-131.

[51] Floner D, Lamy C, Leger J-M. Electrocatalytic oxidation of hydrogen on polycrystal and single-crystal nickel electrodes. Surf. Sci. 1990;234:87-97.

[52] Grden M, Klimek K, Czerwinski A. A quartz crystal microbalance study on a metallic nickel electrode. J. Solid State Electrochem. 2004;8:390-397.

[53] Grden M, Klimek K. EQCM studies on oxidation of metallic nickel electrode in basic solutions. J. Electroanal. Chem. 2005;581:122-131.

[54] Seyeux A, Maurice V, Klein LH, Marcus P. In situ scanning tunnelling microscopic study of the initial stages of growth and of the structure of the passive film on $\mathrm{Ni}$ (111) in 1 $\mathrm{mM} \mathrm{NaOH}(\mathrm{aq})$. J. Solid State Electrochem. 2005;9:337-346.

[55] Seyeux A, Maurice V, Klein LH, Marcus P. In situ STM study of the effect of chloride on passive film on nickel in alkaline solution. J. Electrochem. Soc. 2006;153:B453-B463.

[56] Suggs DW, Bard AJ. Scanning Tunneling Microscopic Study with Atomic Resolution of the Dissolution of $\mathrm{Cu}(111)$ in Aqueous Chloride Solutions. J. Am. Chem. Soc.

1994;116:10725-10733.

[57] Suggs DW, Bard AJ. Scanning Tunneling Microscopic Study with Atomic Resolution of the Dissolution of $\mathrm{Cu}(100)$ Electrodes in Aqueous Chloride Media. J. Phys. Chem.

1995;99:8349-8355.

[58] Moffat TP, Mat. STM Study of the Influence of Adsorption on Step Dynamics. Res. Soc. Symp. Proc. 1997;451:75. 
[59] Vogt MR, Lachenwitzer A, Magnussen OM, Behm RJ. In-situ STM study of the initial stages of corrosion of $\mathrm{Cu}(100)$ electrodes in sulfuric and hydrochloric acid solution. Surf. Sci. 1998;399:46-69.

[60] Magnussen OM, Vogt MR, Scherer J, Behm RJ. Double-layer structure, corrosion and corrosion inhibition of copper in aqueous solution. Appl Phys A 66 (1998) S447-S451.

[61] Broekmann P, Anastasescu M, Spaenig A, Lisowski W, Wandelt K. Atomic structures and dynamics of a $\mathrm{Cu}(100)$ electrode in dilute hydrobromic acid: An in situ STM study. J. Electroanal. Chem. 2001;500:241-254.

[62] Magnussen OM, Zitzler L, Gleich B, Vogt MR, Behm RJ. In-situ atomic-scale studies of the mechanisms and dynamics of metal dissolution by high-speed STM. Electrochim. Acta 2001;46:3725-3733.

[63] Broekmann P, Hai NTM, Wandelt K. Copper dissolution in the presence of a binary 2Dcompound: $\mathrm{CuI}$ on $\mathrm{Cu}(100)$. J. Appl. Electrochem. 2006;36:1241-1252.

[64] Phan TH, Kosmala T, Wandelt K. Potential dependence of self-assembled porphyrin layers on a $\mathrm{Cu}(111)$ electrode surface: In-situ STM study. Surf. Sci. 2015;631:207-212.

[65] Allgaier W, Heusler KE. Steps and kinks on $\{211\}$ iron surfaces and the kinetics of the iron electrode. J. Appl. Electrochem. 1979; 9:155-60.

[66] Dietterle M, Will T, Kolb D.M. Step dynamics at the Ag(111)-electrolyte interface. Surf. Sci. 1995;327:L495-L500.

[67] Suzuki T, Yamada T, Itaya K. In situ Electrochemical Scanning Tunneling Microscopy of Ni(111), Ni(100), and Sulfur-Modified Ni(100) in Acidic Solution. J. Phys. Chem. 1996;100:8954-8961.

[68] Ando S, Suzuki T, Itaya K. In situ electrochemical scanning tunneling microscopy of $\mathrm{Co}(0001)$ single-crystal electrodes in acidic solution. J. Electroanal. Chem. 431 (1997) 277284.

[69] K. Itaya, Atomic-scale aspects of anodic dissolution of metals: Studies by in situ scanning tunneling microscopy. In: Wieckowski A. editor. Interfacial Electrochemistry Theory, Experiments and Applications. New York: Marcel Dekker; 1999: pp. 187-210.

[70] Ando S, Suzuki T, Itaya K. Layer-by-layer anodic dissolution of sulfur-modified ni(100) electrodes: in situ scanning tunneling microscopy. J. Electroanal. Chem. 1996;412:1996.

[71] Teshima T, Ogaki, Itaya K. Effect of Adsorbed Iodine on the Dissolution and Deposition Reactions of $\operatorname{Ag}(100)$ : Studies by In situ STM. J. Phys. Chem. B 1997;101:2046-2053.

[72] Sashikata K, Matsui Y, Itaya K, Soriaga MP. Adsorbed-Iodine-Catalyzed Dissolution of Pd Single-Crystal Electrodes: Studies by Electrochemical Scanning Tunneling Microscopy. J. Phys. Chem. 100 (1996) 1996.

[73] Hai NTM, Huemann S, Hunger R, Jaegermann W, Wandelt K, Broekmann P, Combined Scanning Tunneling Microscopy and Synchrotron X-Ray Photoemission Spectroscopy Results on the Oxidative CuI Film Formation on Cu(111). J. Phys. Chem. C 2007, 111, 14768-14781.

[74] Lützenkirchen-Hecht D, Waligura CU, Strehblow H-H. An in situ exafs-study of corrosion products. Corrosion Sci. 1998;40:1037-1041.

[75] Pickering HW, Swann PR, Electron Metallography of Chemical Attack Upon Some Alloys Susceptible to Stress Corrosion Cracking. Corrosion 1963;19:373-389. 
[76] Stratmann M, Rohwerder M, Materials science: A pore view of corrosion. Nature 2001; 410:420-422.

[77] Newman RC. Stress-Corrosion Cracking Mechanisms. In: Marcus P, editor. Corrosion Mechanisms in Theory and Practice. 3rd ed. CRC Press, Taylor and Francis; 2011: pp. 499544.

[78] Oppenheim I.C, Trevor DJ, Chidsey CED, Trevor PL, Sieradzki K. In situ scanning tunneling microscopy of corrosion of silver-gold alloys. Science 1991;254:687-689.

[79] Moffat TP, Fan FR, Bard AJ, Electrochemical and scanning tunneling microscopic study of dealloying of Cu3Au. J. Electrochem. Soc. 1991;138:3224-3235.

[80] Chen SJ, Sanz F, Ogletree DF, Hallmark VM, Devine TM, Salmeron M. Selective dissolution of copper from $\mathrm{Au}-$ rich $\mathrm{Cu}-\mathrm{Au}$ alloys: an electro chemical STM study. Surf. Sci. 1993;292:289-297

[81] Renner FU, Stierle A, Dosch H, Kolb DM, Lee TL, Zegenhagen J. In situ X-ray diffraction study of the initial dealloying and passivation of $\mathrm{Cu} 3 \mathrm{Au}(111)$ during anodic dissolution. Phys. Rev. B 2008;77:235433.

[82] Renner FU, Eckstein GA, Lymperakis L, Dakkouri-Baldauf A, Rohwerder M, Neugebauer J, Stratmann M. In situ scanning tunneling microscopy study of selective dissolution of $\mathrm{Au3Cu}$ and $\mathrm{Cu} 3 \mathrm{Au}$ (001). Electrochim. Acta 2011;56:1694-1700.

[83] Pareek A, Borodin S, Bashir A, Ankah GN, Keil P, Eckstein GA, Rohwerder M, Stratmann M, Gruender Y, Renner FU. Initiation and Inhibition of Dealloying of SingleCrystalline Cu3Au (111) Surfaces. J. Am. Chem. Soc. 2011;133:18264-18271.

[84] Ankah GN, Pareek A, Cherevko S, Topalov AA, Rohwerder M, Renner, FU. The influence of halides on the initial selective dissolution of $\mathrm{Cu} 3 \mathrm{Au}$ (111). Electrochim. Acta 2012;85:384- 392.

[85] Ankah GN, Meimandi S, Renner FU, Dealloying of Cu3Pd Single-Crystal Surfaces. J. Electrochem. Soc. 2013;160:C390-C395.

[86] Pareek A, Ankah GN, Cherevko S, Ebbinghaus P, Mayrhofer KJJ, Erbe A, Renner FU. Effect of thiol self-assembled monolayers and plasma polymer films on dealloying of $\mathrm{Cu}-\mathrm{Au}$ alloys. RSC Adv. 2013;3:6586-6595.

[87] Ankah GN, Pareek A, Cherevko S, Zegenhagen J, Renner FU. Hierarchical nanoporous films obtained by surface cracking on $\mathrm{Cu}-\mathrm{Au}$ and ethanethiol on $\mathrm{Au}(001)$. Electrochim. Acta 2014;140:352-358.

[88] Shrestha BR, Bashir A, Ankah GN, Valtiner M, Renner FU. Localized dealloying corrosion mediated by self-assembled monolayers used as an inhibitor system. Faraday Discussions 2015;180:191-204.

[89] Damian A, Maroun F, Allongue P. Electrochemical de-alloying in two dimensions: role of the local atomic environment. Nanoscale 2016;8:13985-13996.

[90] Renner FU, Stierle A, Dosch H, Kolb DM, Zegenhagen J. The influence of chloride on the initial anodic dissolution of $\mathrm{Cu} 3 \mathrm{Au}(111)$. Electrochem. Comm. 2007;9:1639-1642.

[91] Parida S, Kramer D, Volkert CA, Roesner H, Erlebacher J, Weissmueller J. Volume Change during the Formation of Nanoporous Gold by Dealloying. Phys. Rev. Lett. 2006; 97:035504. 
[92] Macdonald DD. Passivity - the key to our metals-based civilization, Pure Appl. Chem. 1999;71:951-978.

[93] Schmuki P., From Bacon to barriers: a review on the passivity of metals and alloys. J. Solid State Electrochem. 2002;6:145-154.

[94] Olsson COA, Landolt D. Passive films on stainless steels - chemistry, structure and growth. Electrochim. Acta 2003;48:1093-1104.

[95] Strehblow H-H, Maurice V, Marcus P. Passivity of Metals. In: Marcus P, editor. Corrosion Mechanisms in Theory and Practice. 3rd edition. CRC Press, Taylor and Francis; 2011: pp. 235-326.

[96] Marcus P, Maurice V. Oxide Passive Films and Corrosion Protection. In: Pacchioni G Valeri S, editors. Oxide Ultrathin Films. Science and Technology. Weinheim: Wiley-VCH Verlag GmbH \& Co. KGaA; 2012: pp. 119-144.

[97] Maurice V, Marcus P. Passive films at the nanoscale. Electrochim. Acta 2012;84:129138.

[98] Strehblow H-H. Passivity of Metals Studied by Surface Analytical Methods, a Review. Electrochim. Acta 2016;212:630-648.

[99] Ikemiya N, Kubo T, Hara S. In situ AFM observations of oxide film formation o n $\mathrm{Cu}(111)$ and $\mathrm{Cu}(100)$ surfaces under aqueous alkaline solutions. Surf. Sci. 1995;323:81-90.

[100] Strehblow H-H, Maurice V, Marcus P. Initial and later stages of anodic oxide formation on $\mathrm{Cu}$, chemical aspects, structure and electronic properties. Electrochimica Acta 2001;46:3755-3766.

[101] Kunze J, Maurice V, Klein LH, Strehblow H-H, Marcus P. In situ STM study of the duplex passive films formed on $\mathrm{Cu}(111)$ and $\mathrm{Cu}(001)$ in $0.1 \mathrm{M} \mathrm{NaOH}$. Corrosion Sci. 2004;46:245-264.

[102] Maurice V, Talah H, Marcus P. Ex situ STM imaging with atomic resolution of Ni (111) electrodes passivated in sulfuric acid. Surf. Sci. 1993;284:L431-L436.

[103] Maurice V, Talah H, Marcus P. A scanning tunneling microscopy study of the structure of thin oxide films grown on $\mathrm{Ni}$ (111) single-crystal surfaces by anodic polarization in acid electrolyte. Surf. Sci. 1994;304:98-108.

[104] Yau SL, Fan FR, Moffat TP. Bard AJ. In situ Scanning Tunneling Microscopy of $\mathrm{Ni}(100)$ in $1 \mathrm{M} \mathrm{NaOH}$. J. Phys. Chem. 1994;98:5493-5499.

[105] Zuili D, Maurice V, Marcus P. Surface structure of nickel in acid solution studied by in situ scanning tunneling microscopy. J. Electrochem. Soc. 2000;147: 1393-1400.

[106] Hirai N, Okada H, Hara S. In-situ Electrochemical Atomic Force Microscopy with Atomic Resolution of Ni(110) in Neutral and Alkaline Aqueous Solution. Transaction JIM 2003;44:727-730.

[107] Scherer J, Ocko BM, Magnussen OM. Structure, dissolution, and passivation of Ni(111) electrodes in sulfuric acid solution: an in situ STM, X-ray scattering, and electrochemical study. Electrochim. Acta 2003;48:1169-1191.

[108] Nakamura M, Ikemiya N, Iwasaki A, Suzuki Y, Ito M. Surface structures at the initial stages in passive film formation on $\mathrm{Ni}\left(\begin{array}{lll}1 & 1 & 1\end{array}\right)$ electrodes in acidic electrolytes. J. Electroanal 65 Chem. 2004;566:385-391. 
[109] Bhardwaj RC, Gonzalez-Martin A, Bockris JO’M. In situ Scanning Tunneling Microscopy Studies on Passivation of Polycrystalline Iron in Borate Buffer. J. Electrochem. Soc. 1991;138:1901-1908.

[110] Ryan MP, Newman RC, Thompson GE. An STM Study of the Passive Film Formed on Iron in Borate Buffer Solution. J. Electrochem. Soc. 1995;142:L177L179.

[111] Li J, Meier DJ. An AFM study of the properties of passive films on iron surfaces. J. Electroanal. Chem. 1998;454:53-58.

[112] Diez-Pérez I, Gorostiza P, Sanz F, Müller C, First Stages of Electrochemical Growth of the Passive Film on Iron. J. Electrochem. Soc. 2001;148-307.

[113] Rees EE, Ryan MP, MacPhail DS, An STM Study of the Nanocrystalline Structure of the Passive Film on Iron. Electrochem. Solid-State Lett. 2002;5:B21-B23.

[114] Deng H, Nanjo H, Quian P, Santosa A, Ishikawa I, Kurata Y. Potential dependence of surface crystal structure of iron passive films in borate buffer solution. Electrochim. Acta 2007;52:4272-4277.

[115] Maurice V, Yang W, Marcus P. XPS and STM Investigation of the Passive Film Formed on Cr (110) Single-Crystal Surfaces. J. Electrochem. Soc. 1994;141:3016-3027.

[116] Zuili D, Maurice V, Marcus P. In situ scanning tunneling microscopy study of the structure of the hydroxylated anodic oxide film formed on $\mathrm{Cr}$ (110) single-crystal surfaces. J. Phys. Chem. B 1999;103:7896-7905.

[117] Foelske A, Kunze J, Strehblow H-H. Initial stages of hydroxide formation and its reduction on $\mathrm{Co}(0001)$ studied by in situ STM and XPS in $0.1 \mathrm{M} \mathrm{NaOH}$. Surf. Sci. 2004;554:10-24.

[118] Ryan MP, Newman RC, Thompson GE. A scanning tunnelling microscopy study of structure and structural relaxation in passive oxide films on $\mathrm{Fe}-\mathrm{Cr}$ alloys. Philosophical Mag. B 1994;70:241-251.

[119] Ryan MP, Newman RC, Thompson GE. Atomically Resolved STM of Oxide Film Structures on Fe-Cr Alloys during Passivation in Sulfuric Acid Solution. J. Electrochem. Soc. 141 (1994) L164-L165.

[120] Maurice V, Yang W, Marcus P. XPS and STM Study of Passive Films Formed on Fe22Cr (110) Single-Crystal Surface. J. Electrochem. Soc. 1996;143:1182-1200.

[121] Nanjo H, Newman RC, Sanada N. Atomic images of 304SS surface after electrochemical treatments. Appl. Surf. Sci. 1997;121:253-256.

[122] Maurice V, Yang W, Marcus P. X-Ray Photoelectron Spectroscopy and Scanning Tunneling Microscopy Study of Passive Films Formed on (100) Fe-18Cr-13Ni Single-Crystal Surfaces. J. Electrochem. Soc. 1998;145:909-920.

[123] Vignal V, Olive J-M, Desjardins D, Effect of molybdenum on passivity of stainless steelsin chloride media using ex situ near field microscopy observations. Corrosion Sci., 1999;41:969-884.

[124] Massoud T, Maurice V, Klein LH, Marcus P, Nanoscale morphology and atomic structure of passive films on stainless steel. J. Electrochem. Soc. 2013;160:C232-C238.

[125] Maurice V, Peng H, Klein LH, Seyeux A, Zanna S, Marcus P, Effects of molybdenum66 on the composition and nanoscale morphology of passivated austenitic stainless steel surfaces. Faraday Discussions 2015;180:151-170. 
[126] Machet A, Galtayries A, Zanna S, Klein LH, Maurice V, Jolivet P, Foucault M, Combrade P, Scott P, Marcus P. XPS and STM study of the growth and structure of passive films in high temperature water on a nickel-base alloy. Electrochim. Acta 2004;49:3957-3964.

[127] Magnussen OM, Scherer J, Ocko BM, Behm RJ, In situ X-ray Scattering Study of the Passive Film on Ni(111) in Sulfuric Acid Solution. J. Phys. Chem. B 2000;104:1222-1226.

[128] Toney MF, Davenport AJ, Oblonsky LJ, Ryan MP, Vitus CM, Atomic Structure of the Passive Oxide Film Formed on Iron. Phys. Rev. Lett. 1997;79:4282.

[129] Davenport AJ, Oblonsky LJ, Ryan MP, Toney MF. The Structure of the Passive Film That Forms on Iron in Aqueous Environments. J. Electrochem. Soc. 2000;147:2162-2173.

[130] Reikowski F, Maroun F, Di N, Allongue P, Ruge M, Stettner J, Magnussen OM, In situ surface X-ray diffraction study of ultrathin epitaxial Co films on Au(111) in alkaline solution. Electrochim. Acta 2016;197:273-281.

[131] Maurice V, Klein LH, Marcus P. Atomic structure of metastable pits formed on nickel. Electrochem. Solid-State Lett. 2001;4:B1-B3.

[132] Maurice V, Nakamura T, Klein L, Marcus P. Initial stages of localised corrosion by pitting of passivated nickel surfaces studied by STM and AFM. In: Oltra R, Maurice V, Akid R, Marcus, P, editors. Local Probe Techniques for Corrosion Research. EFC Publications $\mathrm{N}^{\circ}$ 45. Cambridge: Woodhead Publishing Ltd; 2007: pp. 71-83.

[133] Marcus P, Strehblow H-H, Maurice V. Localized corrosion (pitting): A model of passivity breakdown including the role of the oxide layer nanostructure. Corrosion Sci. 2008;50:2698-2704.

[134] Seyeux A, Maurice V, Marcus P. Breakdown kinetics at nanostructure defects of passive films. Electrochem. Solid State Lett. 2009;12:C25-C27.

[135] Strehblow H-H, Titze B. The investigation of the passive behaviour of copper in weakly acid and alkaline solutions and the examination of the passive film by ESCA and ISS.

Electrochim. Acta 1980;25:839-850.

[136] Kautek W, Gordon JG. XPS Studies of Anodic Surface Films on Copper Electrodes. J Electrochem. Soc. 1990;137:2672-2677.

[137] Millet B, Fiaud C, Hinnen C, Sutter EMM. A correlation between electrochemical behaviour, composition and semiconducting properties of naturally grown oxide films on copper. Corrosion Sci. 1995;37:1903-1918.

[138] Feng Y. Siow K-S, Teo W-K, Tan K-L, Hsieh A-K. Corrosion Mechanisms and Products of Copper in Aqueous Solutions at Various pH Values. Corrosion 1997;53:389-398.

[139] Sander U, Strehblow H-H, Dohrmann JK. In situ photoacoustic spectroscopy of thin oxide layers on metal electrodes. Copper in alkaline solution. J. Phys. Chem. 1981;85:447450.

[140] De Chiavo MRG, Salvarezza RC, Arvia A. The mechanism of oxidation of copper in alkaline solutions. J. Appl. Electrochem. 1984;14:165-175.

[141] Chan HYH, Takoudis CG, Weaver MJ. Oxide Film Formation and Oxygen Adsorption on Copper in Aqueous Media As Probed by Surface-Enhanced Raman Spectroscopy. J. Phys. Chem. B 1999;103:357-365. 
[142] Melendres CA, Bowmaker GA, Leger J-M, Beden BJ. In-situ synchrotron far infrared spectroscopy of surface films on a copper electrode in aqueous solutions. J. Electroanal. Chem. 1998;449:215-218.

[143] Islam MM, Diawara B, Maurice V, Marcus P. First principles investigation on the stabilization mechanisms of the polar copper terminated Cu2O(111) surface. Surf. Sci. 2009;603:2087-2095.

[144] Mac Dougall B, Cohen M. Anodic Oxide Films on Nickel in Acid Solutions. J. Electrochem. Soc. 1976;123:191-197.

[145] Mac Dougall B, Cohen M. Mechanism of the Anodic Oxidation of Nickel. J. Electrochem. Soc. 1976;123:1783-1789.

[146] Dickinson T, Povey AF, Sherwood PMA. Dissolution and passivation of nickel. An Xray photoelectron spectroscopic study. J. Chem. Soc. Faraday Trans. I 1977;73:327343.

[147] Marcus P, Oudar J, Olefjord I. X-Ray Photoelectron Spectroscopy Study of the Passive Film on Nickel. J. Microsc. Spectrosc. Electron. 1979;4:63-72.

[148] Hoppe HW, Strehblow H-H. XPS and UPS examinations of passive layers on Ni and FE53Ni alloys. Corrosion Sci. 1980;20:167-177.

[149] Mitchell DF, Sproule GI, Graham MJ, Measurement of hydroxyl ions in thin passive oxide films using secondary ion mass spectrometry. Appl. Surf. Sci., 1985;21:199-209.

[150] Wagner FT, Moylan TE. Electrochemically and UHV-Grown Passive Layers on Ni (100): A Comparison by AC Impedance, XPS, LEED, and HREELS. J. Electrochem. Soc. 1989;136:2498-2506.

[151] Bouzoubaa A, Diawara B, Maurice V, Minot C, Marcus P. Ab initio study of the interaction of chlorides with defect-free hydroxylated $\mathrm{NiO}$ surfaces. Corrosion Science 2009;51:941-948.

[152] Bouzoubaa A, Diawara B, Maurice V, Minot C, Marcus P. Ab initio modelling of localized corrosion: Study of the role of surface steps in the interaction of chlorides with passivated nickel surfaces. Corrosion Science 2009;51:2174-2182.

[153] Oblonsky LJ, Davenport AJ, Ryan MP, Isaacs HS, Newman R. C., In situ X-Ray Absorption Near Edge Structure Study of the Potential Dependence of the Formation of the Passive Film on Iron in Borate Buffer. J. Electrochem. Soc. 1997;144:2398-2404.

[154] Lu Z, Macdonald DD. Transient growth and thinning of the barrier oxide layer on iron measured by real-time spectroscopic ellipsometry. Electrochim. Acta 2008;53:7696-7702.

[155] Forti MD, Alonso PR, Gargano PH, Balbuena PB, Rubiolo GH. A DFT study of atomic structure and adhesion at the Fe (BCC)/Fe 3 O 4 interfaces. Surf. Sci. 2016;647:55-65.

[156] Seo M. Sato N. Differential composition profiles in depth of thin anodic oxide films on iron-chromium alloy. Surf. Sci., 1979;86:601-609.

[157] Hultquist G, Seo M, Leitner T, Leygraf C, Sato N, The dissolution behaviour of iron, chromium, molybdenum and copper from pure metals and from ferritic stainless steels. Corrosion Sci. 1987;27: 937-946.

[158] Mitchell DF, Graham M, Comparison of Auger and SIMS analysis of a thin passive oxide film on iron-25\% chromium. Surf. Interf. Anal. 1987;10:259-261.

[159] Mischler S, Mathieu HJ, Landolt D, Investigation of a passive film on an ironchromium alloy by AES and XPS. Surf. Interf. Anal. 1988;11:182-188. 
[160] Marcus P, Olefjord I. Round Robin on combined electrochemical and AES/ESCA characterization of the passive films on $\mathrm{Fe}-\mathrm{Cr}$ and $\mathrm{Fe}-\mathrm{Cr}-\mathrm{Mo}$ alloys. Corrosion Sci. 1988;11:569-576.

[161] Calinski C, Strehblow H-H. ISS Depth Profiles of the Passive Layer on Fe/Cr Alloys. J. Electrochem. Soc. 1989;136:1328-1331.

[162] Kirchheim R, Heine B, Fischmeister H, Hofmann S, Knote H, Stolz U, The passivity of iron-chromium alloys. Corrosion Sci. 1989;29:899-917.

[163] Castle JE, Qiu JH. A co-ordinated study of the passivation of alloy steels by plasma source mass spectrometry and $\mathrm{x}$-ray photoelectron spectroscopy-1. characterization of the passive film. Corrosion Sci. 1989; 29:591-603.

[164] Castle JE, Qiu JH. A co-ordinated study of the passivation of alloy steels by plasma source mass spectrometry and x-ray photoelectron spectroscopy-II. growth kinetics of the passive film. Corrosion Sci. 1989;29:605-616.

[165] Yang WP, Costa D, Marcus P. Resistance to Pitting and Chemical Composition of Passive Films of a Fe-17\% Cr Alloy in Chloride-Containing Acid Solution. J. Electrochem. Soc. 1994;141:2669-2676.

[166] Haupt S, Strehblow H-H. A combined surface analytical and electrochemical study of the formation of passive layers on $\mathrm{FeCr}$ alloys in $0.5 \mathrm{M} \mathrm{H}_{2} \mathrm{SO}_{4}$. Corrosion Sci. 1995;37:43-54.

[167] Oblonsky LJ, Ryan MP, Isaacs HS. In situ Determination of the Composition of Surface Films Formed on Fe-Cr Alloys. J. Electrochem. Soc. 1998;145:1922-1932.

[168] Hamm D, Ogle K, Olsson C-OA, Weber S, Landolt D. Passivation of Fe-Cr alloys studied with ICP-AES and EQCM. Corrosion Sci. 2002;44:1443-1456.

[169] P. Keller, H.-H. Strehblow, XPS investigations of electrochemically formed passive layers on Fe/Cr-alloys in 0.5 M H2SO4. Corrosion Sci. 2004;46: 1939-1952.

[170] Mischler S, Vogel A, Mathieu HJ, Landolt D, The chemical composition of the passive film on Fe-24Cr and Fe-24Cr-11Mo studied by AES, XPS and SIMS Corrosion Sci. 1991;32:925-944.

[171] Hashimoto K, Asami K, Teramoto K. An X-ray photo-electron spectroscopic study on the role of molybdenum in increasing the corrosion resistance of ferritic stainless steels in HCl. Corrosion Sci. 1979; 19:3-14.

[172] Tan M-W, Akiyama E, Kawashima A, Asami K, Hashimoto K. The effect of air exposure on the corrosion behavior of amorphous Fe-8Cr-Mo-13P-7C alloys in $1 \mathrm{M} \mathrm{HCl}$. Corrosion Sci. 1995;37:1289-1301.

[173] Olefjord I, Elfström B-O. The Composition of the Surface during Passivation of Stainless Steels. Corrosion Sci. 1982;38:46-52.

[174] De Vito E, Marcus P. XPS study of passive films formed on molybdenum-implanted austenitic stainless steels. Surf. Interf. Anal. 1992;19:403-408.

[175] Olsson C-OA, Hörnström SE. An AES and XPS study of the high alloy austenitic stainless steel 254 SMO® tested in a ferric chloride solution. Corrosion Sci. 1994;36: 141151.

[176] Hakiki NE, Belo MDC, Simões AMP, Ferreira MGS, Semiconducting Properties of 69 Passive Films Formed on Stainless Steels Influence of the Alloying Elements. J. Electrochem. Soc. 1998;145:3821-3829. 
[177] Bojinov M, Fabricius G, Laitinen T, Mäkelä K, Saario T, Sundholm G. Electrochim. Acta 2001;46:1339-1358.

[178] Yamamoto T, Fushimi K, Seo M, Tsuri S, Adachi T, Habazaki H. Depassivationrepassivation behavior of type-312L stainless steel in $\mathrm{NaCl}$ solution investigated by the micro-indentation. Corrosion Sci. 2009;51:1545-1553.

[179] Sugimoto K, Sawada Y. The role of molybdenum additions to austenitic stainless steels in the inhibition of pitting in acid chloride solutions. Corrosion Sci. 1977;17:425-445.

[180] H. Ogawa, H. Omata, I. Itoh, H. Okada, Auger electron spectroscopic and electrochemical analysis of the effect of alloying elements on the passivation behavior of stainless steels. Corrosion 1978;34:52-60.

[181] Olefjord I. The passive state of stainless steels. Materials Science and Engineering 1980;42:161-171.

[182] Yang W, Ni R-C, Hua H-Z, Pourbaix A. The behavior of chromium and molybdenum in the propagation process of localized corrosion of steels. Corrosion Sci. 1984;24:691-707.

[183] Olefjord I, Brox B, Jelvestam U. Surface composition of stainless steels during anodic dissolution and passivation studied by ESCA. J. Electrochem. Soc. 1985;132:2854-2861.

[184] Brooks AR, Clayton CR, Doss K, Lu YC. On the role of Cr in the passivity of stainless steel. J. Electrochem. Soc. 1986;133:2459-2464.

[185] Clayton CR, Lu YC. A bipolar model of the passivity of stainless steel: the role of Mo addition. J. Electrochem. Soc. 1986;133:2465-2473.

[186] Lu YC, Clayton CR, Brooks AR. A bipolar model of the passivity of stainless steelsII. The influence of aqueous molybdate. Corrosion Sci. 1989;29:863-880.

[187] Clayton CR, Lu YC. A bipolar model of the passivity of stainless steels-III. The mechanism of MoO42- formation and incorporation. Corrosion Sci. 1989;29:881-898.

[188] Olefjord I, Wegrelius L. Surface analysis of passive state. Corrosion Sci. 1990;31:8998.

[189] Habazaki H, Kawashima A, Asami K, Hashimoto K. The corrosion behavior of amorphous Fe-Cr-Mo-PC and Fe-Cr-WPC alloys in $6 \mathrm{M} \mathrm{HCl}$ solution. Corrosion Sci. 1992;33:225-236.

[190] Macdonald DD. The Point Defect Model for the Passive State. J. Electrochem. Soc. 1992;139:3434-3449.

[191] Elbiache A, Marcus P. The role of molybdenum in the dissolution and the passivation of stainless steels with adsorbed Sulphur. Corrosion Sci. 1992;33:261-269.

[192] Marcus P, Maurice V. Comparison of atomic structures of passive films on chromium and on ferritic and austenitic stainless steels. In: Natishan P, Isaacs HS, Janik-Czachor M, Macagno VA, Marcus P, Seo M, editors. Passivity and Its Breakdown, The Electrochemical Society Proceedings Series. Pennington, NJ: 1998; PV 97-26: pp. 254-265.

[193] Massoud T, Maurice V, Wiame F, Klein, LH, Seyeux A, Marcus P. Nanostructure and local properties of oxide layers grown on stainless steel in simulated pressurized water reactor environment. Corrosion Sci. 2014;84:198-203.

[194] Evans UR. The passivity of metals. Part. I. The isolation of the protective film, J. Chein? Soc. 1927:1020-1040. 
[195] Kolotyrkin JM. Pitting corrosion of metals. Corrosion 1963;19:261-268.

[196] Hoar TP, Mears DC, Rothwell GP. The relationships between anodic passivity, brightening and pitting. Corrosion Sci. 1965;5:279-289.

[197] Hoar TP, Jacob WR. Breakdown of passivity of stainless steel by halide ions. Nature 1967;216:1299-1301.

[198] Szklarska-Smialowska Z. Review of literature on pitting corrosion published since 1960. Corrosion 1971;27:223-233.

[199] Szklarska-Smialowska, Z, ZS-Smialowska. Pitting and crevice corrosion. Houston, TX: NACE International, 2005.

[200] Frankel GS, Newman RC, editors, Critical factors in localized corrosion, The Electrochemical Society Proceedings Series. Pennington, NJ: 1992; PV 92-9.

[201] Frankel GS. Pitting corrosion of metals a review of the critical factors. J. Electrochem. Soc. 1998;145:2186-2198.

[202] Strehblow H-H, Marcus P. Mechanisms of Pitting Corrosion. In: Marcus P, editor. Corrosion Mechanisms in Theory and Practice. 3rd edition. CRC Press, Taylor and Francis; 2011: pp. 349-393.

[203] Soltis J. Passivity breakdown, pit initiation and propagation of pits in metallic materials-review. Corrosion Sci. 2015;90:5-22.

[204] Böhni H, Uhlig H-H. Environmental factors affecting the critical pitting potential of aluminum. J. Electrochem. Soc. 1969;116:906.

[205] Strehblow H-H, Nucleation and repassivation of corrosion pits for pitting on iron and nickel. Werkst. Korros. 1976;27:792-799.

[206] MacDougall B. Breakdown of oxide films on nickel. J. Electrochem. Soc. 1977;124:1185.

[207] Strehblow H-H, Titze B, Loechel BP. The breakdown of passivity of iron and nickel by fluoride. Corrosion Sci. 1979;19:1047-1057.

[208] Loechel BP, Strehblow H-H. Breakdown of passivity of nickel by fluoride I. Electrochemical studies. J. Electrochem. Soc. 1984;131:522.

[209] Loechel BP, Strehblow H-H. Breakdown of passivity of nickel by fluoride II. Surface analytical studies. J. Electrochem. Soc. 1984;131:713-723.

[210] Boxley CJ, White HS. Relationship Between Al2O3 Film Dissolution Rate and the Pitting Potential of Aluminum in NaCl Solution. J. Electrochem. Soc. 2004;151:B256-B270.

[211] Chao CY, Lin LF, MacDonald DD. A point defect model for anodic passive films II. Chemical breakdown and pit initiation. J. Electrochem. Soc. 1981;128:1194-1198.

[212] Urquidi M, MacDonald DD. Solute-Vacancy Interaction Model and the Effect of Minor Alloying Elements on the Initiation of Pitting Corrosion. J. Electrochem. Soc. 1985;132:555558.

[213] Zavadil KR, Ohlhausen JA, Kotula PG. Nanoscale void nucleation and growth in the passive oxide on aluminum as a prepitting process. Journal of the Electrochemical Society 2006;153:B296-B303.

[214] Richardson JA, Wood GC. A study of the pitting corrosion of Al by scanning electron microscopy. Corrosion Sci. 1970;10:313-323. 
[215] Vetter KJ, Strehblow H-H, Entstehung und Gestalt von Korrosionslöchern bei Lochfraß an Eisen und theoretische Folgerungen zur Lochfraßkorrosion. Berichte der Bunsengesellschaft für physikalische Chemie. 1970;74:1024-1035.

[216] Sato N. A theory for breakdown of anodic oxide films on metals. Electrochim. Acta 1971;16:1683-1692.

[217] MacDougall B. Effect of chloride ion on the localized breakdown of nickel oxide films. J. Electrochem. Soc. 1979;126:919-925.

[218] Maurice V, Klein LH, Marcus P. Atomic-scale investigation of the localized corrosion of passivated nickel surfaces. Surf. Interf. Anal. 2002;34:139-143.

[219] Bouzoubaa A, Costa D, Diawara B, Audiffen N, Marcus P. Insight of DFT and atomistic thermodynamics on the adsorption and insertion of halides onto the hydroxylated NiO (111) surface. Corrosion Sci. 2010;52:2643-2652.

[220] Abell GC. Empirical chemical pseudopotential theory of molecular and metallic bonding. Phys. Rev. B 1985;31:6184.

[221] Tersoff J. Empirical interatomic potential for carbon, with applications to amorphous carbon. Phys. Rev. Lett. 1988;61:2879.

[222] D. W. Brenner, Empirical potential for hydrocarbons for use in simulating the chemical vapor deposition of diamond films. Phys. Rev. B 1990;42:9458.

[223] Jeon B, Sankaranarayanan SKRS, Van Duin ACT, Ramanathan S. Reactive Molecular Dynamics Study of Chloride Ion Interaction with Copper Oxide Surfaces in Aqueous Media. ACS Appl. Mater. Interfaces. 2012;4:1225-1232.

[224] Narayanan B, Deshmukh SA, Sankaranarayanan SKRS, Ramanathan S. Strong correlations between structural order and passive state at water-copper oxide interfaces. Electrochim. Acta 2015;179:386-393.

[225] van Duin ACT, Dasgupta S, Lorant F, Goddard WA. ReaxFF: A Reactive Force Field for Hydrocarbons. J. Phys. Chem. A 2001;105:9396-9409.

[226] Mortier WJ, Ghosh SK, Shankar S. Electronegativity-equalization method for the calculation of atomic charges in molecules. J. Am. Chem. Soc. 1986;108:4315-4320.

[227] Rahaman O, van Duin ACT, Bryantsev VS, Mueller JE, Solares SD, Goddard WA, Doren DJ. Development of a ReaxFF reactive force field for aqueous chloride and copper chloride. J. Phys. Chem. A 2010;114:3556-3568.

[228] van Duin ACT, Bryantsev VS, Diallo MS, Goddard WA, Rahaman O, Doren DJ, Raymand D, Hermansson KJ. Development and validation of a ReaxFF reactive force field for $\mathrm{Cu}$ cation/water interactions and copper metal/metal oxide/metal hydroxide condensed phases. J. Phys. Chem. A 2010;114:9507-9514.

[229] Maurice V, Inard V, Marcus P, STM investigation of the localized corrosion of passivated Ni(111) single-crystal surfaces. In: Natishan PM, Kelly RG, Frankel GS, Newman RC, editors. Critical Factors In Localized Corrosion III. The Electrochemical Society Proceedings Series. Pennington, NJ: 1999; PV 98-17: pp. 552-562.

[230] Lang ND. Spectroscopy of single-atoms in the scanning tunneling microscope. Phys. Rev. B 1986;34:5947-5950.

[231] Feenstra RM, Stroscio JA, Fein AP. Tunneling spectroscopy of the Si (111) $2 \times 1$ 
[232] Halbritter J, Repphun G, Vinzelberg S, Staikov G, Lorenz WJ. Tunneling mechanisms in electrochemical STM - distance and voltage tunneling spectroscopy. Electrochim. Acta 1995;40:1385-1394.

[233] Azumi K, Araki K, Seo M. Tunneling spectroscopy of passive films on iron and titanium. J. Electroanal. Chem. 1997;427:15-21.

[234] Diéz-Pérez I, Vericat C, Sanz F, Gorostiza P. The iron passive film breakdown in chloride media may be mediated by transient chloride-induced surface states located within the band gap. Electrochem. Comm. 2006;8:627-632.

[235] Diéz-Pérez I, Sanz F, Gorostiza P. In situ studies of metal passive films. Current Opinion in Solid State and Materials Science 2006;10:144-152.

[236] Diéz-Pérez I, Sanz F, Gorostiza P. Electronic barriers in the iron oxide film govern its passivity and redox behavior: Effect of electrode potential and solution $\mathrm{pH}$. Electrochem.

Comm. 2006;8:1595-1602.

[237] Diéz-Pérez I, Guell AG, Sanz F, Gorostiza P. Conductance maps by electrochemical tunneling spectroscopy to fingerprint the electrode electronic structure. Anal. Chem.

2006;78:7325-7329.

[238] Caballero-Briones F, Artes JM, Diez-Perez I, Gorostiza P, Sanz F. Direct observation of the valence band edge by in situ ECSTM-ECTS in p-type $\mathrm{Cu} 2 \mathrm{O}$ layers prepared by copper anodization. J. Phys. Chem. C 2009;113:1028-1036.

[239] Massoud T, Wiame F, Klein LH, Seyeux A, Marcus P. Local Electronic Properties of the Passive Film on Nickel Studied by Scanning Tunneling Spectroscopy. J. Electrochem. Soc. 2012;159:C351-C356.

[240] Massoud T, Klein LH, Wiame F, Marcus P. Intergranular effects on the local electronic properties of the passive film on nickel. Corrosion Sci. 2013;69:245-251.

[241] Hufner S, Steiner P, Sander I, Reinert F, Schmitt H. The optical gap of NiO. Z. Phys. B 1992;86:207-215.

[242] Di Quarto F, Sunseri C, Piazza S, Romano MC. Semiempirical Correlation between Optical Band Gap Values of Oxides and the Difference of Electronegativity of the Elements. Its Importance for a Quantitative Use of Photocurrent Spectroscopy in Corrosion Studies. J. Phys. Chem. B 1997;101:2519-2525.

[243] Di Quarto F, La Mantia F, Santamaria M. Physicochemical characterization of passive films and corrosion layers by differential admittance and photocurrent spectroscopy. In: Pyun S-I, Lee JW, editors. Moderns Aspects of Electrochemistry No. 46: Progress in Corrosion Science and Engineering I, New York: Springer; 2009: pp. 231-316.

[244] Bonnell DA. Scanning tunneling microscopy and spectroscopy of oxide surfaces. Progress Surf. Sci., 57, 187-252 (1998).

[245] Jang H, Kwon H. Photoelectrochemical analysis of passive films formed on Ni and its alloys and its application to their corrosion behaviors. J. Solid State Electrochem. 2015;19:3427-3438.

[246] Schwenk W. Corrosion control by organic inhibitors. In: Leidheiser H; editor. NACE, Houston, TX, 1981:p. 103.

[247] Raja PB, Sethuraman MG. Natural products as corrosion inhibitor for metals in corrosive media - A review. Materials Lett. 2008;62:113-116. 
[248] Rohwerder,M, Grundmeier G. Corrosion prevention by adsorbed organic monolayers and ultrathin plasma polymer films. In: Marcus P, editor. Corrosion Mechanisms in Theory and Practice. 3rd edition. CRC Press, Taylor and Francis; 2011: pp. 617-667.

[249] Gece G. Drugs: A review of promising novel corrosion inhibitors. Corrosion Sci. 2011;53:3873-3898.

[250] Gece G. The use of quantum chemical methods in corrosion inhibitor studies. Corrosion Sci. 2008;50:2981-2992.

[251] Costa D, Marcus P. Adsorption of organic inhibitor molecules on metal and oxidized surfaces studied by atomistic theoretical methods. In: Taylor CD, Marcus P, editors.

Molecular Modeling of Corrosion Processes - Scientific Development and Engineering Applications. John Wiley \& Sons; 2015: 125-131.

[252] Costa D, Ribeiro T, Cornette P, Marcus P. DFT Modeling of Corrosion Inhibition by Organic Molecules: Carboxylates as Inhibitors of Aluminum Corrosion. J. Phys. Chem. C 2016;120:28607-28616.

[253] Antonijevic MM, Petrovic MB. Copper corrosion inhibitors. A review. Int. J. Electrochem. Sci. 2008; 3:1-28.

[254] Finsgar M, Milosev I. Inhibition of copper corrosion by 1,2,3- benzotriazole. A review. Corrosion Sci. 2010;52:2737.

[255] Kokalj A. Ab initio modeling of the bonding of benzotriazole corrosion inhibitor to reduced and oxidized copper surfaces. Faraday Discussions 2015;180:415-438.

[256] Gattinoni C, Michaelides A. Understanding corrosion inhibition with van der Waals DFT methods: the case of benzotriazole. Faraday Discussions 2015;180:439-458.

[257] Kokalj A, Peljhan S. Density Functional Theory Study of Adsorption of Benzotriazole on Cu2O Surfaces. J Phys Chem C 2015;119:11625-11635.

[258] Youda R., Nishihara, Aramaki K. SERS and impedance study of the equilibrium between complex formation and adsorption of benzotriazole and 4-hydroxybenzotriazole on a copper electrode in sulphate solutions. Electrochim. Acta 1990;35:1011-1017.

[259] Jiang Y, Adams JB, Sun D. Benzotriazole Adsorption on Cu2O(111) Surfaces: A FirstPrinciples Study. J. Phys. Chem. B 2004;108:12851-12857.

[260] Grillo F, Tee DW, Francis SM, Früchtl H, Richardson NV. Initial Stages of Benzotriazole Adsorption on the $\mathrm{Cu}(111)$ Surface. Nanoscale 2013; 5:5269-5273.

[261] Grillo F, Tee DW, Francis SM, Früchtl H, Richardson NV. Passivation of Copper: Benzotriazole Films on Cu(111). J Phys Chem C 2014;118:8667-8675.

[262] Vogt MR, Polewska W, Magnussen OM, Behm RJ. In situ STM Study of (100) Cu Electrodes in Sulfuric Acid Solution in the Presence of Benzotriazole Adsorption, $\mathrm{Cu}$ Corrosion, and Cu Deposition. J Electrochem Soc. 1997; 144:L113-L116.

[263] Vogt MR, Nichols RJ, Magnussen OM, Behm RJ. Benzotriazole adsorption and inhibition of $\mathrm{Cu}$ (100) corrosion in $\mathrm{HCl}$ : A combined in situ STM and in situ FTIR spectroscopy study. J Phys Chem B 1998;102:5859-5865.

[264] Sugimasa M, Wan L-J, Inukai J, Itaya K. Adlayers of Benzotriazole on Cu (110),(100), and (111) in HClO4 Solution In situ Scanning Tunneling Microscopy Study. J Electrochem 74 Soc 2002;149:E367-E373. 
[265] Polewska W, Vogt MR, Magnussen OM, Behm RJ. In situ STM study of Cu (111) surface structure and corrosion in pure and benzotriazole-containing sulfuric acid solution. $\mathrm{J}$ Phys Chem B 1999;103:10440-10451.

[266] Szocs E, Bako I, Kosztolanyi T, Bertoti I, Kalman E. EC-STM study of 5-mercapto-1phenyl-tetrazole adsorption on $\mathrm{Cu}(111)$. Electrochim. Acta 2003;49:1371-1378.

[267] Scherer J, Vogt MR, Magnussen OM, Behm RJ. Corrosion of Alkanethiol-Covered $\mathrm{Cu}(100)$ Surfaces in Hydrochloric Acid Solution Studied by in-Situ Scanning Tunneling Microscopy. Langmuir 1997;13:7045-7051.

[268] Yan CW, Lin HC, Cao CN. Investigation of inhibition of 2-mercaptobenzoxazole for copper corrosion. Electrochim. Acta 2000;45:2815-2821.

[269] Rocca E, Bertrand G, Rapin C, Labrune JC. Inhibition of copper aqueous corrosion by non-toxic linear sodium heptanoate: mechanism and ECAFM study. J. Electroanal. Chem. 2001;503:133-140. 


\section{Figure captions}

Figure 1. Traditional model of water/ice adsorption on a close-packed metal surface. (a) Water clusters and extended 2D islands at sub-monolayer coverage with ice-like bilayer structure. (b) Ice-like bilayer structure forming a wetting layer in registry with the surface. (c) Ice multilayers grow on top of wetting layer, forming a strained epitaxial arrangement. Reproduced from [13]. Copyright 2012 Nature Publishing.

Figure 2. Structure of the metal-water interface as observed by STM on Ru(0001). (a) Intact water stripes composed of hexamer units after deposition at $145 \mathrm{~K}$. (b) Transformation to partially dissociated $\mathrm{H}_{2} \mathrm{O}-\mathrm{OH}$ stripes after 30 min at $145 \mathrm{~K}$. Dark spots can be seen in the center of the hexagons (inset in (b)). In the DFT optimized structures, the $\mathrm{OH}$ group is highlighted by an orange O atom. Reproduced from [14]. Copyright 2015 The American Physical Society.

Figure 3. Core level $\mathrm{O} 1 \mathrm{~s}$ spectra for water on $\mathrm{Cu}(110)$ and $\mathrm{Cu}(111)$ as measured by AP-XPS at $295 \mathrm{~K}$. Gas phase water peak measured around $536 \mathrm{eV}$ is not shown. (a) mixed $\mathrm{H}_{2} \mathrm{O}: \mathrm{OH}$ (0.68:0.34 ML) monolayer on $\mathrm{Cu}(110)$ and adsorbate-free surface on $\mathrm{Cu}(111)$ under 1 Torr of $\mathrm{H}_{2} \mathrm{O}$ partial pressure (5\% relative humidity). (b) mixed $\mathrm{H}_{2} \mathrm{O}: \mathrm{OH}(0.17: 0.26 \mathrm{ML})$ layer on $\mathrm{Cu}(111)$ upon water exposure to surface with $0.12 \mathrm{ML}$ of pre-adsorbed atomic oxygen. Reproduced from [32]. Copyright 2007 The American Chemical Society.

Figure 4. Electroadsorption of $\mathrm{OH}$ at the metal-water interface as observed on $\mathrm{Cu}(111)$ in $0.1 \mathrm{M} \mathrm{NaOH}(\mathrm{aq})$. (a) Electrochemical (voltammetry) data recorded between the hydrogen and 
oxygen evolution limits with marked active and passive regions and in the potential range below oxidation (zoomed in region). (b) $\mathrm{OH}_{\text {ads }}$ adlayer growth as observed in situ by EC-STM at $-0.6 \mathrm{~V} / \mathrm{SHE}$. The adlayer islands and the bare substrate are marked $a d$. and $m$, respectively. (c) EC-STM image and model of the $\mathrm{OH}_{\mathrm{ads}} / \mathrm{Cu}_{\mathrm{R}}$ reconstructed structure. The large and small cells mark the $\mathrm{OH}_{\mathrm{ads}}$ and reconstructed $\mathrm{Cu}_{\mathrm{R}}$ plane lattices, respectively. (a) Adapted from [35,36]. (b) Adapted from [35]. (c) Adapted from [37].

Figure 5. Anodic dissolution via isotropic and anisotropic step flow processes as observed in situ by EC-STM on $\mathrm{Cu}(001)$ in $10 \mathrm{mM} \mathrm{H}_{2} \mathrm{SO}_{4}$ (aq.) (180 $\mathrm{nm} \times 180 \mathrm{~nm}$ image) (a), (b), (c) and in $1 \mathrm{mM} \mathrm{HCl}$ (aq.) $(160 \mathrm{~nm} \times 160 \mathrm{~nm}$ image) (d), (e), (f), respectively. Reproduced from [60]. Copyright 1998 Wiley.

Figure 6. (a) Atomic scale dissolution at an outer terrace corner as observed by EC-STM on $\mathrm{Cu}(001)$ in $0.01 \mathrm{M} \mathrm{HCl}($ aq. $)$ at $-0.17 \mathrm{~V} / \mathrm{SCE}$. The observed $\mathrm{c}(2 \times 2)$ ad-lattice is formed by adsorbed chlorine. Active and stable steps, whose initial position is marked by the solid and dashed lines, respectively, dissolve differently. (b) Model of the structure of steps and kinks along the [010] and [001] directions for the (001) surface of a $f c c$ metal (e.g. Cu) covered by an ordered $\mathrm{c}(2 \times 2)$ adlayer (e.g. $\mathrm{Cl})$. The reactive $\mathrm{Cu}$ atom (black disc at site marked $\mathrm{R}$ ) is bonded to $2 \mathrm{Cl}$ atoms (dark and light grey discs) whereas the stable $\mathrm{Cu}$ atom (black disc at site marked $\mathrm{S}$ ) is bonded to $1 \mathrm{Cl}$ atom (dark grey disc). Reproduced from [62].

Figure 7. (a-c) Copper dissolution in the presence of the 2D CuI film as observed by EC-STM on $\mathrm{Cu}(111)$ in $5 \mathrm{mM} \mathrm{H}_{2} \mathrm{SO}_{4}+1 \mathrm{mM} \mathrm{KI}($ aq. $)$ at $0.13 \mathrm{~V} / \mathrm{RHE}:(27 \mathrm{~nm} \times 27 \mathrm{~nm})$. (d and e) 
Schematic drawing illustrating the receding step flow mechanism in the presence of the $2 \mathrm{D}$ CuI film. Reproduced from [73]. Copyright 2007 The American Chemical Society.

Figure 8. Nucleation sites (pointed) and propagation for 2D pitting as observed in situ by ECSTM on $\mathrm{Ag}(111)$ covered by a 2 $\mathrm{D}_{2} \mathrm{O}(111)$-like adlayer in $0.1 \mathrm{M} \mathrm{NaOH}(\mathrm{aq})$ at +0.15 V/SHE. 3D oxide grains are marked. Reproduced from [40]. Copyright 2007 The American Chemical Society.

Figure 9. Dealloying and build-up of epitaxial nanoporous gold on $\mathrm{Cu}_{3} \mathrm{Au}(111)$ in $0.1 \mathrm{M}$ $\mathrm{H}_{2} \mathrm{SO}_{4}$ (aq.). (a) Electrochemical (voltammetry) data recorded up to bulk dealloying above the critical potential $\mathrm{U}_{\mathrm{C}}$ (lower curve) and limited to passivation by the ultrathin Au-rich surface layer (upper curves, 2 cycles). (b) Out-of-plane reciprocal space maps as measured by in situ GIXD and showing the initial crystalline structure of $\mathrm{Cu}_{3} \mathrm{Au}(111)$ at- $0.1 \mathrm{~V} / \mathrm{Ag}-\mathrm{AgCl}$ followed by the formation of CBA-stacked Au islands (intense CBA-Au peak) upon dealloying at 0.45 V/Ag-AgCl and $\mathrm{ABC}$-stacked Au nanoligaments (intense $\mathrm{ABC}$ Au peak) upon further dealloying at $0.6 \mathrm{~V} / \mathrm{Ag}-\mathrm{AgCl}$. The growth of the substrate-oriented ligaments above $0.45 \mathrm{~V}$ (ABC-Au peak) proceeds at the expense of the initial CBA-Au islands. (c) Schematic reciprocal space of $\mathrm{Au} / \mathrm{Cu}_{3} \mathrm{Au}$ (111). (d) Schematic growth sequence of surface structures as a function of time and potential: ultra-thin Au-rich layer with CBA reverse stacking, thicker CBA-stacked $\mathrm{Au}$ islands and $\mathrm{ABC}$-stacked Au nanoligments forming the nanoporous layer. (a) Reproduced from [81]. Copyright 2008 The American Physical Society. (b,c,d) Reproduced from [83]. Copyright 2011 The American Chemical Society. 
Figure $10 . \mathrm{Cu}(\mathrm{I})$ oxide passive film as observed by EC-STM on $\mathrm{Cu}(111)$ in $0.1 \mathrm{M} \mathrm{NaOH}(\mathrm{aq})$ at $-0.25 \mathrm{~V} / \mathrm{SHE}$ (a) and $-0.20 \mathrm{~V} / \mathrm{SHE}(\mathrm{b})$, and side view model of the 7 monolayer thick $\mathrm{Cu}(\mathrm{I})$ oxide grown in tilted epitaxy on $\mathrm{Cu}(111)$ (c). At low oversaturation for anodic oxidation (a), non-crystalline 2D oxide islands (ox.) separated by the adsorbed $\mathrm{OH}$ layer (ad) partially cover the substrate. At higher oversaturation (b), a 3D crystalline oxide layer fully covers the substrate. Its atomic lattice (inset) corresponds to that of $\mathrm{Cu}_{2} \mathrm{O}(111)$. In (c), the stacking sequence of the $\mathrm{O}^{2-}$ and $\mathrm{Cu}^{+}$planes in the oxide is illustrated by the gray lines. The oxide surface is terminated by a monolayer of hydroxyl/hydroxide groups. The faceted surface corresponds to a tilt of $\sim 5^{\circ}$ between the two lattices. (a,b) Reproduced from [36]. Copyright 2001 The American Chemical Society. (c) Adapted from [36].

Figure 11. Passivation of nickel as observed on $\mathrm{Ni}(111)$ in $0.05 \mathrm{M} \mathrm{H}_{2} \mathrm{SO}_{4}+0.095 \mathrm{M}$ $\mathrm{NaOH}$ (aq.) (pH 2.9). (a) Electrochemical polarization curve with the active, passive and transpassive regions marked. (b) Ni(II) oxide passive film as observed by EC-STM at 0.95 V/SHE. The inset shows the high resolution image recorded in situ, revealing the passive film atomic lattice. (c) Side view model of the hydroxylated $\mathrm{NiO}$ surface with (010) step edges and (111) terraces. (b) Reproduced from [105]. Copyright 2000 The Electrochemical Society. (c) Adapted from [152].

Figure 12. Model of the passive film (LAMM) structure on iron as determined by GIXD on $\mathrm{Fe}(001)$ and $\mathrm{Fe}(110)$ passivated in borate buffer solution ( $\mathrm{pH} \mathrm{8.4)} \mathrm{at} 0.4 \mathrm{~V}$. Only the bottom half of the unit cell is shown (outlined by the solid white lines). The oxygen anion sites (100\% occupied), the octahedral cation sites (80\% occupied) and the tetrahedral cation sites (66\% occupied) are shown by the large green spheres, smaller red spheres, and orange spheres, 
respectively. Four of the eight octahedral interstitial sites are shown by the small purple spheres. In the passive film (LAMM) structure, these interstitial sites are assumed to be randomly occupied (12\% occupancy). Reproduced from [128]. Copyright 1997 The American Physical Society.

Figure 13. Passive film structure as observed by STM on Fe-22Cr(110) (a,c) and Fe-18Cr$13 \mathrm{Ni}(100)(\mathrm{b}, \mathrm{d})$ alloy surfaces after passivation in $0.5 \mathrm{M} \mathrm{H}_{2} \mathrm{SO}_{4}(\mathrm{aq})$ at $0.5 \mathrm{~V} / \mathrm{SHE}$ for $2 \mathrm{~h}$ $(a, b)$ and for $22 \mathrm{~h}(\mathrm{c}, \mathrm{d})$. The nearly hexagonal lattice is marked. The effect of ageing under polarization is evidenced by the extension of the observed crystalline areas. (a,c) Reproduced from [120]. Copyright 1996 The Electrochemical Society. (b,d). Reproduced from [122]. Copyright 1998 The Electrochemical Society.

Figure 14. Nanoscale morphology of the Fe-17Cr-14.5Ni-2.3Mo(100) stainless steel surface observed by STM after passivation in $0.05 \mathrm{M} \mathrm{H}_{2} \mathrm{SO}_{4}(\mathrm{aq})$ at $0.5 \mathrm{~V} / \mathrm{SHE}$ for 2 hours. The oxide film has a granular morphology (some grains are pointed) and covers the substrate terraces and step edges. Substrate terraces display depressions (some are circled) evidencing local protection failure caused by competing transient dissolution during passivation. Substrate step edges (marked by dashed lines) are more corrosion resistant owing to preferential local $\mathrm{Cr}$ enrichment of the passive film. Adapted from [125].

Figure 15. Nanogranular morphology (a) and electrical resistance map (c) as observed by CAFM for 316L stainless steel exposed 2 min to simulated pressurized water reactor environment (water at $325^{\circ} \mathrm{C}$ ). Height (b) and resistance (d) profiles along the green and white arrows in (a) and (c), respectively. Reproduced from [193]. 
Figure 16. (a,b,c) Dissolution of the passive film as observed by EC-STM on Ni(111) at $0.85 \mathrm{~V} / \mathrm{SHE}$ in $0.05 \mathrm{M} \mathrm{H}_{2} \mathrm{SO}_{4}+0.095 \mathrm{M} \mathrm{NaOH}+0.05 \mathrm{M} \mathrm{NaCl}(\mathrm{pH} 2.9)$. The oxide crystallographic directions are indicated. The circles show the areas of localized dissolution. (d) Model of a (111) oriented facet delimited by edges oriented the close-packed directions of the $\mathrm{NiO}$ lattice. Oxygen (surface hydroxyls) and $\mathrm{Ni}$ are represented by large and small spheres, respectively. (a,b,c) Reproduced from [218]. Copyright 2002 Wiley.

Figure 17. DFT modelling of the hydroxylated $\mathrm{NiO}(533)$ surface including a (010) step edge and a (111) terrace. Side view models of Cl-adsorbed structures are shown before and after optimization at coverages of 25 and 100\%. Adapted from [152].

Figure 18. Side view models showing the system and protocol adopted for ReaxFF MD simulation of the interaction of chloride ions with passivated copper surfaces. Left: $\mathrm{Cu}(111)$ slab covered by $\mathrm{Cu}_{2} \mathrm{O}$ thin films with $\mathrm{O}$-deficient (top) and $\mathrm{O}$-enriched (bottom) terminations after thermal relaxation at $300 \mathrm{~K}$. Middle: filling the gap with $20 \mathrm{M} \mathrm{Cl}^{-}$aqueous solution $(\mathrm{pH}$ 7). Right: Complete system after relaxation for 250 ps at $300 \mathrm{~K}$ showing preferential interaction of the chlorides ions with the O-deficient surface. Periodic boundary conditions apply along the $x, y, z$ directions. Adapted from [223]. Copyright 2012 The American Chemical Society.

Figure 19. Cross-sectional distributions of the $\mathrm{Cu}$ and $\mathrm{Cl}$ atomic density and of the average charge on $\mathrm{Cl}$ along the perpendicular $\mathrm{z}$ axis of the $20 \mathrm{M} \mathrm{NaCl}_{\mathrm{aq}} / \mathrm{Cu}_{2} \mathrm{O} / \mathrm{Cu}(111) / \mathrm{Cu}_{2} \mathrm{O} / 20 \mathrm{M}$ $\mathrm{NaCl}_{\mathrm{aq}}$ system relaxed for 1 and $300 \mathrm{ps}$ at $373 \mathrm{~K}$. A defect site has been initially implemented 
in the form of an island of $\mathrm{O}$ vacancies in the topmost plane of the O-enriched terminated $\mathrm{Cu}_{2} \mathrm{O}$ thin film (right-hand side ). Adapted from [223]. Copyright 2012 The American Chemical Society.

Figure 20. Nanoscale pit initiation as observed by AFM (a,b,c) and STM (d) on Ni(111). Surface after pre-passivation for $30 \mathrm{~min}$. in Cl-free $0.05 \mathrm{M} \mathrm{H}_{2} \mathrm{SO}_{4}+0.095 \mathrm{M} \mathrm{NaOH}(\mathrm{pH} 2.9)$ at $0.55 \mathrm{~V} / \mathrm{SHE}$ (a), and subsequent increase of the potential up to $1.05 \mathrm{~V} / \mathrm{SHE}$ in the absence (b) or presence (c) of chloride $(0.05 \mathrm{M} \mathrm{NaCl})$. Surface pre-passivated in Cl-free $0.05 \mathrm{M} \mathrm{H}_{2} \mathrm{SO}_{4}$ $+0.095 \mathrm{M} \mathrm{NaOH}(\mathrm{pH} 2.9)$ at $0.95 \mathrm{~V} / \mathrm{SHE}$ and subsequently in the presence of chloride $(0.05 \mathrm{M} \mathrm{NaCl})$ and showing nanopit formation at intersecting intergranular boundaries (marked) of the passive film (d). (a,b,c) Adapted from [133]. (d) Adapted from [229].

Figure 21. Role of the nanostrucrure in the mechanisms of passivity breakdown and localized corrosion initiation: (a) passivity breakdown driven by the potential drop at the oxide/electrolyte interface, (b) potential drop at the metal/oxide interface with outward cationic transport or (c) inward anionic transport. Reproduced from [133].

Figure 22. Local surface electronic structure as measured by STS on the Ni(111) surface after passivation in $0.05 \mathrm{M} \mathrm{H}_{2} \mathrm{SO}_{4}+0.095 \mathrm{M} \mathrm{NaOH}$ (aq.) (pH 2.3) at $0.815 \mathrm{~V} / \mathrm{SHE}$. The surface density of states curves were obtained from the averages of 251 and $55 \mathrm{I}-\mathrm{V}_{\mathrm{t}}$ curves measured on grains (G) and grain boundaries (GB) of the passive film, respectively. The energy band model deduced from the STS data obtained at the grains and grain boundaries of the passive film is shown. The arrows pointing downwards (upwards) indicate the possible electronic transfer from (to) the passivated surface. Adapted from [97]. 
Figure 23. Configurations for adsorbed molecular BTAH (a-d) and dissociated BTA (e-i) benzotriazole on copper surfaces, as obtained by DFT calculations, and dependence of adsorption (binding) energy of $\mathrm{BTAH}, \mathrm{BTA}, \mathrm{Cl}, \mathrm{H}$ and $\mathrm{H}_{2} \mathrm{O}$ on coordination number of surface $\mathrm{Cu}$ atoms at adsorption site (j). (a) Perpendicular molecular adsorption modes BTAH $\perp$ weakly chemisorbed to the surface via triazole nitrogen atoms. (b) Parallel molecular adsorption mode $\mathrm{BTAH}_{\| \mid}$more strongly bonded on $\mathrm{Cu}(110)$ and labeled "apparent chem + phys" for apparent chemisorption + physisorption. (c) Nearly parallel molecular adsorption and physisorbed mode $\mathrm{BTAH}_{\|\|}$(d) Physisorbed networks $\mathrm{BTAH}_{\|++\mathrm{H}}$ stabilized by intermolecular H-bonding. (e) Perpendicular deprotonated adsorption modes BTA $\perp$ strongly chemisorbed on $\mathrm{Cu}(100)$ and $\mathrm{Cu}(110)$ and (f) highly tilted and (g) almost parallel variants. (h) Benzotriazole-copper organometallic [BTA-Cu-BTA] dimer and (i) [BTA-Cu]n polymer. (j) Adsorption energy of the most stable adsorbed configuration identified at a given coordination number. Adapted from [255].

Figure 24. BTAH adsorption on $\mathrm{Cu}(111)$ as observed at medium coverage by UHV-STM. (Left) (a) molecular chain; (b) pseudo hexagonal packing; (c) six-membered starlike feature; (d) junction. Black arrows indicate the three rotational domains of the $(2 \times 1)-\mathrm{Cu}(111)$ surface reconstruction. (Right) Magnification of pseudo hexagonal island with unit cell and substrate directions marked in blue. One orientation of the basic building block is highlighted in the oval (a) and in the inset with superposed molecular models where adsorption sites are indicative only. In inset, $\mathrm{Cu}$ lattice atoms are white circles; $\mathrm{Cu}$ incorporated atoms, orange, $\mathrm{N}$ atoms blue, C atoms dark gray and $\mathrm{H}$ atoms light gray. Reprinted from [261]. Copyright 2014 The American Chemical Society. 
Figure 25. Inhibited dissolution of copper as observed on $\mathrm{Cu}(111)$ in $0.01 \mathrm{M} \mathrm{H}_{2} \mathrm{SO}_{4}+\mathrm{x} \mathrm{M}$ BTAH. (Top) Electrochemical polarization curves showing the anodic shift of the onset of dissolution with increasing BTAH concentration. (Bottom) EC-STM images recorded in situ in $0.01 \mathrm{M} \mathrm{H}_{2} \mathrm{SO}_{4}+10^{-4} \mathrm{M}$ BTAH showing the initial stages of localized dissolution at -0.33 (a,b) followed by surface roughening $-0.06 \mathrm{~V} / \mathrm{SCE}(\mathrm{c}, \mathrm{d})$ below the onset of macroscopic dissolution measured electrochemically at about $-0.05 \mathrm{~V} / \mathrm{SCE}$. The arrows in (b) point the formation of 2D etch pits. Reprinted from [265]. Copyright 1999 The American Chemical Society.

Figure 26. Adlayers on $\mathrm{Cu}(001)$ as observed in situ by EC-STM in $0.1 \mathrm{M} \mathrm{HCl}+0.075 \mathrm{M}$ BTAH. Large (a) and smaller (b) ordered domains of the chemisorbed BTAH adlayer at $0.7 \mathrm{~V} / \mathrm{SCE}$ and substituting $\mathrm{c}(2 \times 2)$ ordered adlayer of chemisorbed $\mathrm{Cl}$ at $-0.45 \mathrm{~V} / \mathrm{SCE}$ (c). Reprinted from [263]. Copyright 1998 The American Chemical Society. 
Figure 27

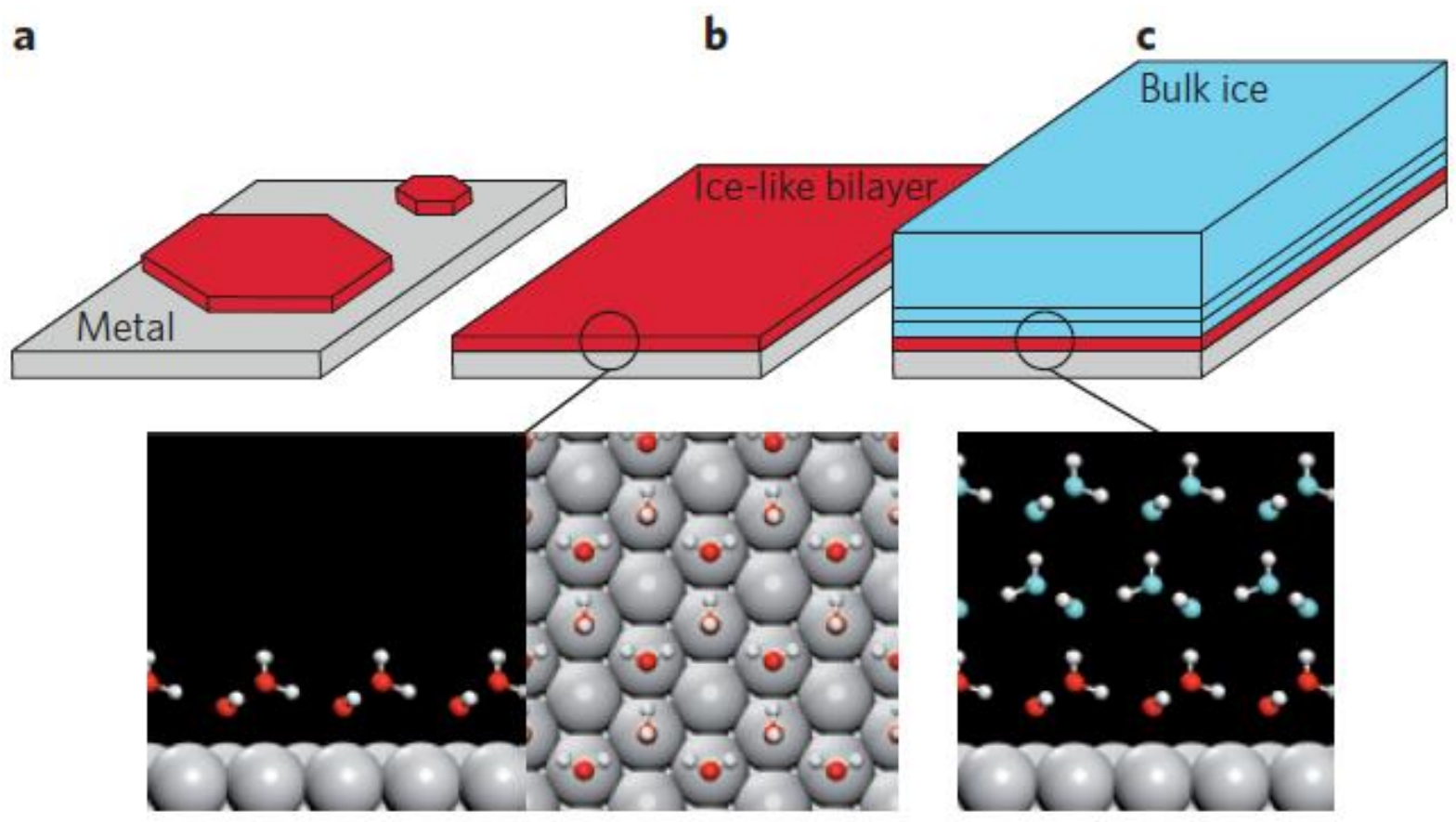


Figure 28
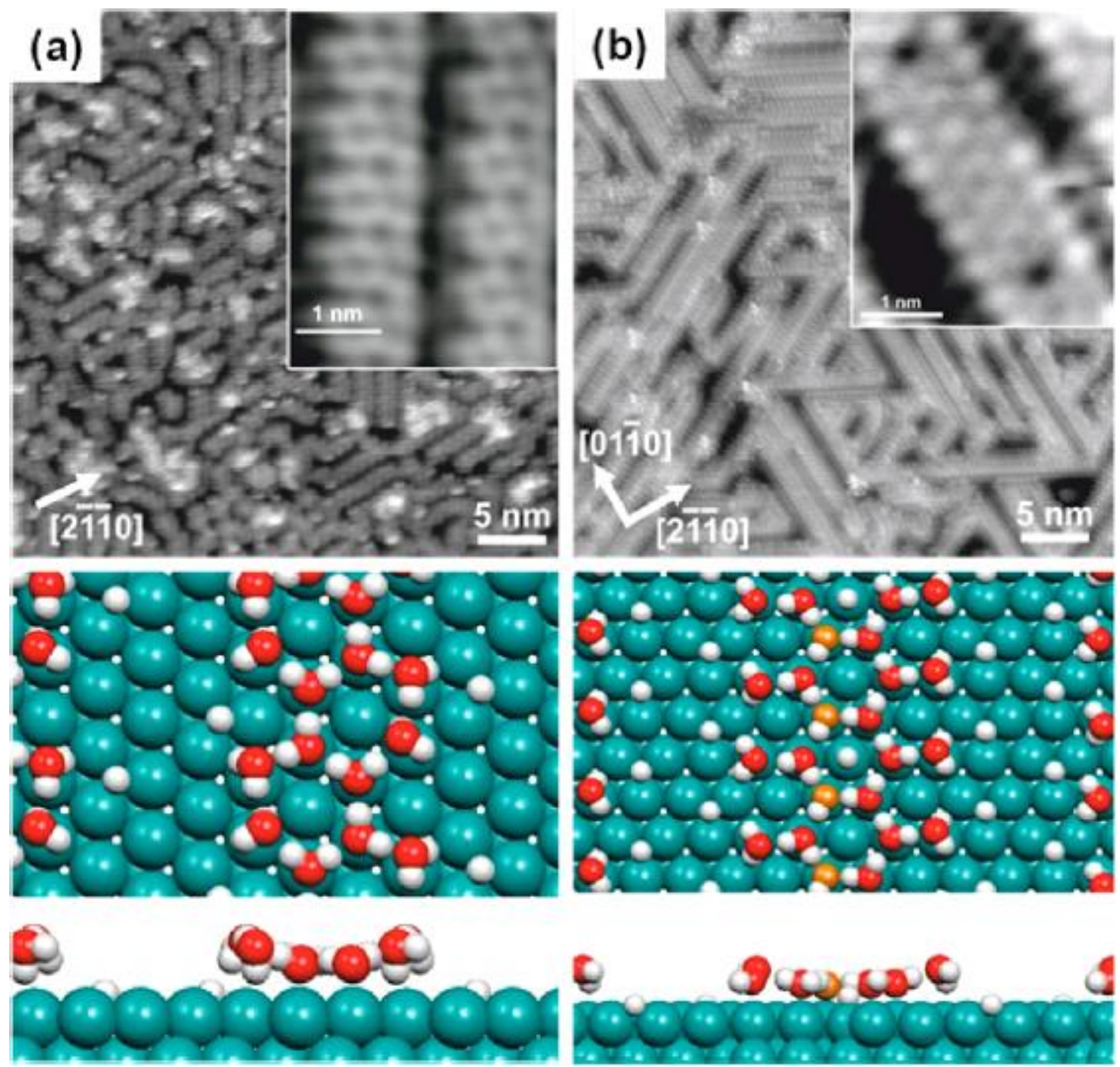
Figure 29

(a)

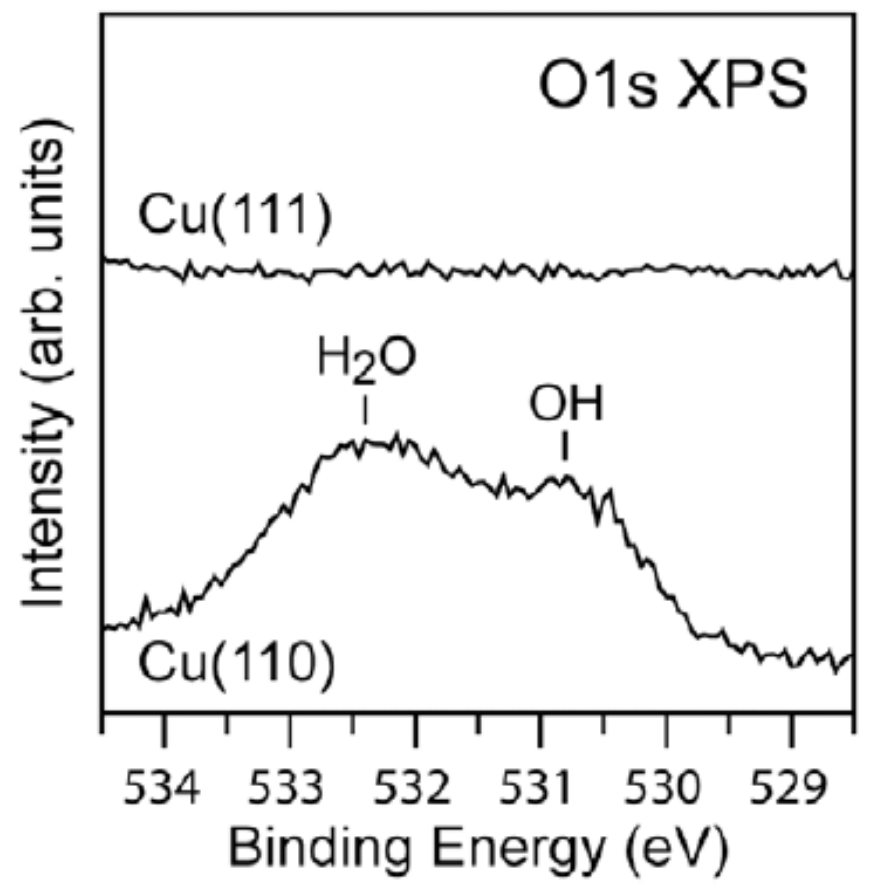

(b)

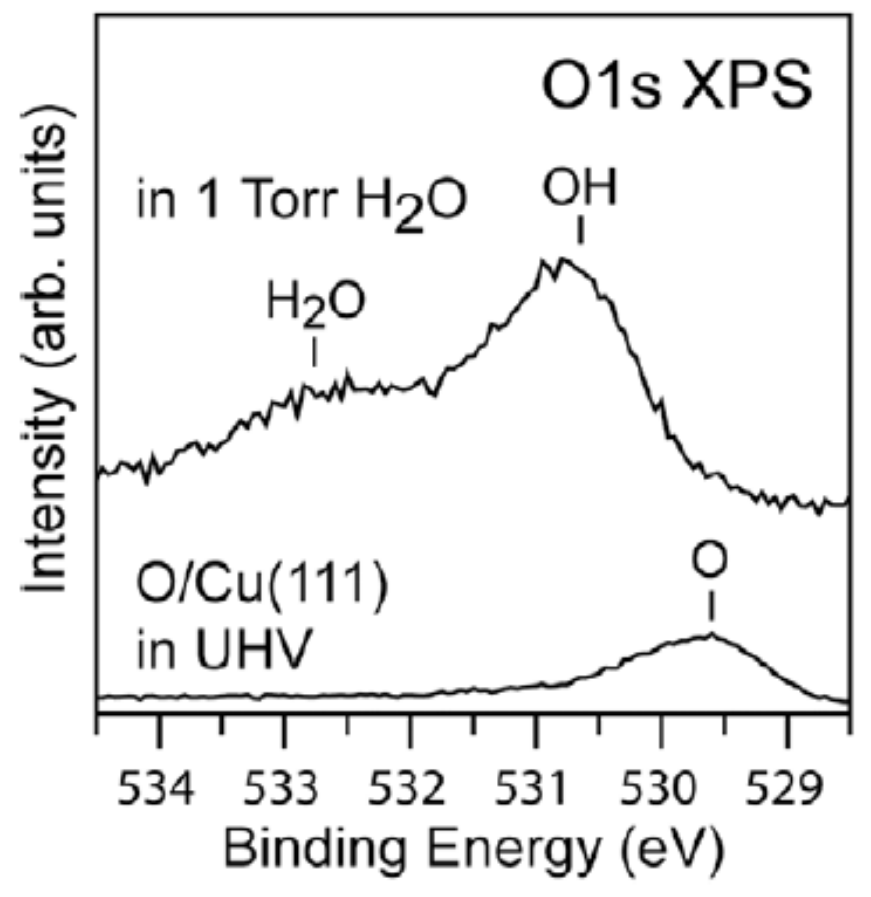


Figure 30

(a)

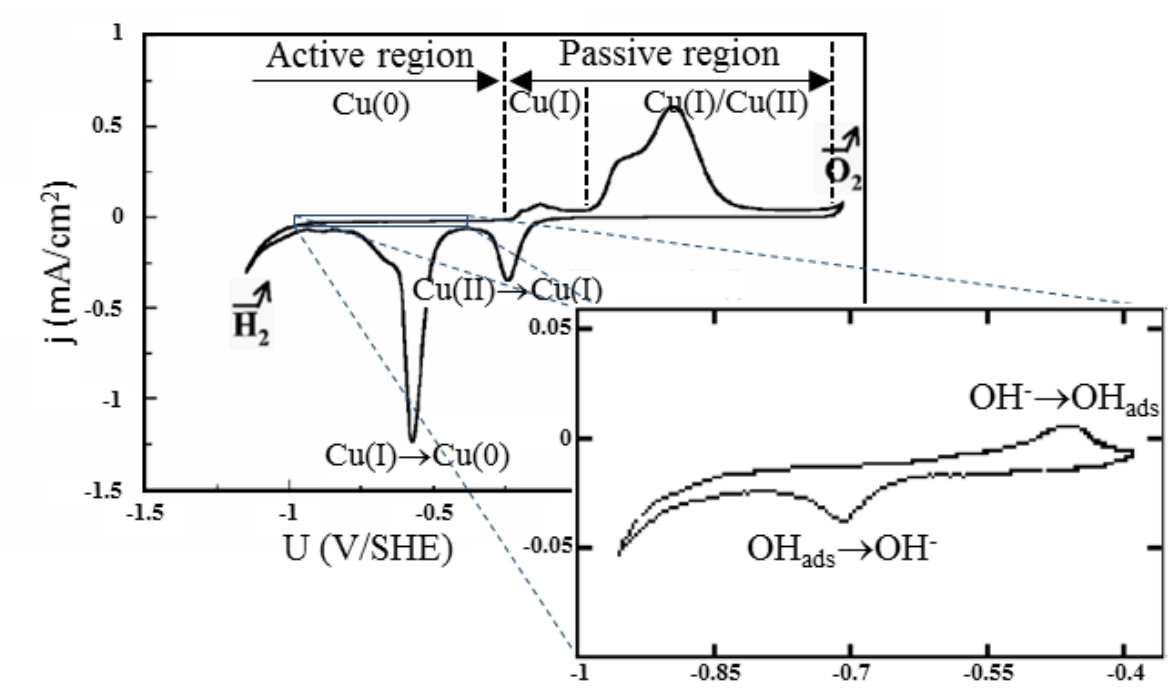

(b)
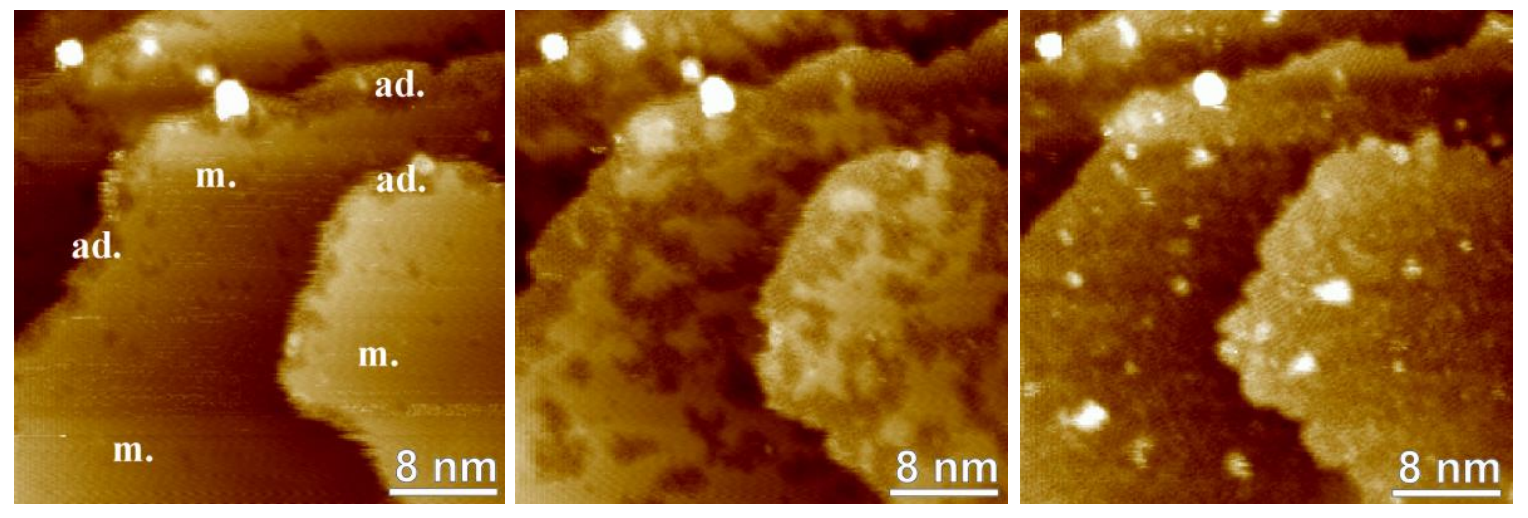

(c)

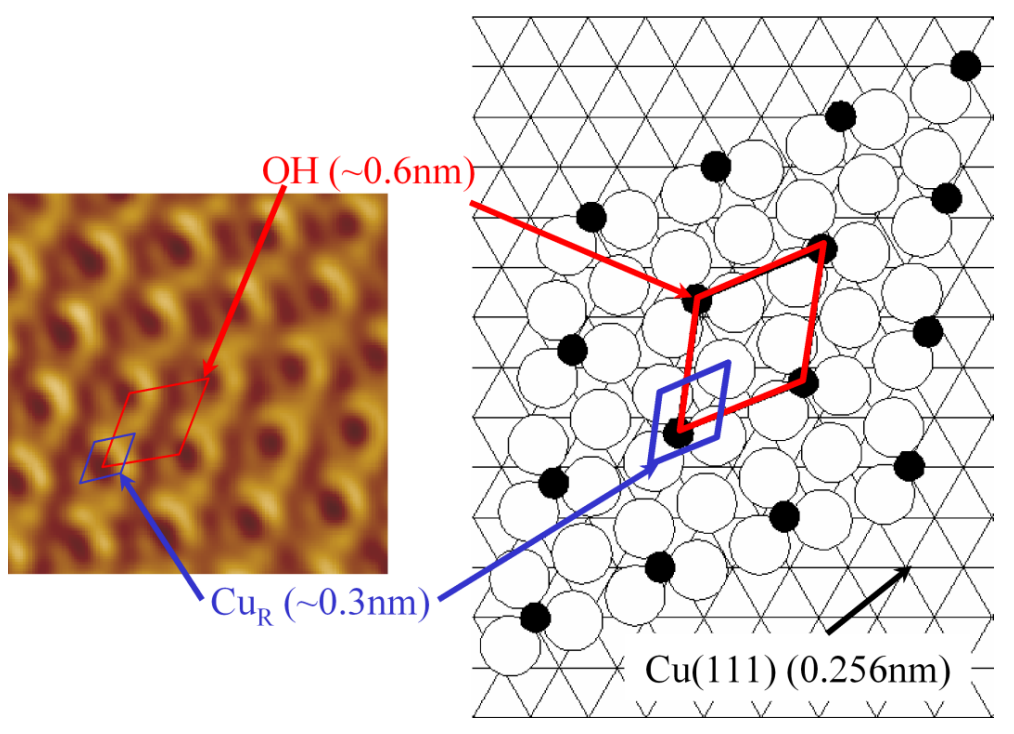


Figure 31
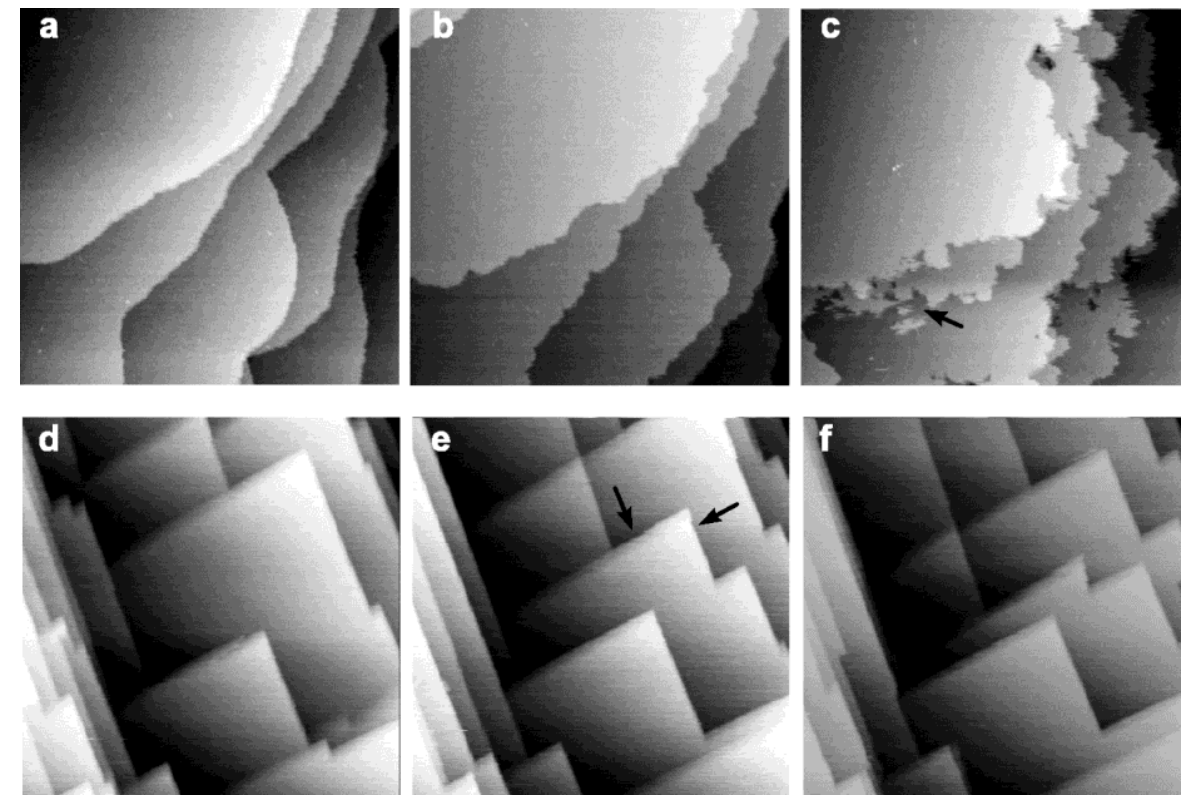
Figure 32

(a)
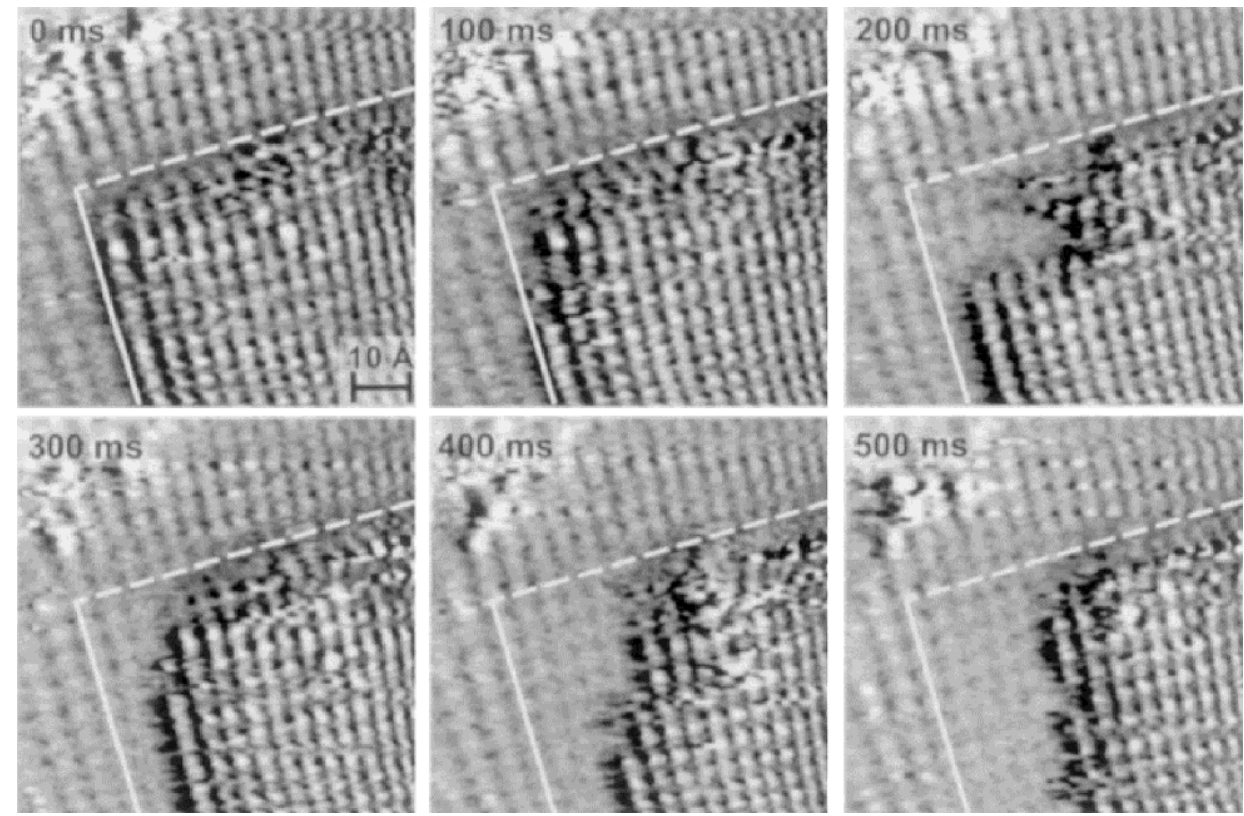

(b)

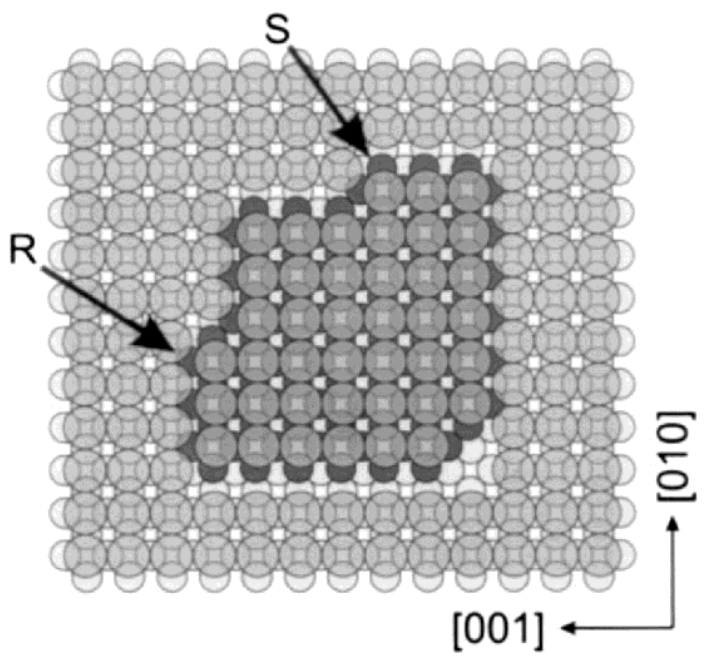


Figure 33
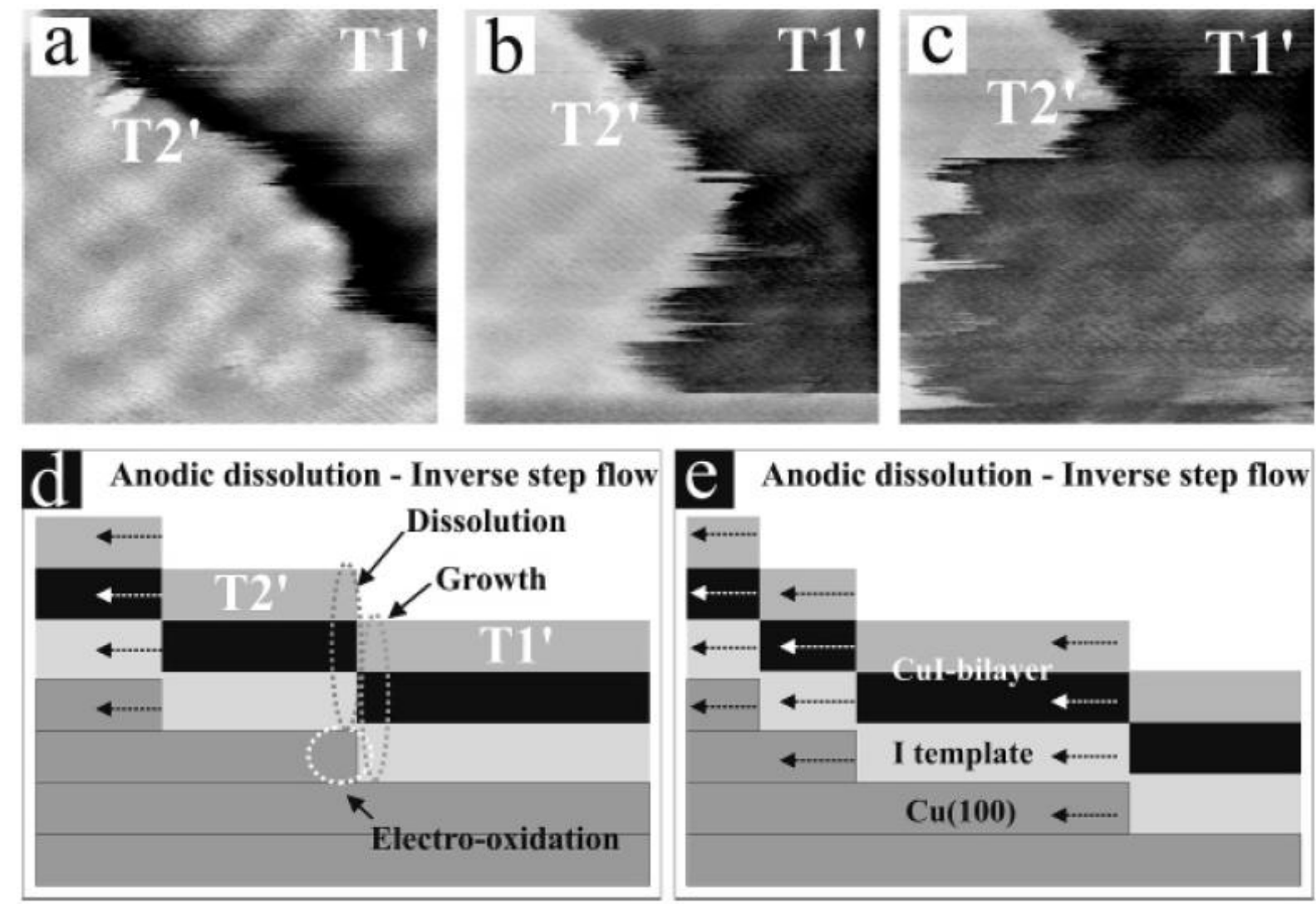
Figure 34
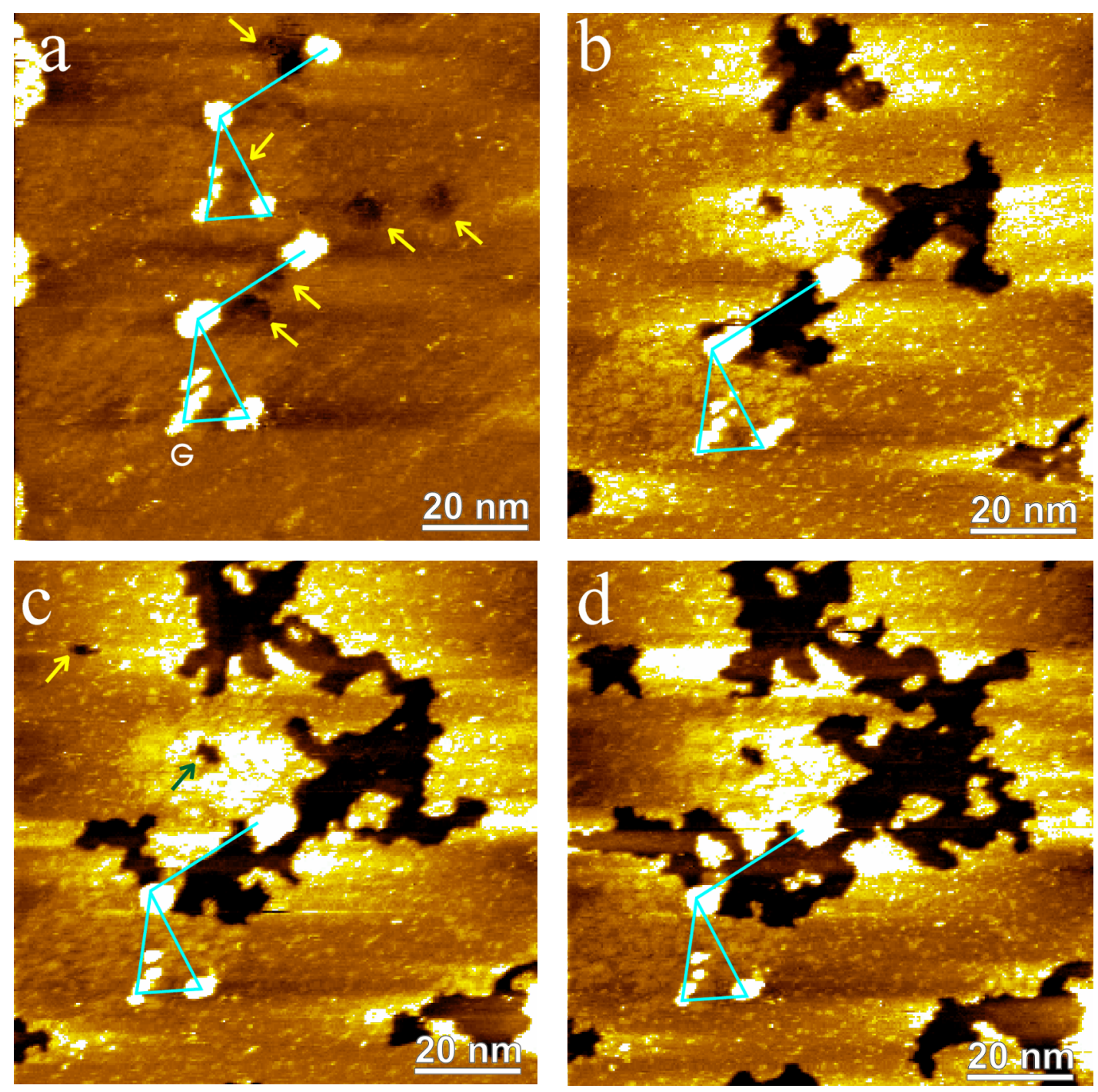
Figure 35
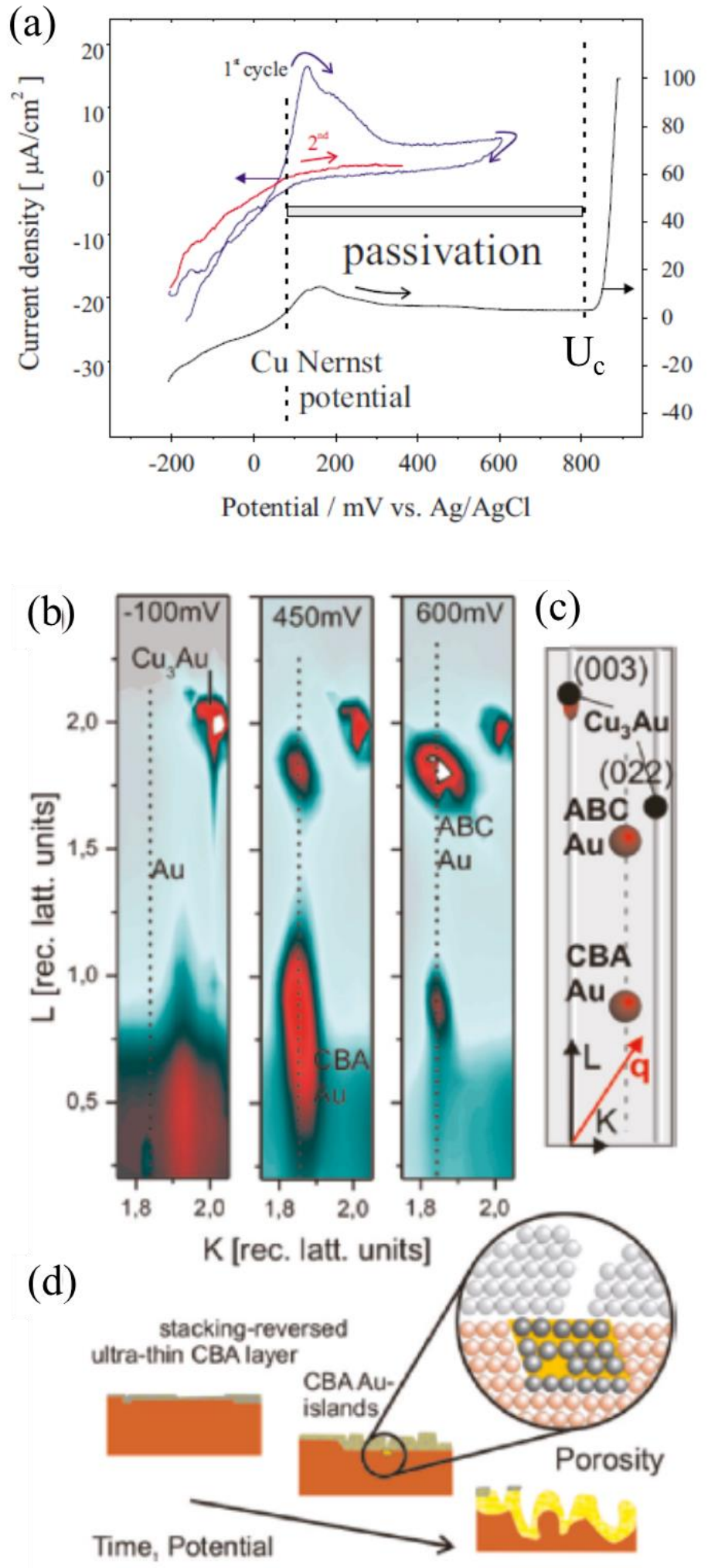
Figure 36

(a)

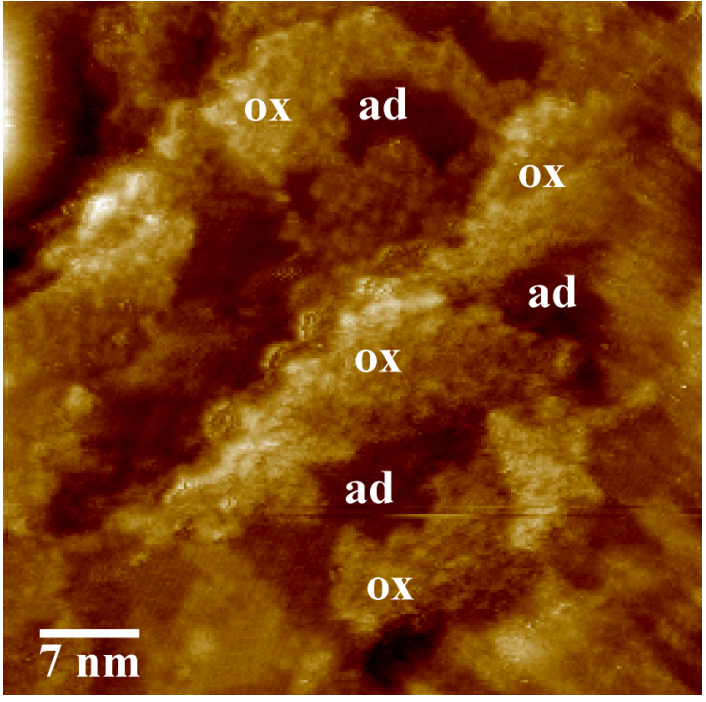

(b)

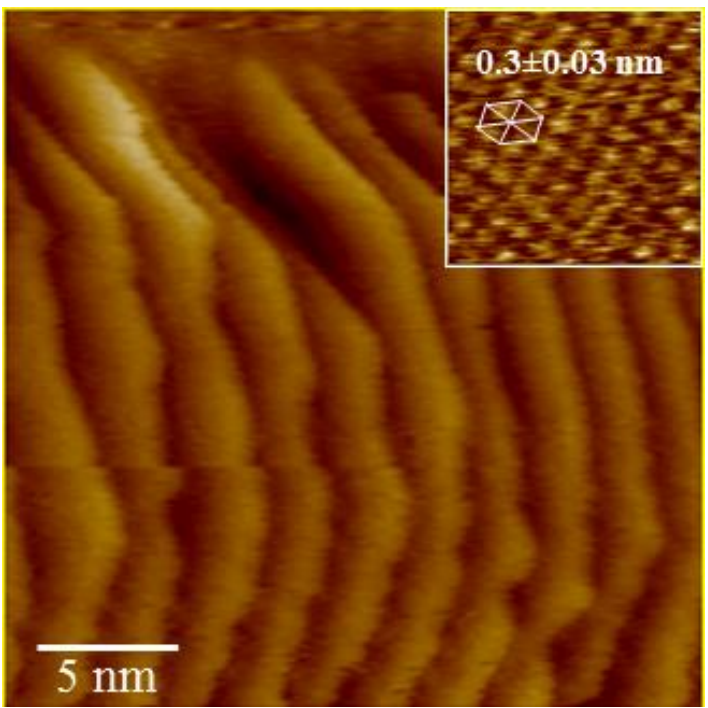

(c)

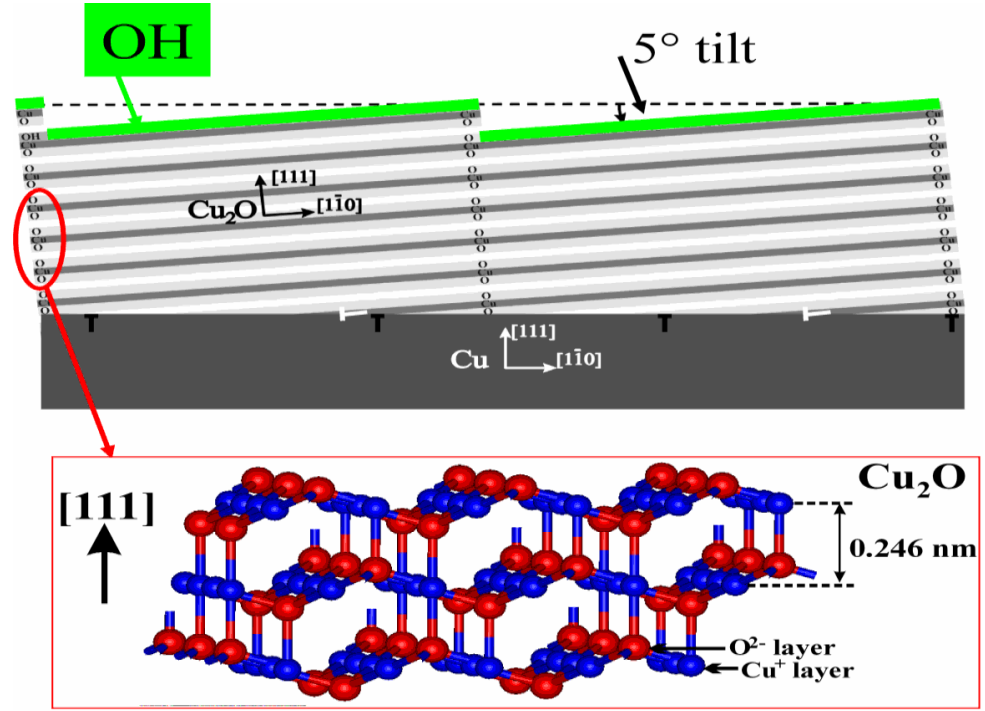


Figure 37

(a)

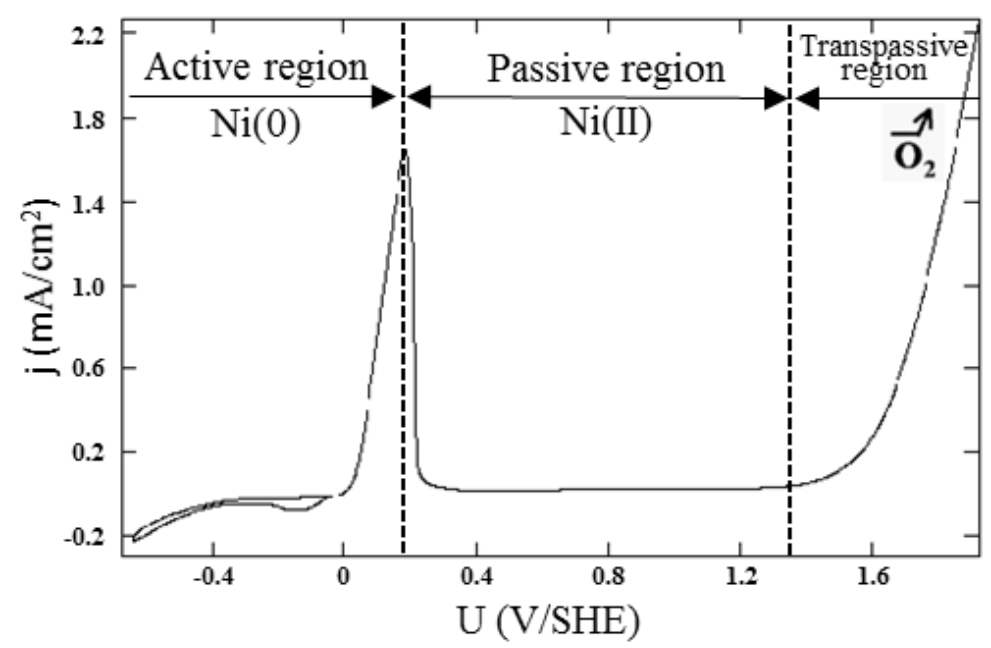

(b)

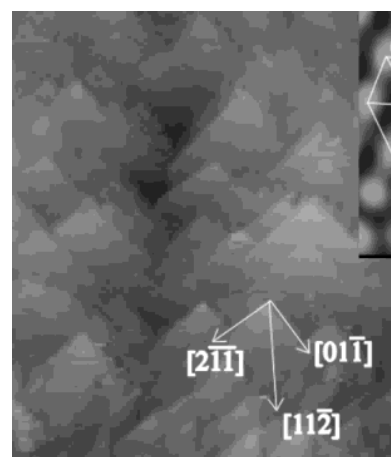

\section{$20 \mathrm{~nm}$}

(c)

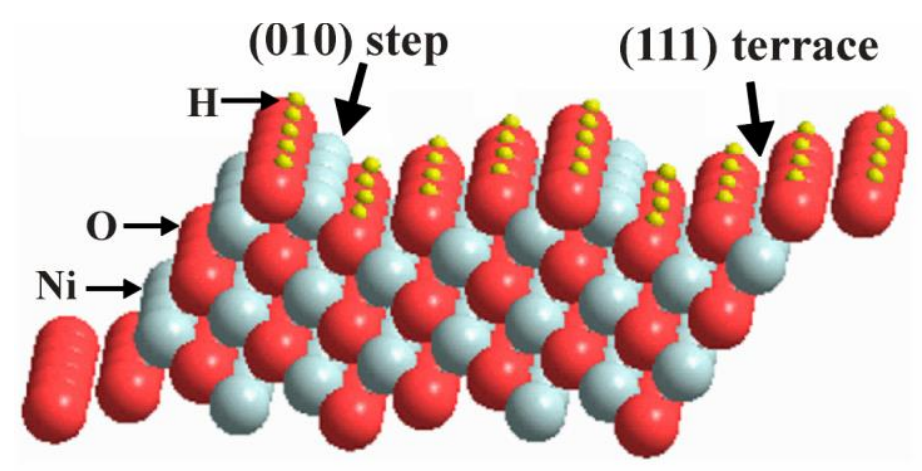


Figure 38

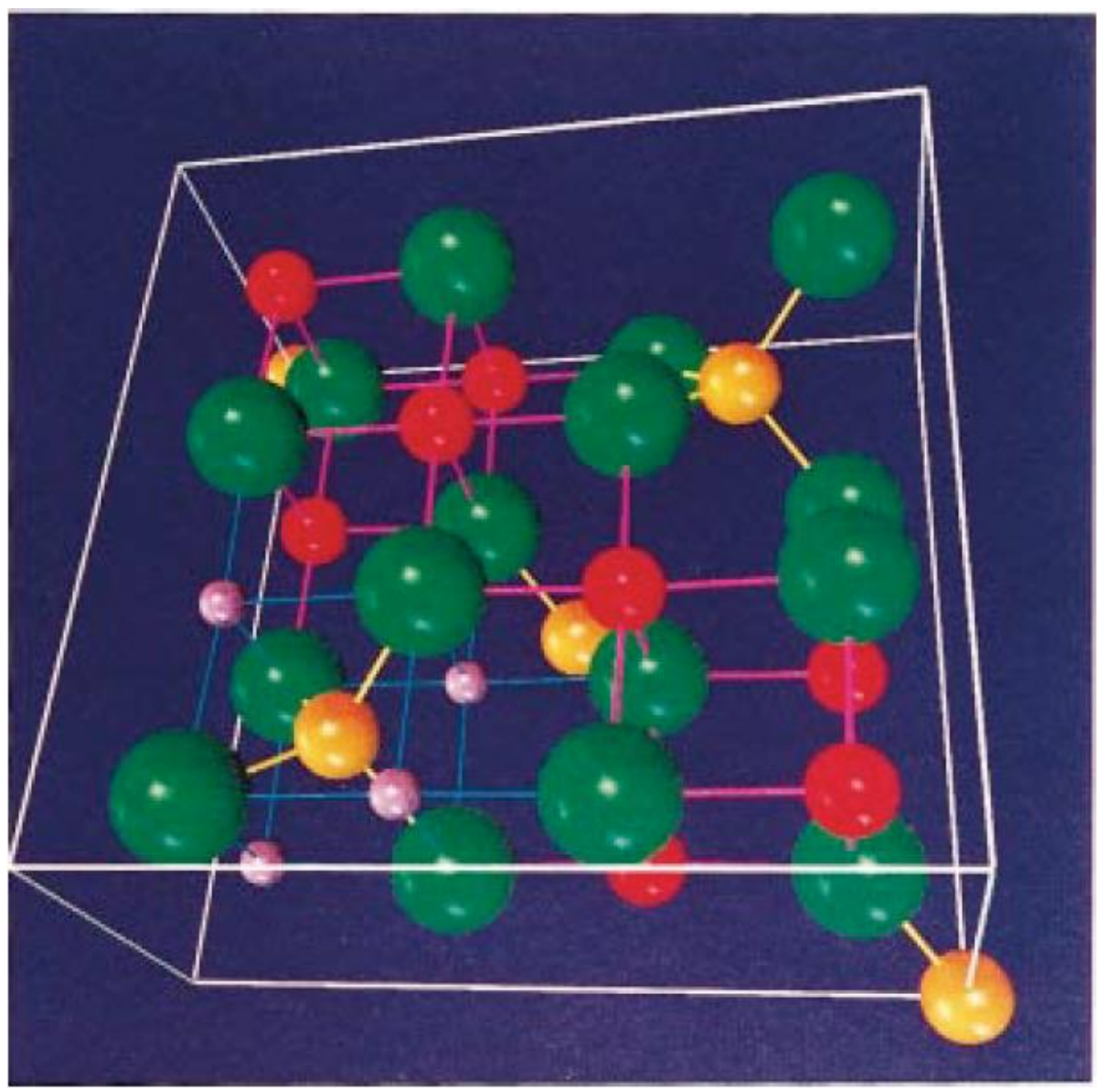


Figure 39
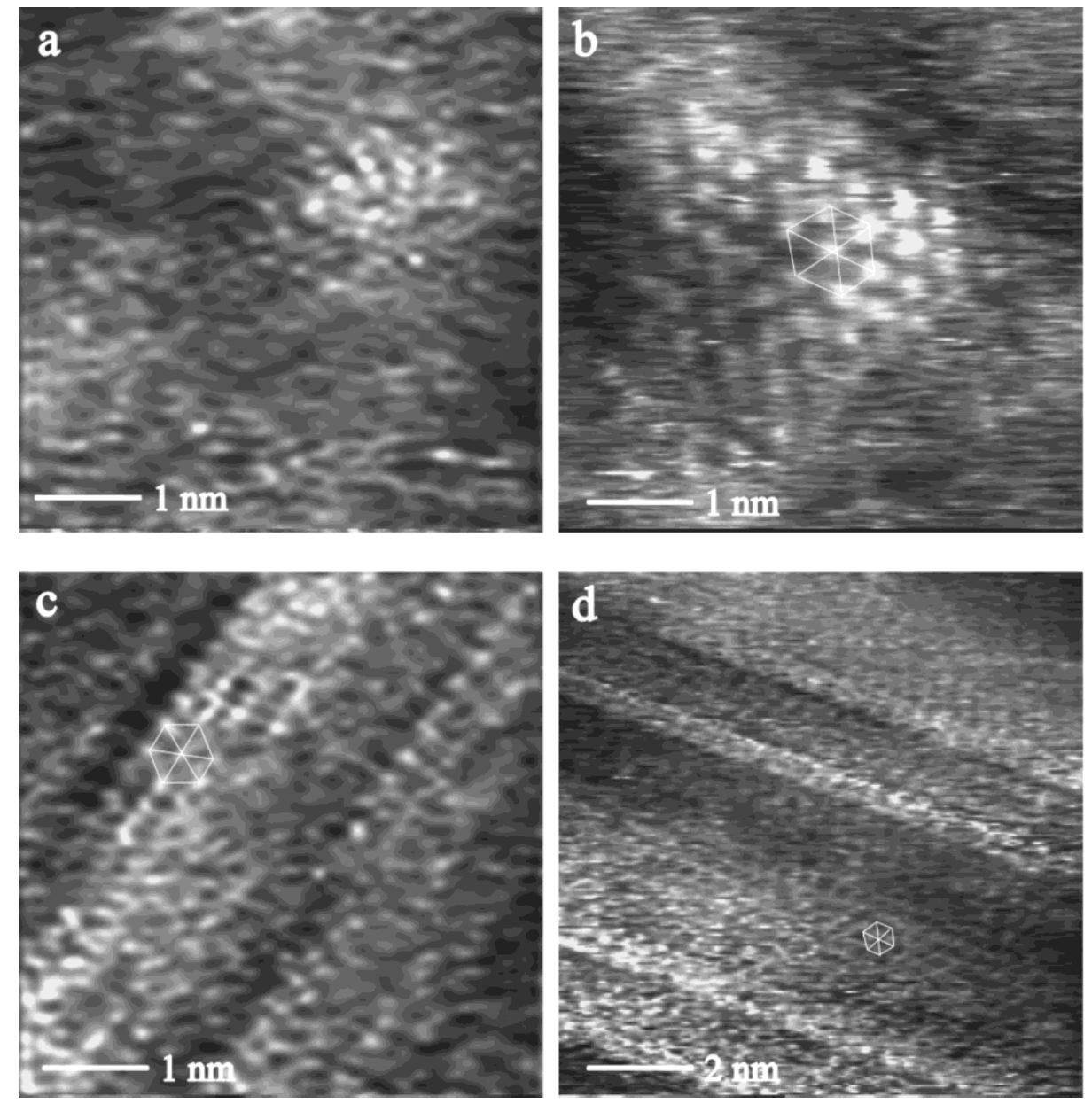
Figure 40

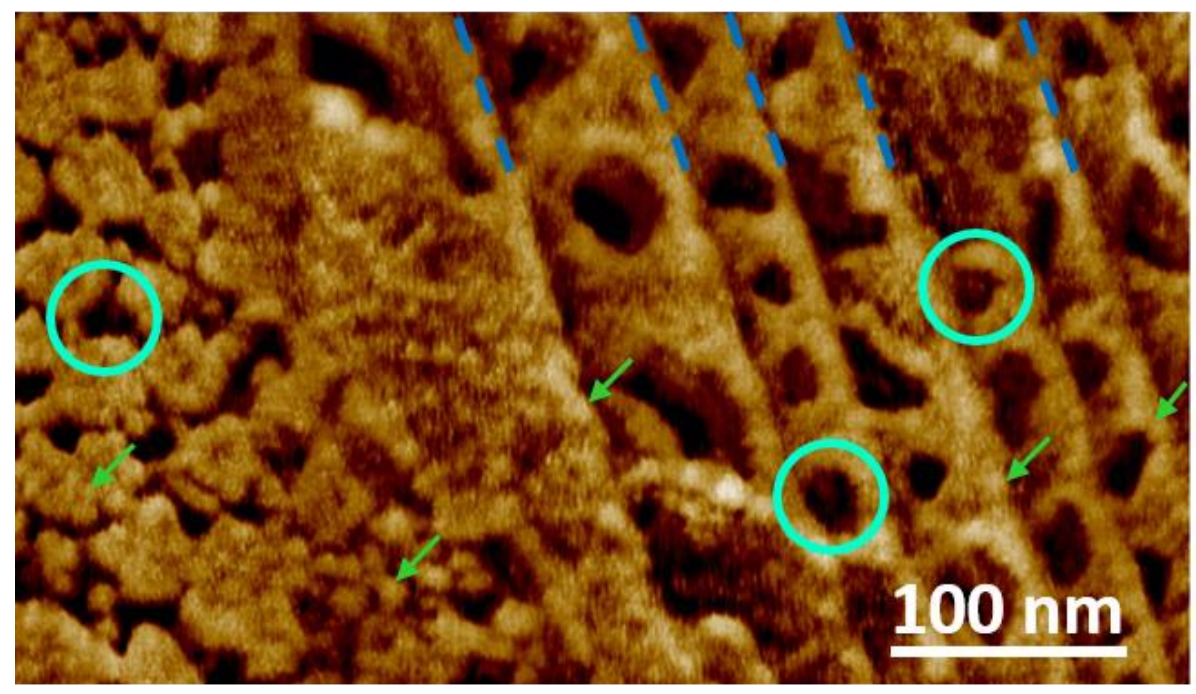


Figure 41
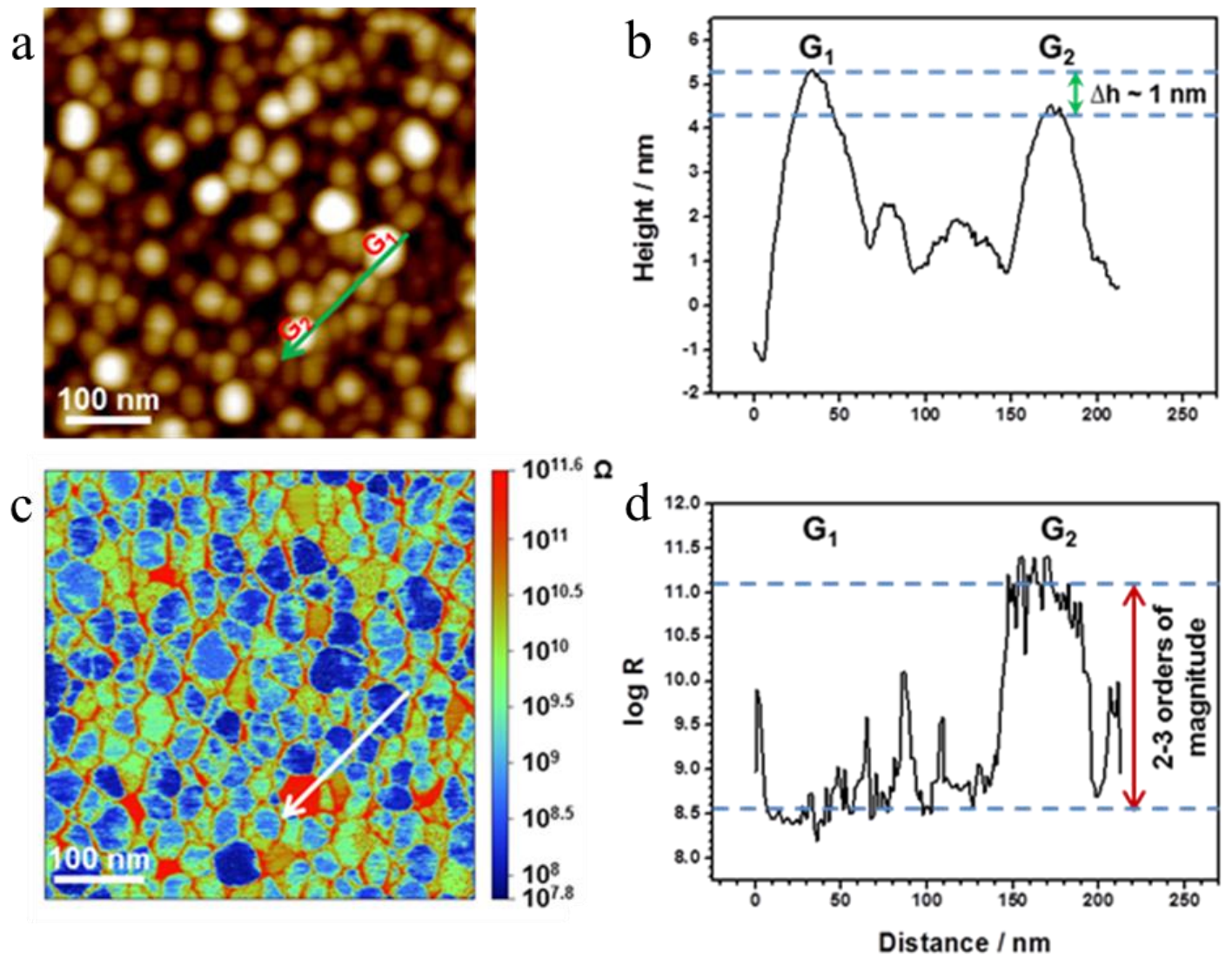
Figure 42

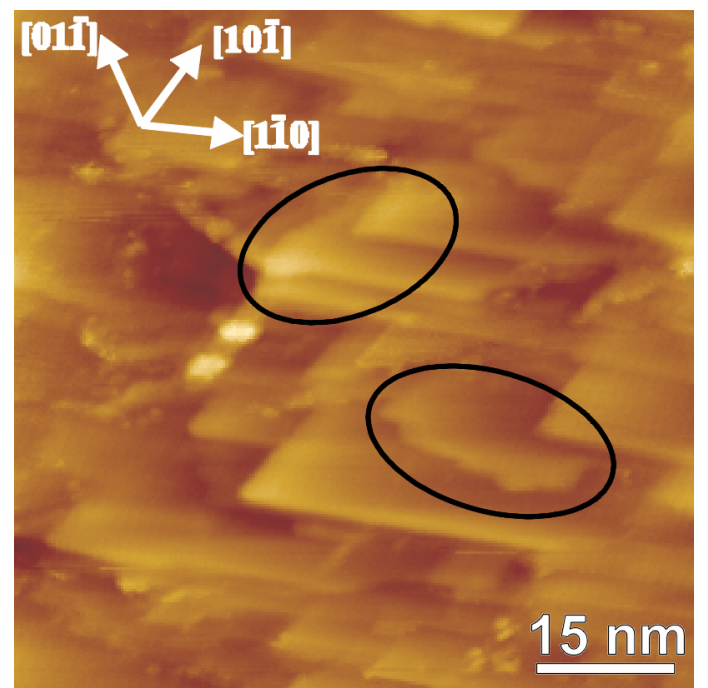

(a)

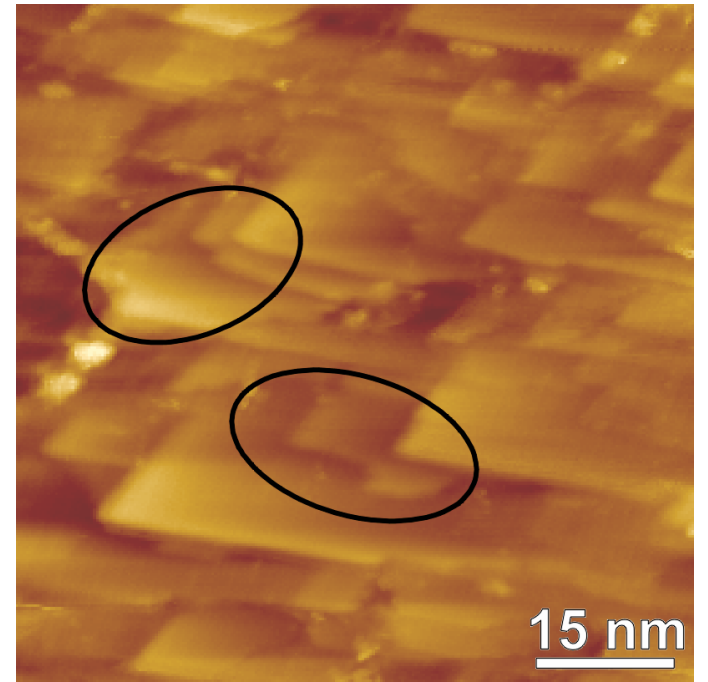

(c)

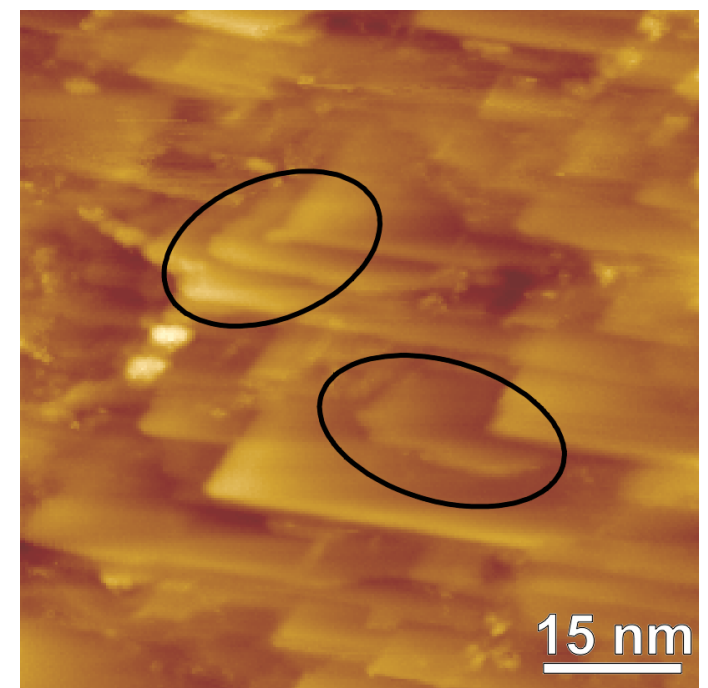

(b)

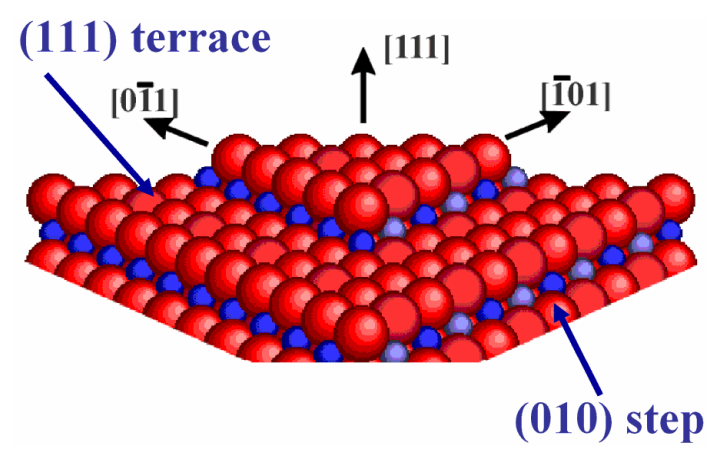

(d) 
Figure 43

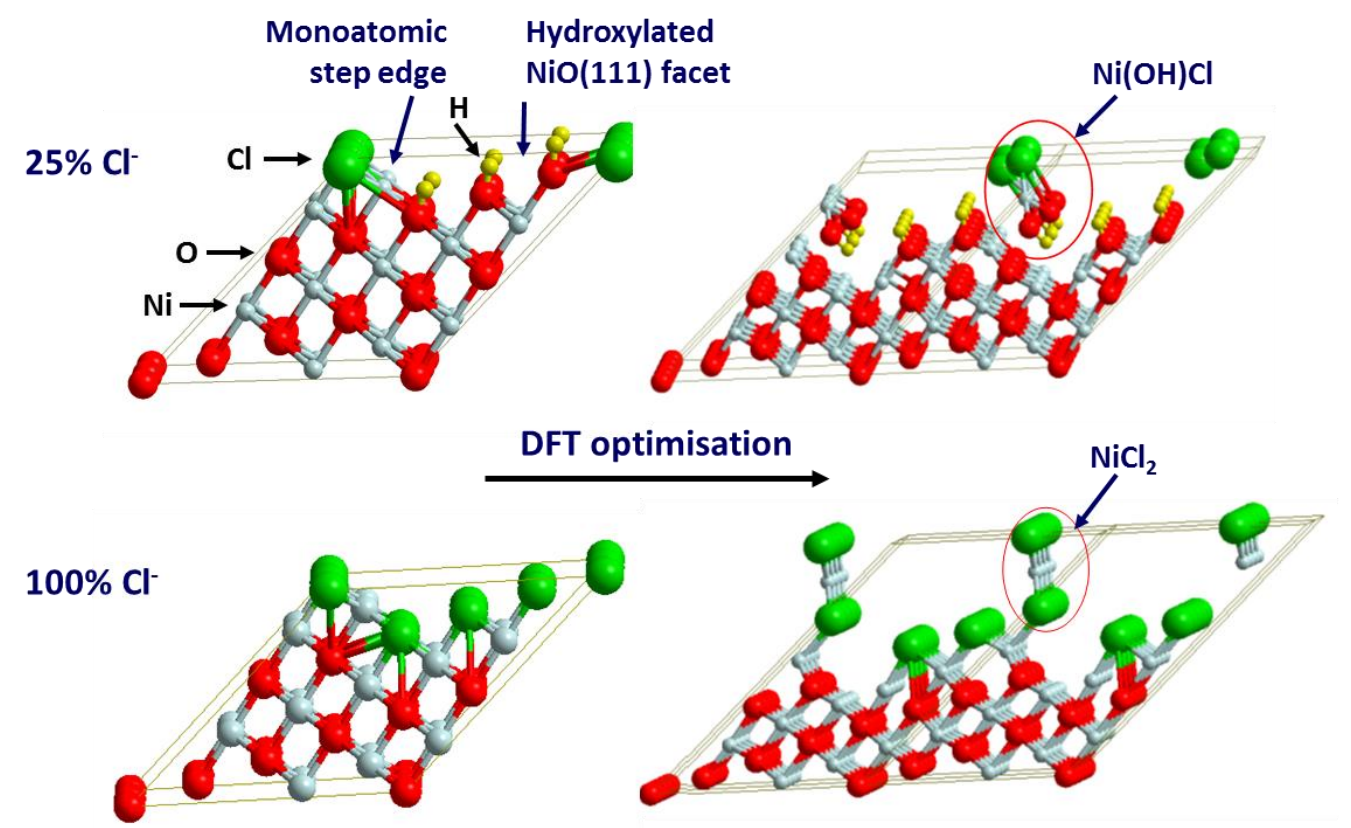


Figure 44
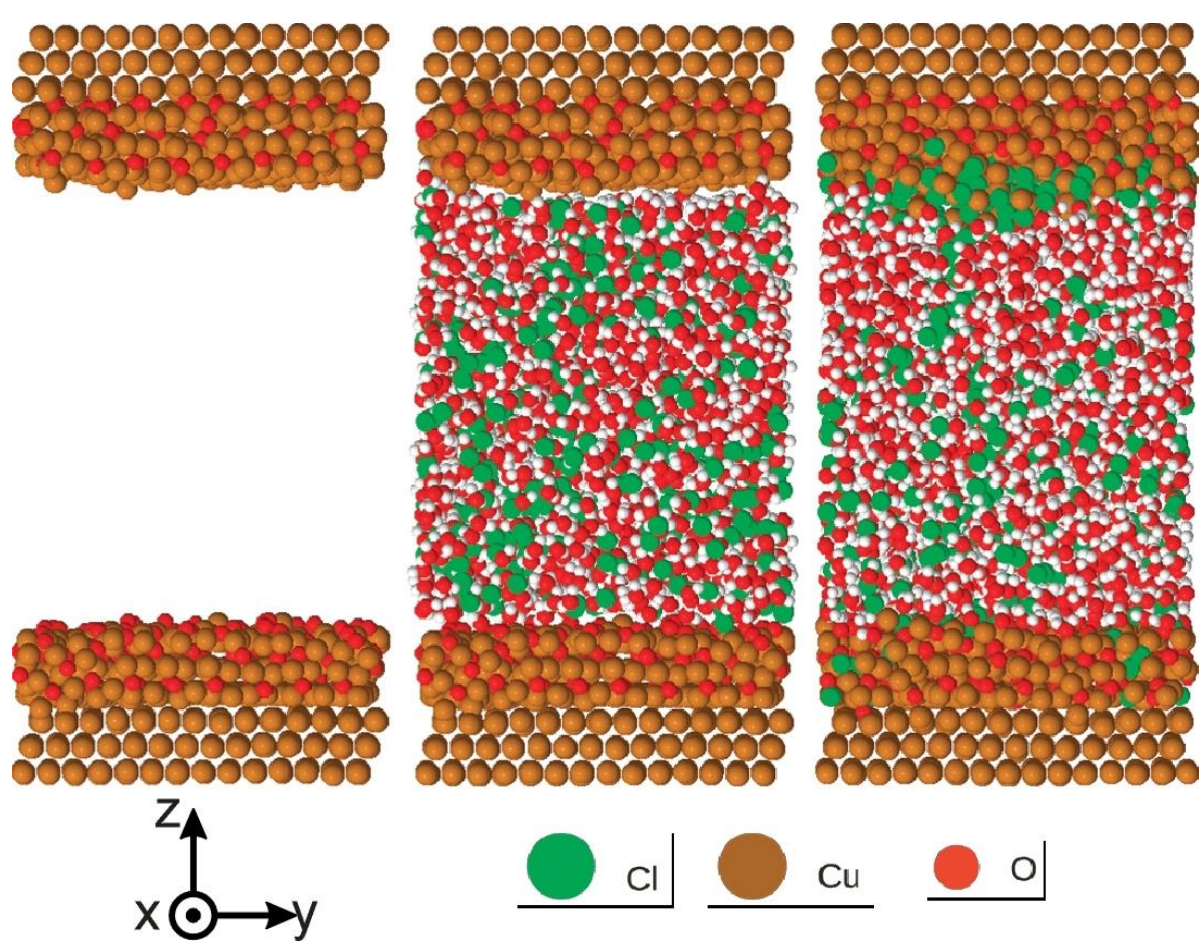

이 으무음 
Figure 45

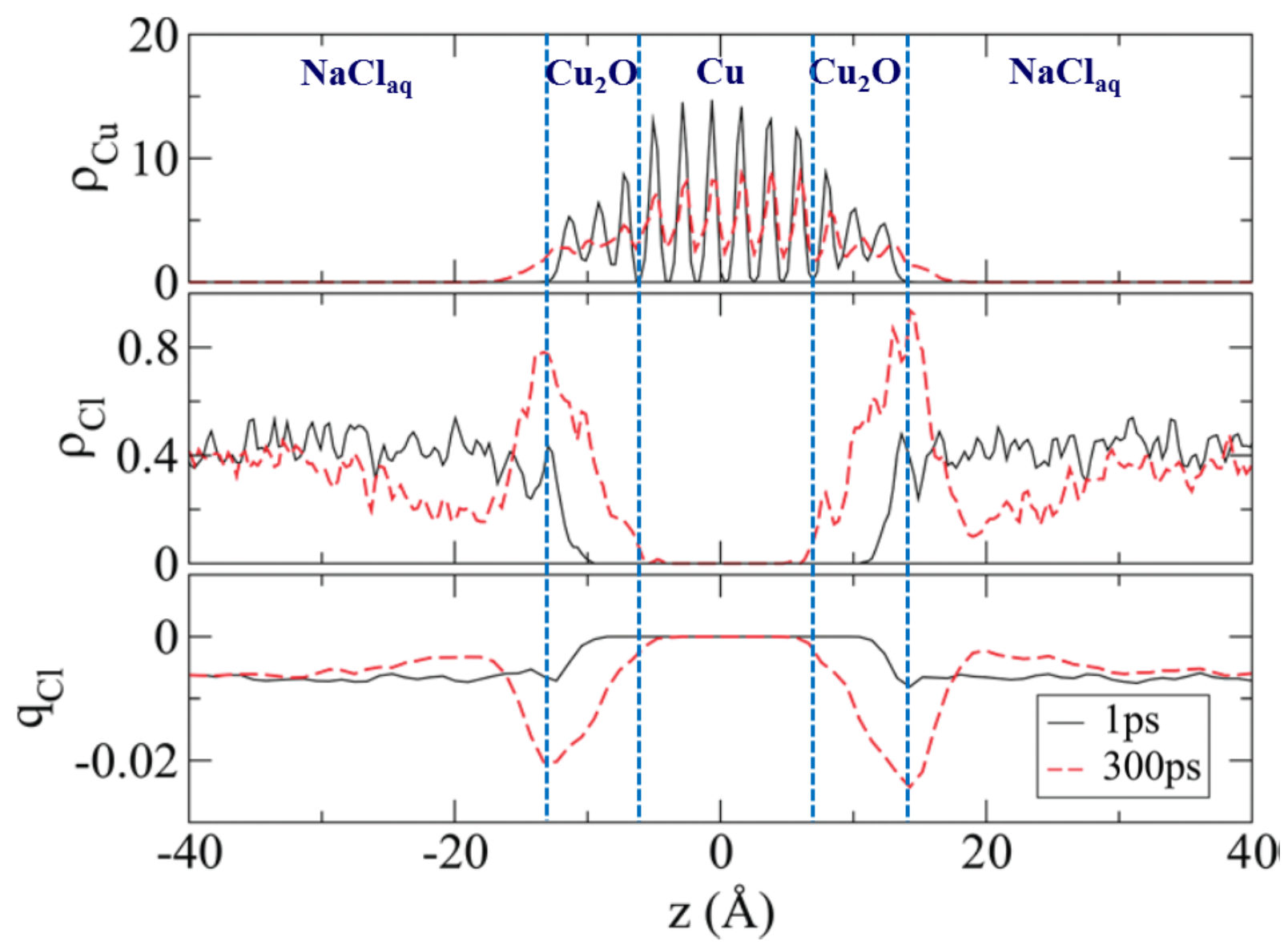


Figure 46
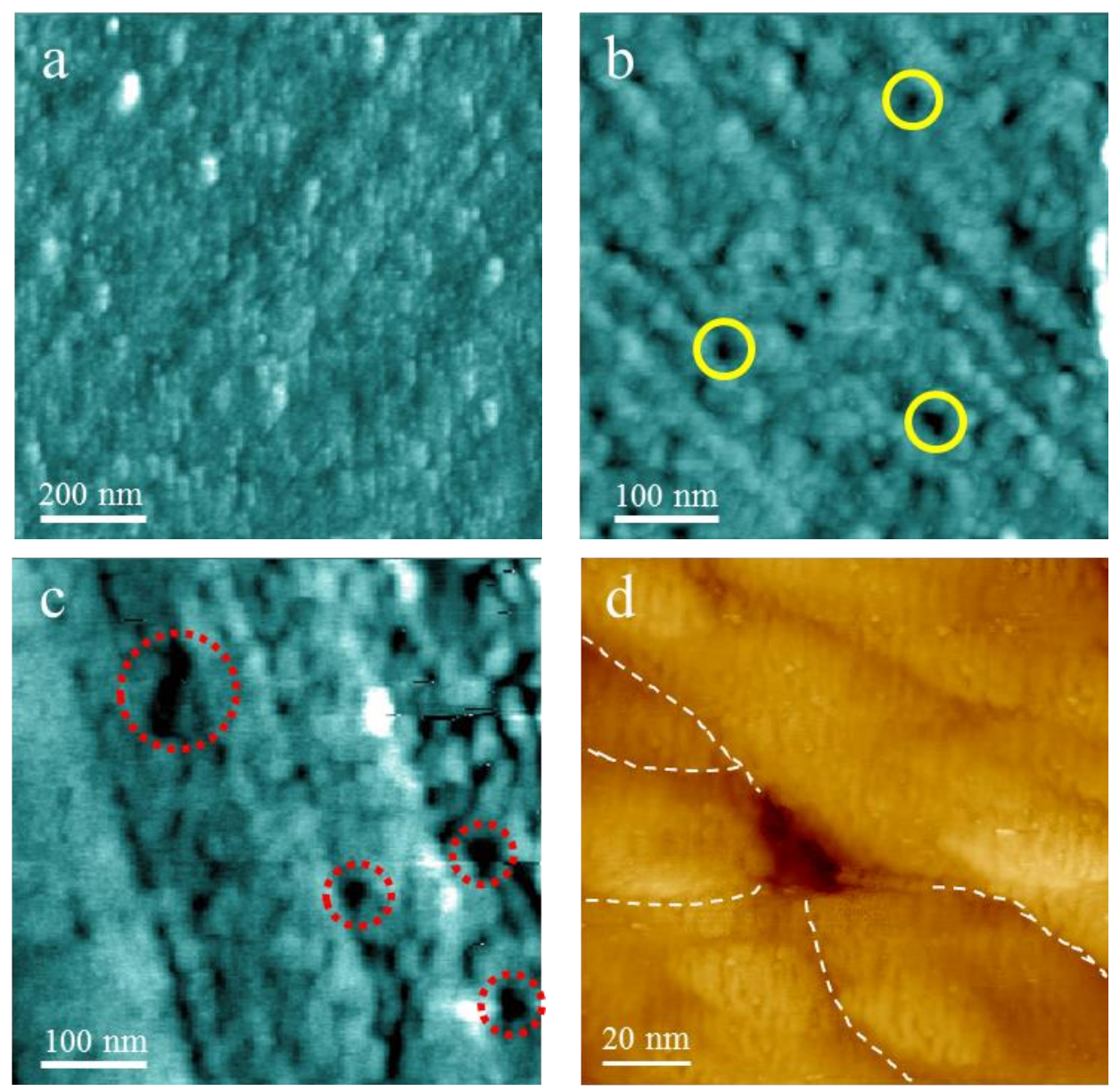


\section{Figure 47}
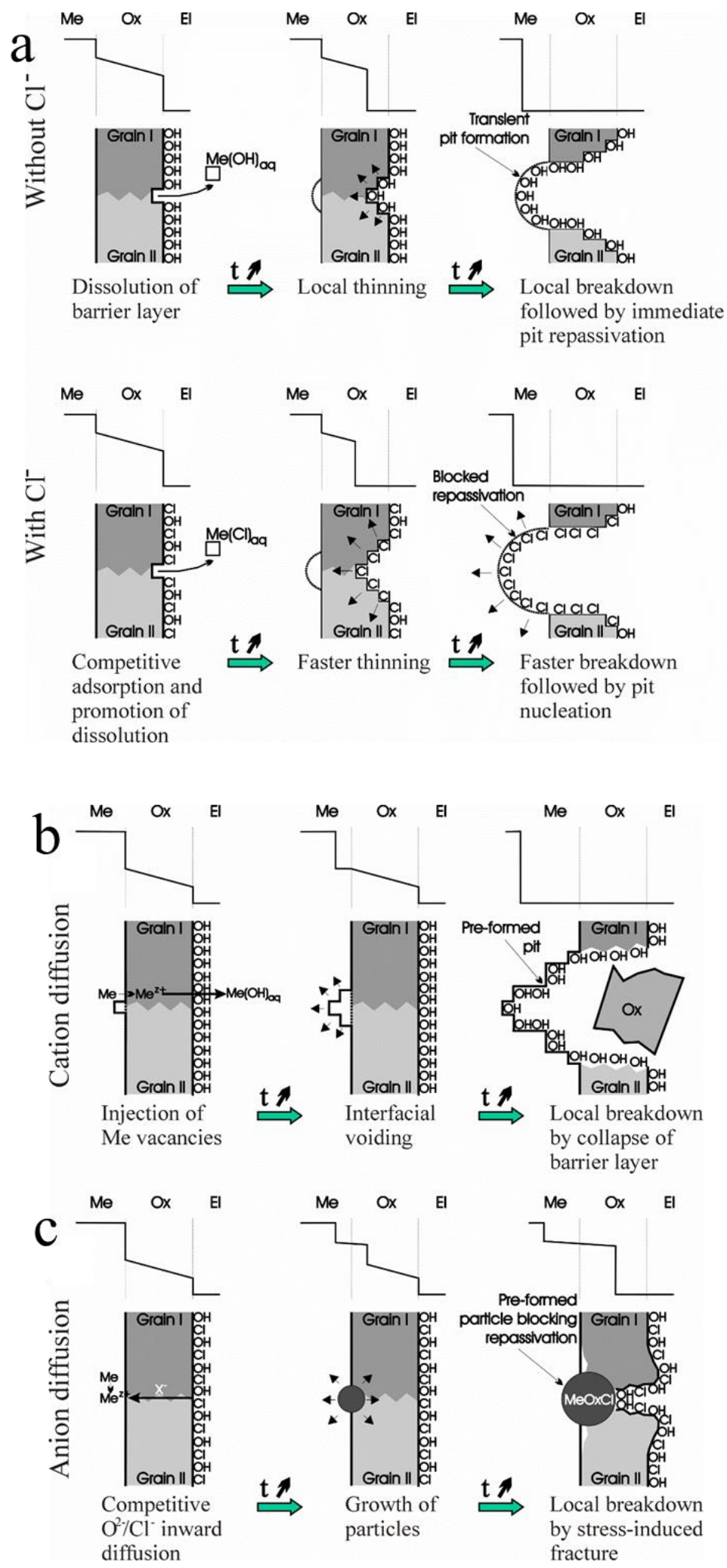
Figure 48

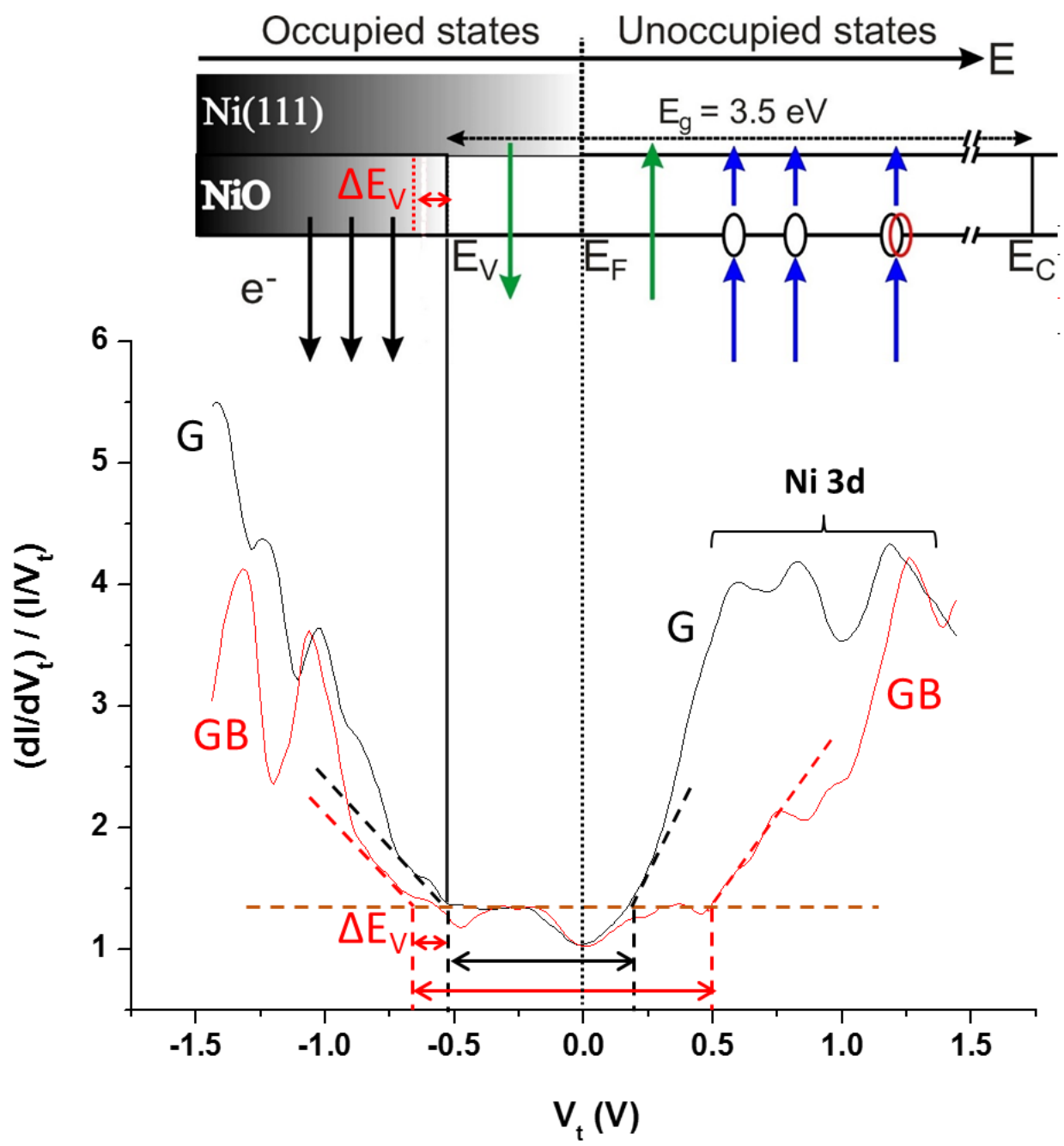


Figure 49

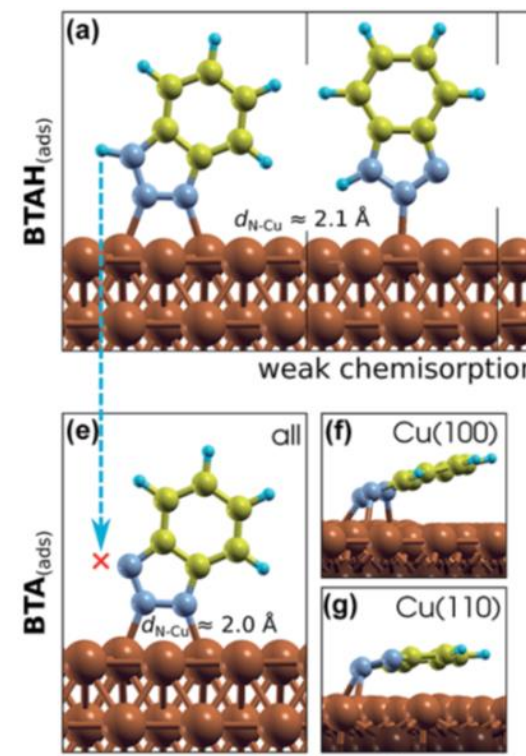

strong chemisorption

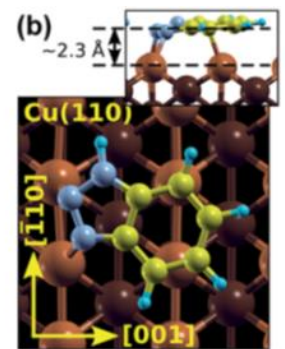

apparent chem+phys

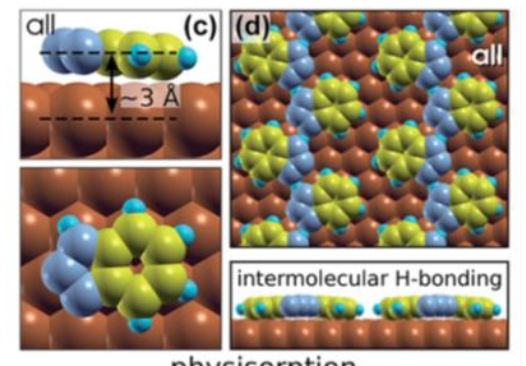

physisorption
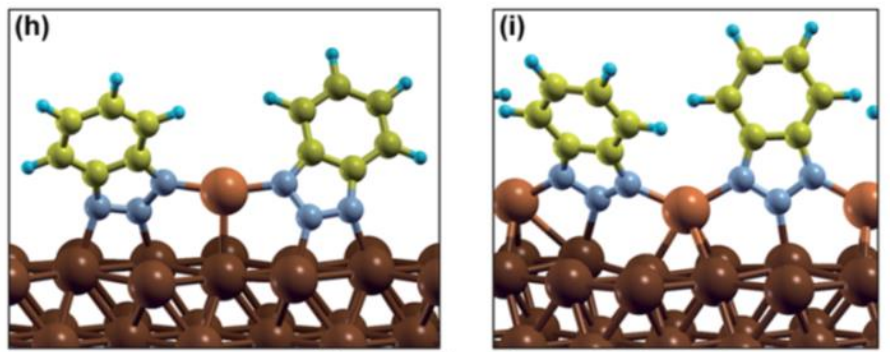

- $\mathrm{H}$

- $\mathrm{C}$

O N

organometallic complexation - $\left[\mathrm{BTA}_{x} \mathrm{Cu}_{y}\right]$

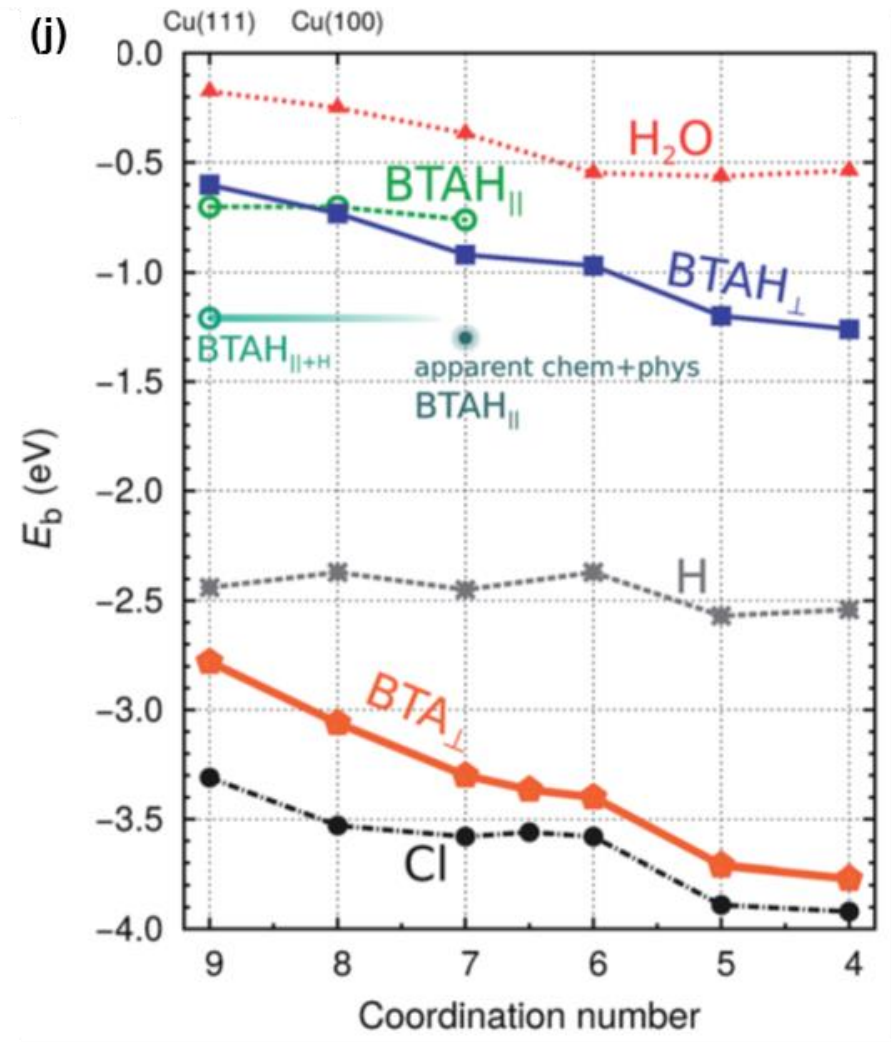


Figure 50
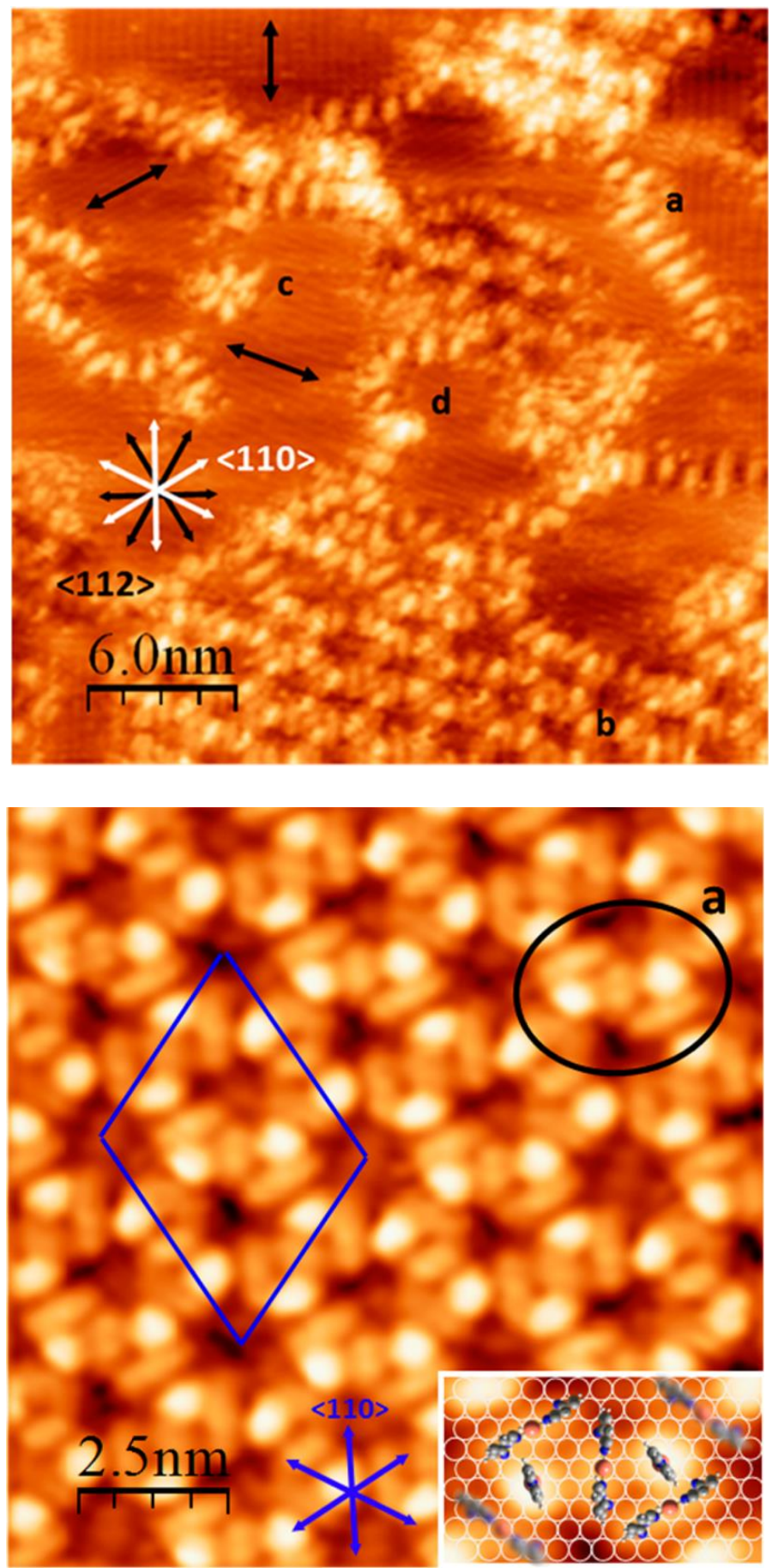
Figure 51
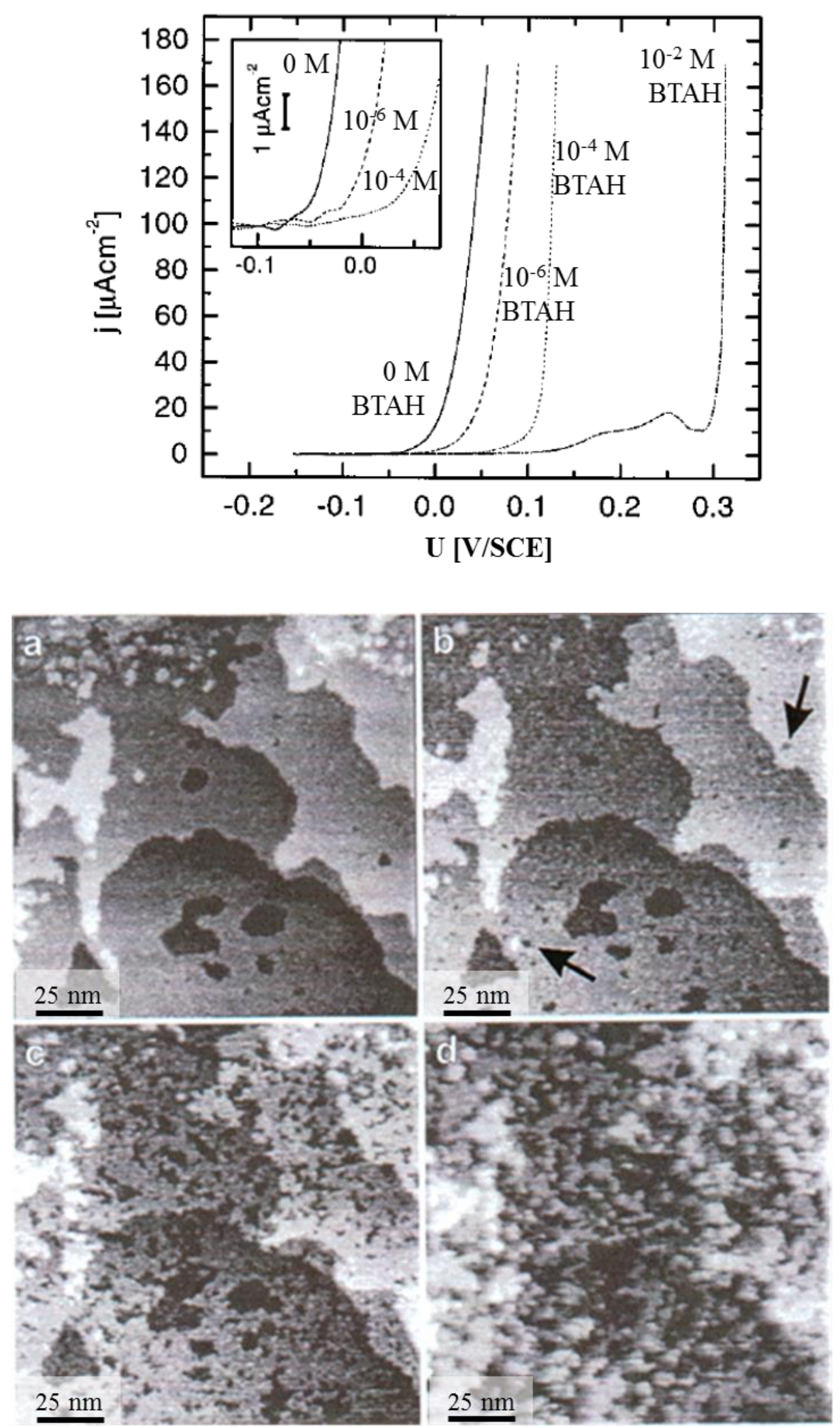
Figure 52
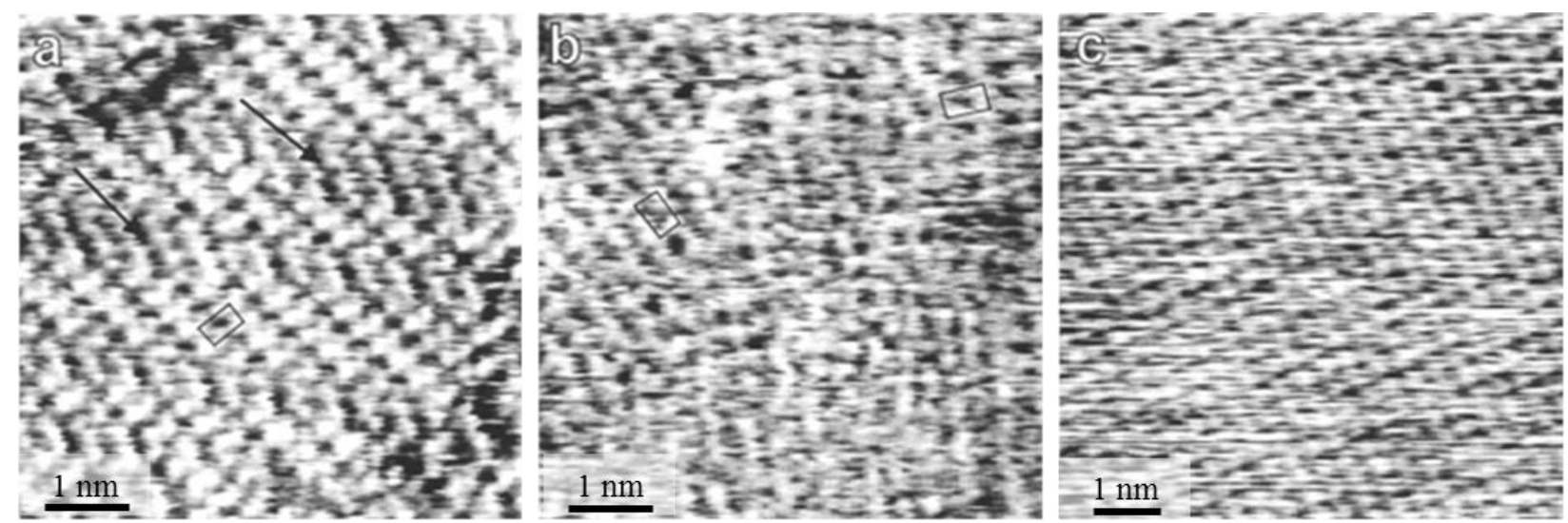